\title{
Dynamic joint stability in athletes : the value of isokinetic dynamometry
}

Citation for published version (APA):

van Cingel, E. H. R. (2007). Dynamic joint stability in athletes : the value of isokinetic dynamometry.

[Doctoral Thesis, Maastricht University]. Universiteit Maastricht. https://doi.org/10.26481/dis.20071012ec

Document status and date:

Published: 01/01/2007

DOI:

10.26481/dis.20071012ec

Document Version:

Publisher's PDF, also known as Version of record

\section{Please check the document version of this publication:}

- A submitted manuscript is the version of the article upon submission and before peer-review. There can be important differences between the submitted version and the official published version of record.

People interested in the research are advised to contact the author for the final version of the publication, or visit the DOI to the publisher's website.

- The final author version and the galley proof are versions of the publication after peer review.

- The final published version features the final layout of the paper including the volume, issue and page numbers.

Link to publication

\footnotetext{
General rights rights.

- You may freely distribute the URL identifying the publication in the public portal. please follow below link for the End User Agreement:

www.umlib.nl/taverne-license

Take down policy

If you believe that this document breaches copyright please contact us at:

repository@maastrichtuniversity.nl

providing details and we will investigate your claim.
}

Copyright and moral rights for the publications made accessible in the public portal are retained by the authors and/or other copyright owners and it is a condition of accessing publications that users recognise and abide by the legal requirements associated with these

- Users may download and print one copy of any publication from the public portal for the purpose of private study or research.

- You may not further distribute the material or use it for any profit-making activity or commercial gain

If the publication is distributed under the terms of Article $25 \mathrm{fa}$ of the Dutch Copyright Act, indicated by the "Taverne" license above, 


\section{Dynamic joint stability in athletes}

The value of isokinetic dynamometry 
Dynamic joint stability in athletes, The value of isokinetic dynamometry

Thesis, Maastricht University, The Netherlands

ISBN: 978-90-8|0576-5-3

(C) 2007, Robert van Cingel

No part of this thesis may be reproduced, stored or transmitted

in any way or by any means, without prior permission of the author

Cover design: Birgit Dejaco, Innsbruck, Austria

Production: Drukkerij Het Centrum Utrecht BV, Utrecht, The Netherlands 


\title{
Dynamic joint stability in athletes
}

\section{The value of isokinetic dynamometry}

\author{
PROEFSCHRIFT
}

ter verkrijging van de graad van doctor aan de Universiteit Maastricht

op gezag van de Rector Magnificus, Prof. mr. G.P.M.F. Mols volgens het besluit van het College van Decanen

in het openbaar te verdedigen op vrijdag I 2 oktober 2007 om I2.00 uur

door

Eltjo Herman Robert van Cingel 


\section{Promotores:}

Prof. dr. H. Kuipers

Prof. dr. R.A. de Bie

\section{Co-promotor:}

Dr. G.J. Kleinrensink (Erasmus Universiteit Rotterdam)

\section{Beoordelingscommissie:}

Prof. dr. H. van Mameren (voorzitter)

Prof. dr. P.R.G. Brink

Dr. F. Hartgens

Dr. K. Meijer

Dr. B. Pluim (Koninklijke Nederlandse Lawn Tennisbond)

Prof. dr. E.Witvrouw (Rijksuniversiteit Gent, België)

In de drukkosten van dit proefschrift werd bijgedragen door:

Koninklijk Nederlands Genootschap voor Fysiotherapie Nederlands Olympisch Comité * Nederlandse Sport Federatie Nederlandse Vereniging voor Fysiotherapie in de Sportgezondheidszorg Sport Medisch Centrum Papendal Stichting Anna Fonds 
Voor Carla, Noor en Maartje 



\section{CONTENTS}

Chapter

Page

I General Introduction

2 Training and testing in open versus closed kinetic chain

3 Strength values of shoulder internal and external rotators in elite volleyball players

4 Isokinetic strength values, conventional ratio and dynamic control ratio of shoulder rotator muscles in elite badminton players

5 Learning effect in isokinetic testing of ankle invertors and evertors

6 Repeated ankle sprains and delayed neuromuscular response: acceleration time parameters

7 General Discussion

8 Summary

Samenvatting

Dankwoord

Curriculum Vitae 

Chapter I

General Introduction 


\section{Sports injuries}

Based on the OBiN report 2005, every year around I.5 million Dutch recreational and elite athletes sustain new injuries. ${ }^{54}$ These sports injuries are divided into acute and overuse injuries and it is estimated that each year in the Netherlands there are I.2 million acute injuries and 300.000 overuse injuries. About $50 \%$ of all injuries require medical attention, mostly from a physician or physiotherapist and direct medical costs are approximately $€ 180$ million per year (absenteeism not included). Medical attention to overuse injuries is higher than to acute injuries (56\% versus $50 \%$ ). Given the 7.7 million athletes in The Netherlands, this theoretically means that every year, one out of five athletes will get injured. Top three of injuries concern the knee (20\%), ankle (I7\%) and shoulder/arm/wrist regions (14\%). However, the OBiN report, including other sports injury registrations, poorly documents overuse injuries. Moreover, changeable government (sport) policies over time, differences in various registration methods and the inability to fine-tune different outcomes make it difficult to determine exact numbers of sports injuries. ${ }^{30}$

Physiotherapy plays an important role in the prevention and treatment of sports injuries. Therefore, research is needed to establish a solid basis of rehabilitation programs and injury prevention. Sports Medical Center Papendal (SMCP) co-operates closely with the Netherlands Olympic Committee * Netherlands Sports Confederation. This enabled us to study both healthy and injured (elite) athletes, training at the Olympic Training Center Papendal. We had the opportunity to select a homogeneous group of (elite) athletes that were at risk of overuse or had repetitive injuries due to the high intensity and frequency of specific training.

The aim of this thesis is to gain a better insight into mechanisms that are the basis of overuse and repetitive injuries of the ankle and shoulder joints, to provide clinicians and trainers with appropriate information regarding the prevention and rehabilitation of those injuries. Important issues of this thesis are dynamic joint stability during demanding motor tasks, measured with an isokinetic dynamometer, and the pathokinesiology that occurs after sports injuries.

\section{Dynamic joint stability}

Traditionally joint stability is divided into passive and dynamic stability. ${ }^{38}$ Where passive stability refers to bony structures, capsules and ligaments, dynamic stability refers to the sensorimotor system. This system is represented by sensory (afferent) and motor (efferent) components and their central integration and processing. In joint stability maintenance during functional activity all aspects are involved. ${ }^{36}$ Important components of this system are propriocepsis (afferent signals) and neuromuscular control (motor 
response). For optimal and efficient motor performance proprioceptive information is a critical source of afferent information. ${ }^{36}$

Due to partial deafferentiation injuries of the locomotor system (e.g. ligament injury) can affect joint stability. Damage of mechanoreceptors and associated nerve fibers reduce the afferent information arising from the injured structure and affects neuromuscular performance. ${ }^{25}$ Studies of the knee joint show that injury to this joint can lead to selective inhibition of quadriceps muscle activity, delayed muscle reaction times and alterations in muscle recruitment patterns which are more pronounced in more demanding motor tasks. ${ }^{16,25,49,60}$ However, in most successful chronic anterior cruciate ligament $(A C L)$ deficient individuals, the neuromuscular system attempts to adapt to the muscle recruitment patterns seen in uninjured knees. This autoconditioning of protective musculature may be one of the reasons why some knee patients achieve better function than others; they may have developed a compensatory mechanism that enhances their dynamic stability.

Obviously, muscle activity plays an important role in dynamic joint stability. While concentric muscle actions of agonists function primarily to move body parts, eccentric actions of antagonists function to decelerate and control skeletal motion and joint stability.This holds especially for demanding motor tasks (i.e. sports activities) where high forces occur in different joint positions and where adequate joint stability is required during the total range of motion.

\section{Pathokinesiology}

Prevention and rehabilitation of sports injuries ask for studies to expand the body of knowledge of pathokinesiology related to neuromuscular alterations. Pathokinesiology goes beyond pathology and morphology; it deals with individual adaptation and compensation strategies as a reaction to pathology, all in terms of motor control and motor learning aspects. When focusing on pathokinesiology as a consequence of sports injuries, there is a need for reference values from healthy individuals active in the same type of sports. In elite sports such as badminton and volleyball there is limited information about how shoulder rotator muscles react (i.e. concentric and eccentric contractions) to high load activities and retain shoulder stability.

For the ankle it has been shown that six months after an inversion trauma many patients still complain of giving way and instability of the injured ankle. ${ }^{15,47}$ To explain remaining symptoms, studies have focused on mechanical laxity, proprioceptive deficits and muscle strength. ${ }^{5,7,19,23,28,34,35,50}$ In addition to capsules, ligaments and muscles, arthrokinetic reflexes play an important role in protecting joints against damage due to large loading forces. ${ }^{8,20,58}$ Reaction time is an essential element in joint protection, especially in sports 
activities, as they require fast and coordinated muscle actions. Therefore, muscle reaction times were examined by using trapdoor experiments, measuring surface electromyography (EMG) response of lower leg muscles. To assess muscle recruitment, latency time (defined as the time between disturbance of the equilibrium and the first EMG signal) is often used as the outcome measure. Several studies showed no significant differences in latency times during ankle inversions when comparing stable ankles to sprained ankles ${ }^{11,17,26,27,41}$, whereas others showed a significant difference in evertor muscle latency time when comparing stable and unstable ankles during inversion movement of $30^{\circ} .31,32,33,37,42,53$ These conflicting results require further research using different methods. The trapdoor experiment is a static situation with small inversion movements not exceeding $35^{\circ}$ of inversion. Since most inversion traumas occur in dynamic situations like walking and running it is important to use a dynamic test that allows an inversion/eversion movement over a large range of motion. Isokinetic dynamometry seems an alternative method since it enables the force-time relationship to be studied in a more dynamic manner. However, in the literature no studies related to the ankle joint were found.

Referring to pathokinesiology, we studied muscular performance and muscular activation characteristics related to dynamic joint stability in athletes. Muscular performance (e.g. torque) was assessed by using an isokinetic dynamometer, which is designed primarily for reliable quantification of dynamic muscle function. ${ }^{6,9,10,36,44}$ Shoulder rotator muscles of healthy elite volleyball and badminton players were examined for peak torque and different strength ratios in different test modes (concentric and eccentric). For the ankle, the acceleration time parameter (i.e. the time required to accelerate to a preset dynamometer speed) was used. The acceleration time parameter is a muscle activation characteristic, derived from a maximal voluntary contraction. Since we used subjects not familiar with isokinetic testing, we did not know whether a possible motor learning effect would occur during inversion/version muscle testing. This was not examined in previous studies. Therefore, we first determined whether in healthy recreational athletes a motor learning effect exists during isokinetic inversion/eversion muscle testing. Secondly, students in sports training (CIOS) with chronic ankle instability where examined for differences in the acceleration time parameter.

\section{Isokinetic dynamometry}

The term isokinetic refers to a specific situation in which a muscle or muscle group contracts against a controlled accommodating resistance, which causes a limb segment to move at a constant angular (or linear) velocity within a prescribed range of motion. In isokinetic dynamometry different types of muscle performance (i.e. isometric, concentric 
and eccentric) can be measured. ${ }^{10,46}$ Isokinetic dynamometers commonly measure muscular forces that produce a rotational moment about a joint or a fixed body axis, with torque as the parameter of measurement of force. ${ }^{46}$ Studies of these systems showed that they are intrinsically accurate in their measurements of torque and have good or excellent test and retest reliability, particularly after proper instruction and familiarization of the patient with the testing procedures. ${ }^{46}$ Our studies were carried out on a Cybex 6000 isokinetic dynamometer.

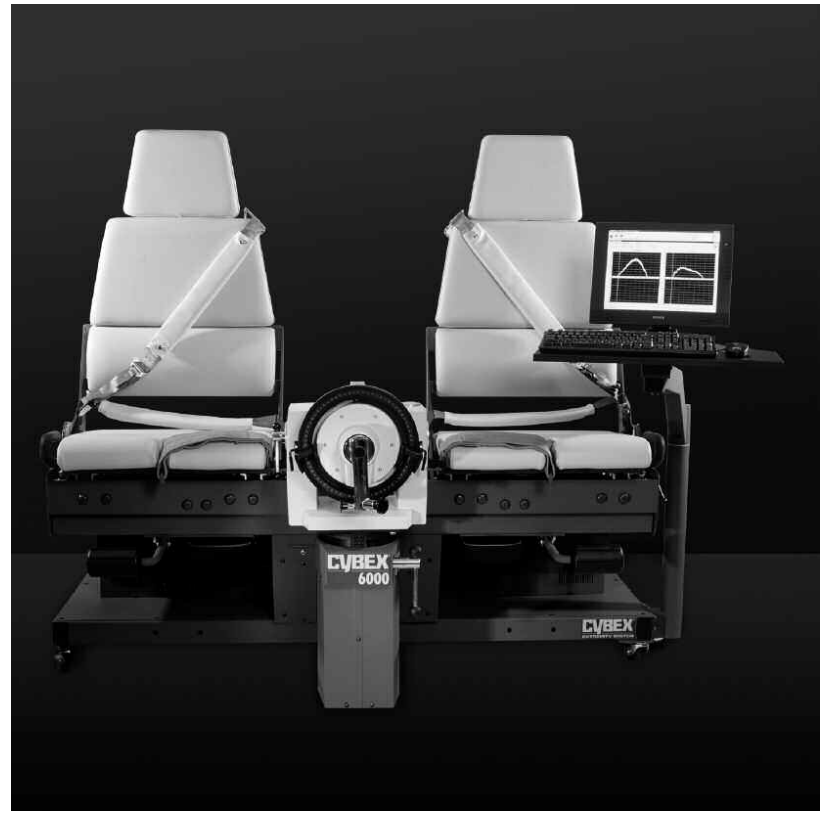

History

In the late 1960s J. Perrine developed the concept of isokinetic exercise which proved to be a revolution in exercise training and rehabilitation. The concept was born in a laboratory to help measure human muscle performance. Instead of the traditional exercises that involve a constant weight or resistance, Perrine developed the concept of isokinetics, which involves a dynamic pre-set fixed speed with resistance that is totally accommodating throughout the range of motion. The first published article describing isokinetic exercise was by Hislop and Perrine in 1967. ${ }^{24}$ Since the inception of isokinetics, this manner of testing and exercise has become increasingly popular in clinical, athletic and research settings. ${ }^{9,10,44,46}$ One of the main reasons for this popularity were the problems with manual muscle testing (MMT) clinicians experienced in their daily practice, when using a six-level scale that is nearly identical to the one that was originally proposed by Lovett and Martin in 1916 for the evaluation of victims of poliomyelitis. ${ }^{39}$ Using this grading system 5 means normal, or full motion with full 
resistance and 0 means no contractility of the muscle. The subjective element in grading the findings, as well as other weaknesses of the method, revealed the flaws of using this method in patients without paralytic disease. ${ }^{46}$ Using isokinetic dynamometry it was possible to make quantitative, objective measurements of human muscular performance. In the early 1990s Wilk et al. ${ }^{57}$ demonstrated isokinetic knee extension deficits ranging from 23-31\% in subjects bilaterally exhibiting a normal MMT score. Ellenbecker et al. ${ }^{12}$ reported similar findings with shoulder patients. It appears that not until $25-30 \%$ isokinetic muscular strength deficit exists, the clinician will be able to detect the deficiency with MMT techniques. 2 , 12,46,57

Many isokinetic studies of the knee joint were carried out and the popularity of isokinetic testing and training reached its peak in the 1980s. Later, in the 1990s, emphasis shifted to closed kinetic chain (CKC) exercises as these appeared to be safer and more related to functional movements. Consequently, the pendulum has swung from the use of open kinetic chain (OKC) exercises (e.g. isokinetics) to CKC exercises. Several studies indicated that no correlation exists between isokinetic testing and functional performance.,22 Other studies demonstrated a positive correlation between isokinetic testing and functional performance. 4,43,45,52,55,56 Unfortunately, many clinicians are unaware of numerous articles demonstrating the reliability, validity and efficiency of using isokinetics as a part of the total testing and training process. ${ }^{6,9,10,44}$

During the late 1990s it was shown that a combination of OKC and CKC exercises is necessary to achieve optimal knee rehabilitation programs. ${ }^{14,40,48,59}$ Considering this the clinical relevance of isokinetics increased and they became a valuable tool of treating and diagnosing the 'weak link' of the kinetic chain and possible compensation mechanisms in motor performance could be detected.

\section{Data analysis and interpretation}

Each isokinetic system has its own particular format for data collection and reporting. Common parameters of data analysis are the following $6,9,10$ :

- Peak torque: the single highest point on the torque curve and considered to be the gold standard in isokinetic measurements. ${ }^{21,29}$ The unit of measure for peak torque is Newton-meter ( $\mathrm{Nm}$ ) or foot-pounds (ft-lb).

- $\quad$ Peak torque to body weight: the measurements in which the peak torque is compared to body weight (normalized data).

- Angle of peak torque: represents the peak torque at a particular point in the range of motion.

- Total work: the total volume of work under the torque curve with each repetition. The unit of measure for total work is joule (J). 
- Average power: the total work divided by the time it takes to perform the work. The unit of measure for power is watt (W).

- Torque acceleration energy: the greatest amount of work performed in the first I/8 of a second of a single torque production in the test repetitions.

- Acceleration time: the time required to accelerate to a preset dynamometer speed.

- Endurance ratio: the ratio that occurs as the muscles exercise and fatigue.A certain number of reps are sampled (20\%) at the beginning and end of a test and the percent change from the beginning to the end of the test is calculated as the endurance ratio.

- $50 \%$ fatigue work: the amount of time the subject can maintain a repetitive peak torque level of $50 \%$ above the peak torque obtained at the initial contraction.

Thorough interpretation of isokinetic data is the basis of evaluation, treatment and discharge of the subject. There are various ways to interpret test results in isokinetic dynamometry. In the literature most clinical interpretations are based on the following $6,9,10$ :

- Bilateral comparisons: evaluating the differences (e.g. in peak torque, endurance) of the same muscle or muscle group between extremities during various muscle contractions (i.e. isometric, concentric, eccentric). Traditionally, these comparisons were based on concentric muscle contractions.

- Unilateral ratios: evaluating the relationship between the agonist and the antagonist (= reciprocal) in certain muscle groups of one extremity (e.g. knee flexors versus extensors, shoulder internal rotators versus external rotators). It is important whether muscles were measured in the concentric or eccentric mode. The conventional ratio (CVR) refers to concentric measurements of two different muscle groups (e.g. knee extensors and knee flexors). The dynamic control ratio (DCR) refers to dividing eccentric peak torque of the antagonist by the concentric peak torque of the agonist (e.g. eccentric shoulder external rotators by concentric shoulder internal rotators). The DCR is also known as the 'functional ratio' and became popular in de late 1990s.' Initially most studies were carried out on the knee joint. Later, some research was performed on the shoulder joint, especially in overhead athletes.

- Eccentric to concentric ratio: an internal muscle performance parameter (i.e. within the same muscle or muscle group ), performed in relation to functional activities. ${ }^{9}$ For example in throwing there is an eccentric action followed immediately by a concentric contraction of the glenohumeral internal rotators. 
- $\quad$ Peak torque to body weight: enables clinicians to compare and interpret test data from individuals with different anthropometric values. Even though a subject shows equal bilateral symmetry and normal unilateral ratios, the peak torque to body weight relationship can differ within a specific population (e.g. volleyball team).

\section{Terminology}

The terms 'open' and 'closed' kinetic chain have frequently led to polarizing and contradictory discussions both in scientific literature and in everyday practice of clinicians and trainers. The current description of OKC and CKC were defined by Steindler in 1955 and redefined in 1977..$^{1}$ However, Steindler did not use the terms in the context of therapeutic forms of movement, but rather stated that a kinetic chain is a combination of several successively arranged joints constituting a complex motor unit. He differentiated between two distinct forms, the so-called 'open' and 'closed' chain. An OKC was defined as a form of movement in which the distal segment is free to move in space. The seated knee extension (e.g. isokinetic knee testing) is one of the most commonly cited examples of this original definition. However, in this situation the distal segment is fixed to a machine. The CKC was described as a condition or environment in which this distal segment meets considerable external resistance that restrains free motion (e.g. leg press or squat exercise). The term 'considerable' was not well quantified; this led to some confusion and controversy about the exact definition of a CKC movement. Exercises like cycling or using stair climbing machines often referred to as CKC do not clearly belong to this category. The distal part of the extremity remains fixed to the pedal but the movement of the pedal and the trivial resistance level encountered while pedaling do not clearly qualify that exercise as a CKC exercise. It is difficult to speak of purely 'open' or 'closed' kinetic chains in ordinary locomotor performance or even in sports events. Most of these are combinations, like in walking (swing phase versus stand phase). Nevertheless, several attempts were made to implement these definitions in training and testing conditions. Most attention was, and frequently still is, payed to the question of which form of exercise offers advantages with respect to success of training or therapy without causing damage to active and passive joint structures. Many clinicians believe that, compared to OKC exercises, CKC exercises are safer and more functional. ${ }^{18}$ Often differentiation between OKC and CKC exercises is limited to the lower extremities. ${ }^{13}$ Most of the publications focus on movements of the knee joint and in this regard ankle or hip joints are rarely mentioned. ${ }^{13}$ Moreover, little clinical literature discussing the effects on upper extremities of OKC versus CKC exercises can be found. 


\section{Outline of the thesis}

After the General introduction (chapter I), chapter 2 deals with the terminology of 'open' (OKC) and 'closed' (CKC) kinetic chain. The use of OKC and CKC terminology is questionable and to a large extent used in relation to the knee joint. Therefore, a survey of the literature was carried out and a position paper was written. Suggestions were made to use other terms in defining corresponding manners of testing and training. Chapters 3 and 4 are based on the evaluation of muscle performance from shoulder internal and external rotator muscles in asymptomatic elite athletes. In chapter 3 elite Dutch volleyball players are examined to determine; I. whether differences exist between the dominant and non-dominant arm in concentric shoulder internal and external rotation strength; 2 . the external-internal strength ratio, known as the conventional ratio (CVR). In chapter 4 elite Dutch badminton players are examined to determine concentric and eccentric isokinetic peak torque values of shoulder rotator muscles. Derived from this data the CVR and the dynamic control ratio (DCR) are presented. Chapters 5 and 6 refer to studies on muscle activation characteristics of the ankle joint. The acceleration time parameter was used for athletes with chronic ankle instability (CAI). Using a dynamic test on ankle inversion/eversion we first had to determine whether a learning effect exists during concentric isokinetic testing of these ankle muscles (chapter 5). In chapter $\mathbf{6}$ we compare the affected ankle of patients with unilateral CAI with their unaffected ankle and with both ankles of healthy controls. First we test the hypothesis that patients with CAI have a delay in evertor muscle action time. Secondly we studied potential differences in evertor as well as invertor muscle acceleration time at $30^{\circ}$ and $120^{\circ}$ s, between affected and unaffected ankles. In chapter 7 the results of the different studies are discussed and summarized. Practical implications of isokinetic testing in athletes are provided for clinicians and trainers. 


\section{References}

I. Aagaard P, Simonsen EB, Magnusson SP et al.A new concept for isokinetic hamstrings and quadriceps muscle strength ratio. Am J Sports Med. 1998; 2: 23I-237.

2. Andersen $\mathrm{H}$, Jakobsen J.A comparative study of isokinetic dynamometry and manual muscle testing of ankle dorsal and plantar flexors and knee extensors and flexors. Eur Neurol. 1997; 37: 236-238.

3. Anderson MA, Gieck JH, Perrin D et al. The relationship among isometric, isotonic and isokinetic concentric and eccentric quadriceps and hamstring force and three components of athletic performance.J Orthop Sports Phys Ther. 1991; I4: I 14-I 20.

4. Barber SD, Noyes Fr, Mangine RE et al. Quantitative assessment of functional limitations in normal and ACL deficient knees. Clin Orthop. 1990; 255: 204-214.

5. Boruta PM, Bishop JO, Braly WG et al. Acute lateral ankle ligament injuries: a literature review. Foot Ankle. 1990; I: I07-II3.

6. Brown LE. Isokinetics in Human Performance. Leeds, UK: Human Kinetics; 2000.

7. Cass JR, Morey BF.Ankle instability: current concepts, diagnosis and treatment. Mayo Clin Proc. I984; I65- 170.

8. Cohen LA, Cohen ML.Arthrokinetic reflex of the knee. Am J Physiol. 1956; 184: 433-437.

9. Davies GJ. A compendium of isokinetics in clinical usage. Onalaska, Wisconsin: S\&S Publishers; 1992.

10. Dvir Z. Isokinetics: Muscle testing, Interpretation and Clinical Applications. New York, NY: Churchill Livingstone; 2004.

II. Ebig M, Lephart SM, Burdett RG et al.The effect of sudden inversion stress on EMG activity of the peroneal and tibialis anterior muscles in the chronically unstable ankle.J Orthop Sports Phys Ther. 1997; 26: 73-77.

12. Ellenbecker TS. Muscular strength relationships between normal grade manual muscle testing and isokinetic measurement of the shoulder internal and external rotators (abstract).J Orthop Sports Phys Ther. 1994; I: 72.

13. Ellenbecker TS. Closed kinetic chain exercise. Champain, USA: Human Kinetcis; $200 \mathrm{I}$.

14. Escamilla RF, Gleisig GS, Zheng $\mathrm{N}$ et al. Biomechanics of the knee during closed kinetic and open kinetic chair exercises. Med Sci Sports Exerc. 1998; 30: 556-569.

15. Ent van de FWC. Lateral ankle ligament injury [dissertation]. Erasmus University Rotterdam, The Netherlands; 1984.

16. Fahrer $\mathrm{H}$, Rentsch $\mathrm{HU}$, Gerber $\mathrm{NJ}$ et al. Knee effusion and reflex inhibition of the quadriceps.J Bone Joint Surg (Br). 1988; 70-B: 635-638.

17. Fernandes N,Allison GT, Hopper D. Peroneal latency in normal and injured ankles at varying angles of perturbation. Clin Orthop Rel Res. 2000; 375: 193-20I.

18. Fitzgerald GK. Open versus closed kinetic chain exercise: issues in rehabilitation after ACL reconstructive surgery. Phys Ther. 1997; 77: 1747-1754.

19. Freeman MA. Instability of the foot after injuries to the lateral ligament of the ankle.J Bone and Joint Surg (Br). 1965; 47: 669-677.

20. Freeman MA, Dean MR, Hanham IW.The etiology and prevention of functional instability of the foot.J Bone Joint Surg (Br). 1965; 47: 678-685. 
21. Gleeson NP, Mercer TH. The utility of isokinetic dynamometry in the assessment of human muscle function. Sports Med. 1996; I: I8-34.

22. Greenberger HB, Paterno MV. Relationship of knee extensor strength and hoping test performance in the assessment of lower extremity function.J Orthop Sports Phys Ther. 1995; 22: 202-206.

23. Heilman AE, BralyWG, Bishop JO et al.An anatomic study of subtalar instability. Foot Ankle. 1990; 10: 224-228.

24. Hislop H, Perrine JJ.The isokinetic concept of exercise. Phys Ther. 1967; 47: I I4-II 7.

25. Huston MS, Wojtys E. Neuromuscular performance in the ACL-deficient knee. In: Lephart SM, Fu FH, ed. Proprioception and neuromuscular control in joint stability. Leeds: Human Kinetics; 2000: I7I-I80.

26. Isakov E, Mizrahi J, Solzi P et al. response of the peroneal muscles to sudden inversion of the ankle during standing.J Sports Biomech. 1986; 2: 100-109.

27. Johnson MB, Johnson CL. Electromyographic response of peroneal muscles in surgical and nonsurgical injured ankles during inversion.J Orthop Sports Phys Ther. 1993; 18: 497-50I.

28. Kaminski TW. Concentric and eccentric force-velocity relationships between uninjured and functionally unstable ankles [dissertation]. University of Virginia, Charlottesville, NC; 1996.

29. Kannus P. Isokinetic evaluation of muscular performance: implications for muscle testing and rehabilitation. In J Sports Med. 1994; 15: SII-SI8.

30. Kemler HJ, Schmikli SL, Backx FJG. Kwart eeuw landelijke registraties van sportblessures in Nederland. Geneeskunde en Sport. 2005; 5: I35-I4I.

3I. Kleinrensink GJ, Stoeckart R, Meulstee J et al. Lowered motor conduction velocity of the peroneal nerve after inversion trauma. Med Sci Sports Exerc. 1994; 26: 877-883.

32. Konradsen L, Ravn JB.Ankle instability caused by prolonged peroneal reaction time. Acta Orthop Scan. 1990; 61: 388-390.

33. Konradsen L, Ravn JB, Sorensen Al. Proprioception at the ankle: the effect of anaesthetic blockade of ligament receptors.J Bone Joint Surg (Br). 1993; 75: 433-436.

34. Lentell GL, Baas B, Lopez D et al.The contributions of proprioceptive deficits, muscle function, and anatomic laxity to functional instability of the ankle.J Orthop Sports Phys Ther. 1995; 21: 206-21 5.

35. Lentell GL, Katzman LL,Walters MR. The relationship between muscle function and ankle stability.J Orthop Sports Phys Ther. 1990; II:605-6II.

36. Lephart SM, Riemann BL, Fu FH. Introduction to the sensorimotor system. In: Lephart SM, Fu FH, ed. Proprioception and neuromuscular control in joint stability. Leeds: Human Kinetics; 2000: xvii-xxiv.

37. Lofvenberg R, Karrholm J, Sundelin G. Prolonged reaction time in patients with chronic lateral instability of the ankle. Am J Sports Med. 1995; 23: 414-4I7.

38. Lohman AHM. Vorm en beweging. Utrecht: Bohn, Scheltema \& Holkema; 1986.

39. Lovett RW, Martin EG. Certain aspects of infantile paralysis. With a description of a method of muscle testing.J Am Med Assn. 1916; 66: 729-733.

40. Mikkelsen C.,Werber S, Eriksson E. Closed kinetic chain alone compared to combined open and closed kinetic chain exercises for quadriceps strengthening after $A C L$ reconstruction with respect to sports: a prospective matched follow up study. Knee Surg Sports Traumatol Arthrosc. 2000; 8: 337-342. 
4I. Nawoczenski DA, Owen MG, Ecker ML et al. Objective evaluation of peroneal response to sudden inversion stress.J Orthop Sports Phys Ther. 1985; 7: 107-109.

42. Nitz AJ, Dobner JJ, Kersey D. Nerve injury and grades II and III ankle sprains. Am J Sports Med. 1985; I3: |77-| 82.

43. Noyes Fr, Barber SD, Mangine RE. Abnormal lower limb symmetry determined by functional hop test after ACL rupture. Am J Sports Med. 1991; 19: 513-5I8.

44. Perrin DH. Isokinetic Exercise and Assessment. Leeds, UK: Human Kinetics; 1993.

45. Sachs RA, Adniel DM, Stone ML et al. Patellofemoral problems after ACL reconstruction. Am J Sports Med. 1989; 17: 760-765.

46. Sapega AA. Muscle performance evaluation in orthopaedic practice.J Bone Joint Surg (Am). 1990; 10: I562-I574.

47. Schaap GR, de Keizer G, Marti K. Inversion trauma of the ankle. Arch Orthop Trauma Surg. 1989; 108: 273-275.

48. Snyder-Mackler L, Delitto A, Baily SL. Strength of the quadriceps femoris muscle and functional recovery after reconstruction of the ACL.J Bone Joint Surg (Am). 1995; 77, I I66-I I 73.

49. Spencer JD, Hayes KC,Alexander IJ. Knee joint effusion and quadriceps reflex inhibition in man. Arch Phys Med Rehabil. 1984; 65: I7I-174.

50. Staples OS. Result study of ruptures of lateral ligaments of the ankle. Clin Orthop. 1972; 85: 50-58.

5I. Steindler A. Kinesiology of the human body under normal and pathological conditions. Springfield: Charles C Thomas; 1955 and 1977.

52. Tegner Y, Lysholm J, Lysholm M et al.A performance test to monitor rehabilitation and evaluate ACL injuries. Am J Sports Med. 1986; I4: I56-159.

53. Vaes P,Van Gheluwe B, Duquet W. Control of acceleration during sudden ankle supination in people with unstable ankles.J Orthop Sports Phys Ther. 200I; 31:741-752.

54. Vriend I, Kampen van B, Schmikli S et al. Ongevallen en Bewegen in Nederland (OBiN) 2000 - 2003. Amsterdam: Stichting Consument en Veiligheid; 2005.

55. Wiklander J, Lysholm J. Simple test for surveying muscle strength and muscle stiffness in sportsmen. Int J Sports Med. 1987; 8: 50-54.

56. Wilk KE, RomanilloWT, Soscia SM et al.The relationship between subjective knee scores, isokinetic testing and functional testing in the ACL-reconstructed knee.J Orthop Sports Phys Ther. 1994; 20: 60-73.

57. Wilk KE, Arrigo CA, Andrews JR.A comparison of individuals exhibiting normal grade manual muscle test and isokinetic testing of the knee extension and flexion (abstract). Phys Ther. 1992; $72: 6$.

58. Wilkerson GB, Nitz AJ. Dynamic ankle stability: mechanical and neuromuscular interrelationships.J Sports Rehabil. 1994; 3: 43-57.

59. Witvrouw E, Lysens R, Bellemans J et al. Open versus closed kinetic chain exercises for patellofemoral pain: a prospective, randomized study. Am J Sports Med. 2000; 28: 687-694.

60. Young A, Stokes M, Iles JF. Effects of joint pathology on muscle. Clin Orthop Rel Res. 1987; 21 9: 21 -27. 


\section{Chapter 2}

\section{Training and testing in open versus closed kinetic chain}

F. Mayer', A. Schlumberger ${ }^{2}$, R. van Cingel $^{3}$, Y. Henrotin ${ }^{4}$,W. Laube ${ }^{5}$, D. Schmidtbleicher ${ }^{6}$

' Department of Rehabilitation and Prevention Sports Medicine, University Freiburg, Germany.

2 EDEN Reha, rehabilitation clinic, Donaustauf, Germany.

${ }^{3}$ Sports Medical Center Papendal,Arnhem, The Netherlands.

${ }^{4}$ Bone and Cartilage Research Unit, Institute of Pathology, University of Liege, Belgium.

${ }^{5}$ Department of Traumatology, University of Vienna Medical School,Austria.

${ }^{6}$ Department of Sports Sciences, University of Frankfurt, Germany.

Published: Isokinetics and Exercise Science. 2003; 4: I 8 I- I 87 


\begin{abstract}
Optimization of different forms of training and testing in sports and therapy has traditionally been debated by various groups. Especially, the use of so-called open and closed kinetic chain exercises has frequently been a focal point.

Scientific studies have indicated that no specific form of exercise and/or training has any particular advantage over the other. This applies to both assessment of efficiency, consideration of compression and shear forces, muscular activity and the extent of cocontractions. Unlike the broadly-applied non-specific and uncritical assessment of open and closed kinetic chain exercises, a specific application using the advantages of both procedures must be considered due to clinical, therapeutic and training-physiological aspects. Specificity refers to the training of either an isolated joint-muscle unit (arthron) or a system (group) of joints and muscles.

Considering the original definitions and past misinterpretations, it appears logical to emphasize the role of physiological mechanisms operating in each form of training and testing. Therefore, the use the terms: single-joint ( $\mathrm{SJ}$ ) or multi-joint (MJ) training, is recommended since this would best reflect the area of application, according to a recent consensus expressed by EISCSA. Consequently, SJ and MJ exercises should be applied both in isolation and in combination as indicated by the principles of specificity. On the other hand, continuous use of the terms open and closed kinetic chain exercises is confusing, erroneous, leads to polarizing discussions and should hence be relegated to the past.
\end{abstract}

\title{
Introduction
}

The terms 'open' and 'closed' kinetic chain have frequently led to polarizing and contradictory discussions both in scientific literature and in everyday practice of various therapists, clinicians and trainers. Overall, such controversial discussion rarely arose regarding a single method, therapy and/or measurement procedure. As a consequence, many attempts were made to promote one of the two forms but the necessity for these attempts is questionable and has not been successful to date.

Due to controversial arguments for and against open kinetic chain (OKC) and closed kinetic chain (CKC) exercises, the European Interdisciplinary Society for Clinical and Sports Application (EISCSA) has taken on the task of issuing a consensual opinion founded on evidence-based data and practical experience. To this end, a so-called stateof-the-art session was held during the 2nd European EISCSA Congress 2002 in CransMontana Switzerland, during which this topic was addressed by scientists, physiotherapists, doctors, athletic trainers and representatives of industry. Prior to the congress, data and facts were researched in literature and presented during this 
particular session. Finally, an open discussion was held in which the presenters, the keynote speakers of the Congress, EISCSA members and congress attendees participated.At the end of the discussion, a consensus was reached. The following overview thus expresses the current position of EISCSA regarding the topic "Training and testing in open versus closed kinetic chain."

\section{Background}

Originally, the basis for the concept of kinetic chain originated from the field of engineering mechanics. Initial publications date back to Reuleaux in 1875, who studied the coupling of various movements. ${ }^{32}$ Reuleaux understood the combination of movements of various single components as rigid, overlapping segments that are interconnected via pin joints. These joints create a system, whereby a movement in one joint produces or affects movements at other joints in the kinetic link. ${ }^{32}$ Subsequent scientific discussions focused increasingly on the use of the terms 'kinetics' and 'kinematics'. The terms open (OKC) and closed kinetic chain (CKC) were coined in the course of these discussions.

The current descriptions of OKC and CKC were defined by Steindler in 1955 and redefined in $1977 .{ }^{36}$ However, Steindler understood the terms at that time not in the context of therapeutic forms of movement, but rather stated that a "kinetic chain is a combination of several successively arranged joints constituting a complex motor unit." He differentiated between two distinct forms, the so-called 'open' and the 'closed' chain. ${ }^{36}$ An open chain was thereby a form of movement in which the terminal joint was free during performance. On the other hand, in closed chain exercises the terminal joint was restrained in its movement, by application of external resistance. Furthermore, regarding this particular issue Steindler described three separate forms:

I. The external resistance may be overcome and the distal segment comprising the joint may move against this resistance.

2. The external resistance is absolute, in which case the proximal segment moves relative to the distal segment.

3. The limitations of muscular effort may assert themselves both distally and proximally and may be insurmountable, in which case no visible motion is produced. In summary, it can be stated that CKC exercises can be described as "a condition or environment in which the distal segment meets considerable external resistance that restrains free motion." Consideration in assessing athletic movement or movements aimed at accomplishing performance is more difficult. In this respect, Steindler had formulated that in OKC exercises comprising athletic activity, aspects of creating velocity and acceleration take precedence, while CKC exercises focus more on generating 
strength. ${ }^{36}$ This obviously means that an isolated, independent view of the two forms of exercise appears to be inappropriate, at least for athletic movements, but even for everyday motion. Steindler supported this viewpoint in a summarizing statement: "It can be seen, that it is difficult to speak of purely open or closed kinetic chains in ordinary locomotor performance or even in sports events. Most of these are combinations in which speed and force are developed at ratios varying with the specific motor act." 36 Nevertheless, several attempts have been made to implement these original definitions in training and testing conditions. However, from today's point of view, these attempts proved unsuccessful. Most of the attention was, and frequently still is, given to the question of which form of exercise offers advantages with respect to success of training or therapy without causing damage to active and passive joint structures. It has often been claimed that performing in a CKC configuration is advantageous due to its more intimate relationship to functional movements in sports and in activities of everyday living. This approach is offset by a more-or-less unspecific focusing on movement processes involving several segments, within which isolated deficits of individual arthrons are less likely apparent. Open kinetic chain exercises, on the other hand, are rated advantageous in therapy and training in isolated arthromuscular queries. Thus recent discussion focuses less on a polarizing preference for one of the two exercise forms but more on differential indication for their application and their effect on various components. Moreover, consideration must be given to whether the terms OKC and CKC exercise are a meaningful choice in designating forms of exercise, especially since they are apparently no longer used in the sense of the original definition. Consequently, alternative ways of looking at the descriptions of various forms of movement in sports and everyday living as well as in training and therapy, should be discussed, challenging Steindler's original ideas. Dillman et al. suggested the terms 'boundary condition' and 'load' in the context of exercise. ${ }^{10}$ They distinguished between fixed boundary with external load, such as in squats or push-ups, moveable boundary with no external load (segmental movement of an extremity without load) and moveable boundary with external load, without differentiating between open and closed chain exercises. ${ }^{10}$ Lephart and Henry further differentiated the type of load application and addressed especially the upper extremities. ${ }^{23}$ Differentiation was made between fixed or moveable boundary with external axial load (e.g. push-ups vs. bench-press), moveable boundary with external rotational load (e.g. front-lift) and moveable boundary with no load (passive and active positioning). ${ }^{23}$ Additional current and previous publications consider differences between so-called single-joint and multi-joint exercises ${ }^{1,12}$ or between weight-bearing and non-weight-bearing exercises. ${ }^{3,4}$ Blackard et al. postulated that external load was more important than boundary condition in describing human activity. ${ }^{5}$ 


\section{Discussion of open and closed kinetic chain exercises}

The highly controversial issue of kinetic chains can apparently be traced to an incorrectly understood definition on the one hand and on various viewpoints of the examiners, on the other. Thus, it appears meaningful to discuss different points of view, not forgetting that these have reciprocal influence and according to physiological requirements, have the same basis.

Physiological and biomechanical considerations

In accordance to current literature, differentiation must be made between relevance for activities of daily living, impact of shear and compression forces and sensorimotor aspects of motor control. ${ }^{8}$ It is widely accepted that OKC as well as CKC exercises are involved in nearly all movements in sports and activities of everyday living. In various forms of exercise such as human walking and running, as well as shooting or throwing movements, in which axial and/or rotational, external resistance is applied with fixed and/or free distal segment. Hence, isolated preference for the application of a single form of exercise, is not substantiated considering daily or athletic activities respectively. In addition, basic separation of OKC and CKC exercises is difficult. From a biomechanical point of view, it must be considered that shear and compression forces act on a joint in nearly all movements. In this context, Lutz et al. point out that, in differentiating between OKC and CKC exercises, the proportion of shear force in OKC exercises may be greater, while compression forces are more evident in CKC exercises. ${ }^{25}$ However, a more detailed view reveals that both compression and shear forces are created by the applied muscular forces and therefore cannot easily be separated from each other. The 'anterior shear forces' are another often cited influencing parameter in discussing OKC and CKC exercises. Beynnon et al. ${ }^{3,4}$ measured $A C L$ strain via strain gauges in vivo. Results showed no significant differences in average maximal $A C L$ strain values produced by OKC flexion/extension exercises and CKC squats. The findings by Jurist and Otis ${ }^{22}$ indicated that for seated knee extension exercise, tibiofemoral displacements depended both on length of the lever arm and knee flexion angle. Moreover, they found almost no anterior displacement with a proximal pad placement in all knee angles and with a middle pad placement at $60^{\circ}$ and $90^{\circ}$ of knee flexion. ${ }^{22}$

From a neurophysiological point of view, OKC motion consists mainly of one muscle or muscle group that operates on a single joint, whereas CKC motion is mostly a multi-joint movement with controlled co-contractions of synergistic and antagonistic muscles. In addition, there are different activation patterns in relation to the modus of load. Highest quadriceps muscle activity was found to be near full knee flexion in CKC (squat, legpress) whereas such a level of activity is characteristic of near full extension in OKC. Upon executing knee extension in OKC, EMG activity of the antagonist (hamstrings) is 
low and additionally only measurable in the terminal range of motion. ${ }^{2,11}$ Escamilla et al. ${ }^{15}$ compared further biomechanical and electromyographic data for squats, leg-press and knee extension exercises. The authors found more rectus femoris activity in OKC exercises, while CKC produced more muscle activity of the vasti. ${ }^{15}$ Blackard et al. ${ }^{5}$ compared mean integrated EMG activity during biomechanically-comparable CKC (fixed external load) and OKC (moveable, no load and external load) exercises. Results have led to the conclusion that activities of similar biomechanical motions and mass of loading have comparable EMG values.

\section{Clinical considerations: rehabilitation and training}

In the past, discussion of the application of OKC and CKC exercises in rehabilitation following injury has led to considerable changes in rehabilitation strategies. Although OKC exercises were originally propagated, CKC exercises gained increasing attention and preference in everyday clinical setting. As already mentioned, many physicians believe that CKC exercises are safer and more functional compared to OKC exercises. ${ }^{19}$ Often, differentiation between OKC and CKC exercises is limited to the lower extremities. ${ }^{13}$ Most of the publications focused on movements of the knee joint ${ }^{37,38}$ and, in particular, on rehabilitation of the knee after $A C L$ reconstruction. ${ }^{18,35,39}$ Rarely, ankle or hip joints have been mentioned in this regard. ${ }^{5,33}$ Furthermore, almost no clinical literature can be found discussing the effects of OKC vs. CKC exercises on upper extremities.

In the field of rehabilitation, the terms OKC and CKC are frequently used to describe various strengthening exercises, whereas different results have been observed with respect to training efficiency of OKC and CKC exercises. Bynum et al. and Morrissey et al. tried to determine whether 'open' or 'closed' kinetic chain exercises are preferable in ACL rehabilitation. ${ }^{7,29}$ They concluded that only minor differences were present after a 19-month follow-up. In instrumented knee laxity measurements, CKC exercises revealed slightly less laxity, but there was no difference in either the Lysholm Score or the subjective score. ${ }^{7}$ However, Mikkelsen et al. ${ }^{27}$ observed that functional outcome in ACL patients can be increased if single-joint knee extension is added to multiple-joint training. Witvrouw et al. ${ }^{40}$ found that patellofemoral patients who followed either a 5 -week CKC or OKC rehabilitation program showed statistically significant improvement in subjective and clinical outcome after a 3-month follow-up. With respect to isokinetically-tested strength performance, OKC rehabilitation group improved significantly after 3 months. Various scientific methods are applied in assessing clinical relevance of CKC vs. OKC exercises. In simulations, mathematical models showed that squatting exercises should be preferred to isolated, in particular isometric flexion-extension exercises, because of reduced anteriorly directed forces. ${ }^{25}$ Cadaver models revealed that elevated tibiofemoral 
compression under stress leads to a reduction of the resultant ACL force. ${ }^{20,26}$ However, clinical relevance of cadaver models and simulations is a matter of critical discussion with respect to the lack of in-vivo neuromuscular control mechanisms.

In spite of these controversial results, CKC exercises are often favoured by many clinicians because they are considered safe with respect to ACL due to co-activation of the hamstrings. EMG recruitment patterns reveal that in relation to OKC, CKC exercises produce an increased muscular co-contraction at the same angles. Thus, the preference for CKC exercises was initially supported by EMG studies which indicated that the extent of co-contractions of quadriceps and hamstrings in squats was higher than in isolated knee-flexion/extension exercises. " However, even if there is a minimal activation of the hamstrings in order to counteract anterior shear forces, recent EMG studies refuted significant co-contraction in CKC exercises. ${ }^{15,16,17,19}$ Escamilla et al. ${ }^{15}$ found no differences in hamstring co-activation between knee extension and leg-press. On the other hand, squat exercises showed significantly higher co-activation of hamstrings compared to leg-press. ${ }^{15}$

Knee patients frequently demonstrate Lombard's paradox during leg-press training. ${ }^{14,24,31}$ As a compensation mechanism, hamstrings and glutei muscles are activated for knee extension by using punctum fixum at the footplate and extension of the pelvis and hip joint. In this case, co-contraction is tolerated as a compensation mechanism, but not considered a normal movement pattern. Additionally, the amount of antagonistic coactivation in knee extension depends on the training status and training situation. ${ }^{30}$ Consequently, multiple- and single-joint exercises do not necessarily differ with respect to co-activation. Moreover, it is questionable whether co-contractions are always desirable from a clinical point of view.

In several publications it was postulated that OKC exercises led to increased tibial AP displacement and this might be detrimental in rehabilitation, particularly after ACL grafts. ${ }^{8}$ However, contrary to this notion which is widespread especially in the clinical setting, current articles have demonstrated that CKC exercises do not necessarily lead to less ACL stress. Already mentioned is the study by Beynnon, who indicated no difference in maximal $A C L$ strain between squats and isolated knee flexion/extension using implanted transducers in vivo.,4

In addition to a more biomechanical-clinical point of view, a metabolic point of view should also be taken into consideration. It is known that reduction of intra-articular oxygen partial pressure has deleterious consequences for the metabolism of chondrocytes. Miltner concluded that a velocity of $60 \% \mathrm{~s}$ in OKC exercises leads to a reduction of intra-articular $\mathrm{pO} 2$ below the resting value, whereas $180 \%$ results in a very small decrease. ${ }^{28}$ The most dangerous mechanisms for cartilage integrity occur when hypoxia is followed by tissue reoxygenation. Due to exercise-induced rise of intra- 
articular pressure above synovial capillary perfusion pressure which causes intra-articular hypoxia, reperfusion of synovial membrane takes place, thus creating an ischaemiareperfusion process and production of reactive oxygen species. ${ }^{6}$ Persistence of synovial inflammation can be due to exercise-induced hypoxic-reperfusion injury mediated by reactive oxygen species. Measurement of lipid peroxidation products in synovial fluid might give further information. ${ }^{34}$ Nevertheless, differentiated results on intra-articular pressure using OKC and CKC exercises are not yet known. Baratta postulated preference of CKC exercise in osteoarthritis, since qualitative geometrical analysis indicates that antagonists provide regulated stabilizing functions to distraction forces generated by the agonist muscles. ${ }^{2}$ He emphasized evidence of equalizing articular surface pressure distribution to preserve and prolong cartilage integrity.

With respect to the clinical terminology, there are several unclear aspects in the use of OKC and CKC exercises. The original definition of OKC as corresponding to movement with moveable distal segment and CKC as movement with a fixed distal segment contradicts the use in everyday clinical practice. Within the framework of rehabilitation, CKC exercises are usually understood to mean application of a resistance from ground to the foot. Thus, according to Steindler, ergometric exercise in rehabilitation would not be considered $\mathrm{CKC}$, but an OKC. ${ }^{2 I}$ These misunderstandings and the weighting of inappropriately applied definitions led to a subsequent incorrect application of various exercises in rehabilitation. It is therefore recommended to abandon the terms OKC and CKC as used in clinical rehabilitation. ${ }^{9}$

Moreover, the typical approach according to which multiple-joint exercises (or testing procedures) are used to improve (or test) strength and function in a complex manner, whereas single-joint exercises are used to optimize or diagnose strength performance in single muscles or muscle groups, has to be substantiated. For clinical intervention a systematic classification of exercise and movements appears to be more adequate. $A$ more detailed approach in describing exercise might include the specific intervention goal, the type of exercise, training devices and training criteria. Finally, it should be recognized that different exercises have their place in training and therapy as well as in testing. The demand that the definition of terms should support understanding of physiological relationships and in particular should not be used as terms of value judgment in clinical rehabilitation, is common to all cited authors and reflects EISCSA position.

\section{Conclusions}

Concerning the terminology it appears appropriate to abandon the terms OKC and CKC exercises. Rather, it would be helpful to define the corresponding forms of testing 
or training either by the site of resistance application or, preferably, by the muscle groups or joints involved.

No negative effects can be ascribed in principle to single-joint exercises compared to multi-joint exercises. In this context the therapist should work conscientiously with the application of different forms of training and testing. Depending on the task in hand and/or state of rehabilitation, each form of training has its own special importance, which usually requires a combination of both, single and multi-joint applications. It can be assumed that both forms are necessary to improve sensorimotor capacity and function. Specific activation of leg muscles can be observed characterizing each exercise.

Furthermore, within a distinct exercise, muscle activity may depend on muscle action and specific pathology. In this sense, the kinetic chain terminology which has been used till now, does not help in classifying exercises on the basis of muscle activation. This is especially evident when aspects of minimizing joint forces and ligament strain are integrated.

\section{Acknowledgements}

The following persons served as additional co-authors. We acknowledge their contribution to this position stand paper;A. Belli, E. Brassine, S. Bruhn, J.L. Croisier, M. Dahlinger, P. Durjak G. Fenkart, B. Herbeck, G. Huni, H. Martin, L. Radlinger, B. SchulteFrei, P.Voisin (in alphabetical order). 


\section{References:}

I. Augustsson J,Thomee R.Ability of closed and open kinetic chain tests of muscular strength to assess functional performance. Scand J Med Sci Sports 10 (2000), I64-I68.

2. Baratta B, Solomonow M, Zhou BH et al. Muscular coactivation:The role of the antagonist musculature in maintaining knee stability. Am J Sports Med 16 (1988), II3-I 22.

3. Beynnon BD, Johnson RJ, Fleming BC et al.The strain behaviour of the anterior cruciate ligament during squatting and active flexion-extension: a comparison of open and closed kinetic chain exercise. Am J Sports Med 25 (1997), 823-829.

4. Beynnon BD, Fleming BC, Johnson RJ et al.Anterior cruciate ligament strain behaviour during rehabilitation exercises in vivo. Am J Sports Med 23 (1995), 24 - 34.

5. Blackard DO, Jensen RL, Ebben WP. Use of EMG analysis in challenging kinetic chain terminology. Med Sci Sports Exerc 3I (1999), 443-448.

6. Blake DR, Unsworth J, Outhwaite JM et al. Hypoxic-reperfusion injury in the inflamed human joint. The Lancet II (1989), 289-292.

7. Bynum EB, Barrack RL,Alexander AH. Open versus closed kinetic chain exercises after anterior cruciate ligament reconstruction: a prospective randomized study. Am J Sports Med 23 (1995), 40 I-406.

8. Davies GJ, Heiderscheit BC, Schulte $R$ et al. The scientific and clinical rationale for the integrated approach to open and closed kinetic chain rehabilitation. Orthop Phys Ther Clin North Am 9 (2000), 247267.

9. Di Fabio RP. Making jargon from kinetic and kinematic chains.J Orthop Sports Phys Ther 29 (1999), I42143.

10. Dillman CJ, Murray TA, Hintermeister RA. Biomechanical differences of open and closed kinetic chain exercises with respect to the shoulder.J Sport Rehabil 3 (1994), 228-238.

II. Draganich LF, Jaeger RJ, Kralj AR et al. Coactivation of the hamstrings and quadriceps during extension of the knee. JBJS 7I-A (1989), 1075-108I.

12. Dvir Z.An isokinetic study of combined activity of the hip and knee extensors. Clin Biomech II (1996), |35-138.

13. Ellenbecker TS. Closed Kinetic chain exercise. Human Kinetics, Champaign $200 \mathrm{I}$.

14. Ernst GP, Saliba E, Diduch DR et al. Lower extremity compensations following anterior cruciate ligament reconstruction. Phys Ther 80 (2000), 25I-260.

15. Escamilla RF, Fleisig GS, Zheng $\mathrm{N}$ et al. Biomechanics of the knee during closed kinetic and open kinetic chair exercises. Med Sci Sports Exerc 30 (1998), 556-569.

16. Escamilla RF, Fleisig GS, Zheng $\mathrm{N}$ et al. Effects of technique variations on knee biomechanics during the squat and leg press. Med Sci Sports Exerc 33 (200I), I552-I566.

17. Escamilla RF. Knee biomechanics of the dynamic squat exercise. Med Sci Sports Exerc 33 (200I), I27-I4I.

18. Feiring $D C$, Ellenbecker T. Single versus multiple joint isokinetic testing with $A C L$ reconstructed patients. Isokinet Exerc Sci 6 (1996), I09-II 5. 
19. Fitzgerald GK. Open versus closed kinetic chain exercise: issues in rehabilitation after anterior cruciate ligament reconstructive surgery. Phys Ther 77 (1997), I747-I754.

20. Hsieh HH,Walker PS. Stabilizing mechanisms of the loaded and unloaded knee joint.JBJS 58-A (I976), 87-93.

21. Irrgang JJ, Neri R. The rationale for open and closed kinetic chain activities for restoration of proprioception and neuromuscular control following injury, In: Proprioception and neuromuscular control in joint stability, Lephart SM, Fu FH. Human Kinetics 2000, 363-374.

22. Jurist KA, Otis JC.Anteroposterior tibiofemoral displacements during isometric extension efforts, The roles of external load and knee flexion angle. Am J Sports Med (1985), 254 - 258.

23. Lephart SM, Henry TJ.The physiological basis for open and closed kinetic rehabilitation of the upper extremity.J Sports Rehab 5 (1996) $71-87$.

24. Lombard WP.The action of two-joint muscles. Am Phys Educ Rev 8 (1903).

25. Lutz GE, Palmitier RA, An KN et al. Comparison of tibiofemoral joint forces during open-kinetic-chain and closed-kinetic-chain exercises. JBJS 75-A (1993), 732-739.

26. Markolf KL, Gorek JF, Kabo JM. Direct measurement of resultant forces in the anterior cruciate ligament. An in vitro study performed with a new experimental technique.JBJS 72-A (1990), 557-567.

27. Mikkelsen C,Werner S, Eriksson E. Closed kinetic chain alone compared to combined open and closed kinetic chain exercises for quadriceps strengthening after anterior cruciate ligament reconstruction with respect to sports: a prospective matched follow-up study. Knee Surg Sports Traumatol Arthrosc 8 (2000), 337-342.

28. Miltner O, Schneider U, Graf j, Nithard U. Influence of isokinetic and ergometric exercises on oxygen partial pressure measurement in the human knee joint. Oxygen Transport to tissue XVIII, Edited by Nemoto and LaManna, Plenium Press. New York 1997: 183-89.

29. Morrissey M, Hudson ZL, Drechsler WI et al. Effects of open versus closed kinetic chain training on knee laxity in the early period after anterior cruciate ligament reconstruction. Knee Surg Sport Traumatol Arthrosc 8 (2000), 343-348.

30. Osternig LR, Hamill J, Lander JE et al. Co-activation of sprinter and distance runner muscles in isokinetic exercises. Med Sci Sports Exerc 18 (1986), 43I-435.

3I. Osternig LR, Ferber R, Mercer J et al. Human hip and knee torque accommodations to anterior cruciate ligament dysfunction. Eur J Appl Physiol 83(2000), 7I-76.

32. Reuleaux F. Theoretische Kinematik- Grundzüge einer Theorie des Maschinenwesens.Verlag Vieweg Braunschweig (1875).

33. Seto JL, Brewster CE. Treatment approaches following foot and ankle injury. Clin Sports Med I3 (1994), 695-718.

34. Singh D, Nazhat NB, Fairburn K et al. Electron spin resonance spectroscopic demonstration of the generation of reactive oxygen species by diseased human synovial tissue following ex vivo hypoxiareoxygenation. Ann Rheum Dis 54 (1995), 94-9. 
35. Snyder-Mackler L, Delitto A, Bailey SL. Strength of the quadriceps femoris muscle and functional recovery after reconstruction of the anterior cruciate ligament. JBJS 77-A (1995), I I66-I I 73.

36. Steindler A. Kinesiology of the human body under normal and pathological conditions. Springfield, Charles $C$ Thomas 1955 and 1977.

37. Tang SF, Chen CK, Hsu R et al.Vastus medialis obliquus and vastus lateralis activity in open and closed kinetic chain exercises in patients with patellofemoral pain syndrome. Arch Phys Med Rehabil 82 (200I), |44|-| 445 .

38. Wilk KE, Andrews JR. The effects of pad placement and angular velocities on tibial displacement during isokinetic exercise.J Orthop Sports Phys Ther 17 (1993), 23-30.

39. Wilk KE, RomanielloWT, Soscia SM et al.The relationship between subjective knee scores, isokinetic testing and functional testing in the ACL-reconstructed knee.J Orthop Sports Phys Ther 20 (1994), 60-73.

40. Witvrouw E, Lysens R, Bellemans J et al. Open Versus Closed Kinetic Chain Exercises for Patellofemoral Pain:A Prospective, Randomized Study. Am J Sports Med 28 (2000), 687 - 694. 


\section{Chapter 3}

\section{Strength values of shoulder internal and external rotators in elite volleyball players}

R. van Cingel', G.J. Kleinrensink², R. Stoeckart ${ }^{2}$, G. Aufdemkampe ${ }^{3}$, R. de Bie Bi H. Kuipers $^{5}$

I Sports Medical Center Papendal,Arnhem, The Netherlands.

2 University Medical Center Rotterdam, Department Neuroscience, Rotterdam, The Netherlands.

${ }^{3}$ University of Professional Education, Faculty of Health Care, Utrecht, The Netherlands.

${ }^{4}$ Department of Epidemiology, Maastricht University, The Netherlands.

${ }^{5}$ Department of Movement Sciences, Maastricht University, The Netherlands.

Published: Journal of Sports Rehabilitation. 2006; 1 5: 237-245 


\begin{abstract}
Objective:To determine concentric shoulder external-internal rotator strength, dominant and non-dominant shoulder differences and agonist/antagonist ratio's.

Design:A transversal study of isokinetic dynamometry of healthy shoulders, $95 \%$ confidence intervals are presented.

Participants: 35 asymptomatic elite, male volleyball players.

Measurements: Peak torque normalized for body weight was recorded at 60, 180 and $300 \%$ with a Cybex 6000 dynamometer.

Results: I) internal rotators were significantly stronger than external rotators of the same shoulder; 2) internal rotators of the dominant arm were significantly stronger than of the non-dominant arm; 3) no difference existed between external rotators of the dominant and the non-dominant arm; 4) external-internal rotator ratios of the dominant arm were significantly lower than of the non-dominant arm; and 5) no differences were found between the ratios of each arm separately.

Conclusions: Data presented are important for interpreting isokinetic shoulder rotator strength tests in elite volleyball players and could be relevant in rehabilitation and prevention of shoulder injuries.
\end{abstract}

\title{
Introduction
}

The shoulder is a complex joint characterized by a high degree of mobility combined with a significant need for dynamic stability. It has previously been reported that muscles, comprising the rotator cuff, serve as dynamic stabilizers of the shoulder. ${ }^{1,17}$ This neuromuscular aspect is especially important in athletes who perform activities requiring repeated overhead arm positions (e.g. volleyball players, baseball pitchers, tennis players) in order to provide the optimal stabilization required during the immense forces that are produced at the shoulder girdle complex.

In the modern volleyball game the main form of attack is the smash or 'spike'. ${ }^{4} \mathrm{~A}$ highly skilled volleyball player spikes about 40.000 times a year. The impact occurs in an anteversion position of about $170^{\circ}$ to $140^{\circ}$ with neutral rotation. The speed of the hand is approximately $13.1 \mathrm{~m} \mathrm{~s}^{-1}$ accelerating the ball to velocities of up to $120 \mathrm{~km} \mathrm{~h}^{-1} .^{22}$ During the spike quick reactions to changes in ball position, direction, and spin placed on the ball involves added stress on the dynamic stabilizers of the shoulder. ${ }^{21}$ Although each sport requires specific techniques and kinematics, the arm motions needed to perform a volleyball serve or spike resemble, to some extent, those of other overhead sport activities..$^{8,15,21,29,30}$ Rokito et al. ${ }^{29}$ described EMG patterns of the rotator cuff, anterior deltoid, teres major, latissimus dorsi, and pectoralis major muscles during the volleyball 
serve and spike. They showed that during the volleyball spike and serve, muscle activity patterns were comparable to the baseball pitch and the tennis serve.

Comparable to baseball pitchers and tennis players, elite volleyball players frequently suffer from shoulder injuries. 2,19,22,40 Holzgraefe et al. ${ }^{19}$ demonstrated that suprascapular neuropathy is a frequent finding in the dominant arm of elite volleyball players, resulting in a loss of recruitable motor unit potentials during EMG examination, combined with infraspinatus and supraspinatus atrophy. Wang and Cochrane ${ }^{35}$ identified rotator cuff muscle and tendon injuries or involved lesions as the main shoulder injuries in top level English male volleyball athletes in the UK. Factors such as rotator cuff, lower trapezius, and serratus anterior muscle weakness and muscle imbalance have been suggested as intrinsic factors contributing to such injuries. ${ }^{34,35}$ In addition, the duration of the motion combined with the peak force might play an important role as demonstrated in the volleyball spike. For most muscles, Rokito et al. ${ }^{29}$ showed that EMG activity is greater during each phase of the spike because the range of motion takes place in less time compared with the corresponding phase of the serve. This factor allows the athlete to spike in a shorter time but may place the shoulder at more risk for injuries.

Considering the important role active stabilizers play in shoulder biomechanics, it seems imperative to evaluate the shoulder muscle performance of volleyball players that is required during overhead arm activities. Collecting reference values in asymptomatic athletes involved in activities requiring overhead arm positions using isokinetic dynamometry is well documented and clinically accepted method in studying baseball

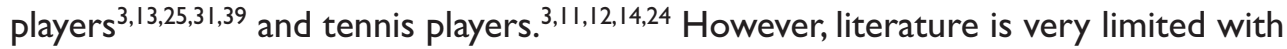
respect to shoulder strength values of asymptomatic male volleyball players. ${ }^{33,34}$ Reference values are important for interpreting isokinetic shoulder rotator strength tests and could be relevant in rehabilitation and prevention of shoulder injuries. Therefore, the purposes of this study were I) to determine whether differences exist between the dominant and non-dominant arm in concentric shoulder external and internal rotation strength and 2 ) to determine external-internal strength ratios in asymptomatic male elite volleyball players.

\section{Methods}

\section{Subjects}

Thirty-five asymptomatic male elite volleyball players were included in the study.All subjects were competing in the highest division of the Dutch volleyball league for at least two years and selected for the Dutch National team. Subjects practiced 4-6 hours per day, 5 days a week. Prior to the start of the competition, all players performed the same preseason strengthening program (i.e. dumbbell training) as described by Pappas et al. ${ }^{27}$, 
with the emphasis on the external rotators and scapular stabilizers. The program was performed 5 days a week over a period of 3 months. Data collection was performed at the end of the preseason.

The physical characteristics of the subjects are displayed in Table I.All players were right dominant. Subjects were included by the team physician after orthopedic examination. Exclusion criteria were shoulder pain, excessive shoulder laxity (using the apprehension-, relocation- and release test, based on the criteria as described by Tennent et al. ${ }^{32}$ ), signs of neuropathy, a history of operation to either shoulder or injury in previous three months requiring cessation of volleyball practice, including the preseason strengthening program. Subjects had previous experience in isokinetic testing, were familiar with the procedures, and were free of pain during actual measurements. All subjects voluntarily participated and gave their written informed consent.

\section{Table I}

Physical characteristics of subjects $(n=35)$.

\begin{tabular}{|c|c|c|c|c|c|}
\hline & N & Minimum & Maximum & Mean & SD \\
\hline Age $(\mathrm{yr})$ & 35 & 18 & 33 & 24,6 & 3,9 \\
\hline Weight $(\mathrm{kg})$ & 35 & 74 & 106 & 90 & 7,4 \\
\hline Length $(\mathrm{cm})$ & 35 & 181 & 214 & 199,2 & 6,2 \\
\hline
\end{tabular}

\section{Interventions}

All tests were performed on a CYBEX 6000 dynamometer, calibrated according to the operating manual. ${ }^{6}$ Testing was performed in supine position with $90^{\circ}$ abduction and $90^{\circ}$ elbow flexion; $0^{\circ}$ of shoulder rotation was defined with the forearm in the neutral position. $4,7,15,29,33,34,38$ Hellwig and Perrin ${ }^{18}$ reported for this position a high test-retest reproducibility ( $r=.90$ to .93 ) for concentric internal-external rotation muscle strength. Testing was conducted with subjects on the Upper Body Extremity Table (UBXT) allowing for muscle isolation and maximal trunk stability. Each subject performed 5 minutes of warm-up stretch and active exercise to the upper limb before testing. The warm-up exercises were standard activities that they would normally perform before a volleyball match. After warm-up, the shoulder joint was placed in line with the dynamometer axis of rotation. The pelvis and trunk were secured with stabilizing straps and the feet were supported. Subjects performed 4 sub maximal and I maximal trial prior to the assessment for the purpose of warm-up and familiarization., ${ }^{7,33,34}$ Actual measurement was performed with 3 maximum repetitions at $60^{\circ}$ and 5 at $180^{\circ}$ and $300^{\circ} \mathrm{s}$. First, the dominant arm was tested. The range of test was between $50^{\circ}$ external rotation and $50^{\circ}$ internal rotation. ${ }^{33,34}$ Subjects were asked to move as fast and as 
powerful as possible throughout the preset range of motion of internal and external rotation. The rest period between each set was 30 seconds. Gravity correction was not used for this testing position because both the internal and external rotator muscles moved with and against gravity as they applied force. ${ }^{13,14,33,34}$ The highest peak torque value of the three to five repetitions was used for subsequent data analysis. To ensure uniformity in testing procedures the same investigators performed all tests.

Data reduction and statistical analysis

Presentation of isokinetic data is expressed as peak torque related to body weight (PT/BW). This enables clinicians to compare and interpret test data from individuals with different anthropometric values. ${ }^{7,10}$ All PT/BW values were tested for normality via Onesample Kolmogorov-Smirnovtest. All data were distributed normally; mean and 95\% confidence intervals were determined at all 3 test velocities. Internal and external rotation strength and strength ratios were examined for significant differences by using a two-tailed paired t-test. Level of significance was set at 0.05 . Statistical analysis was performed in SPSS, version 8.0.

\section{Results}

Mean PT/BW values and 95\% confidence intervals are presented in Table 2. Table 3 presents the external-internal ratios of the shoulder.

Test velocity:

At all test velocities, the internal rotators were significantly stronger $(P<0.000 \mathrm{I})$ than the external rotators for both shoulders. With increasing test velocity, the mean PT/BW values of the external and internal rotators decreased significantly $(P<0.000 \mathrm{I})$ for both arms (Table 2).

\section{Dominant versus non-dominant arm:}

No significant differences were found between the external rotators of the dominant arm versus the non-dominant arm. The internal rotators of the dominant arm were significantly stronger $(P<0.000 \mathrm{I})$ than of the non-dominant arm (Table 2$)$.

\section{Ratio's:}

At all test velocities, the external-internal rotator ratios of the dominant arm were significantly lower $(P<0.0 \mathrm{I})$ than of the non-dominant arm. No significant differences were found between the ratios of each arm separately. There was no significant influence of the test velocity (e.g. $60^{\circ}$ versus $180^{\circ} / \mathrm{s}$ ) on the ratio values (Table 3 ). 
Table 2

Mean and $95 \%$ confidence interval (Cl) of PT/BW in Newton Meter per Kg for shoulder internal and external rotators per test velocity.

\begin{tabular}{|c|c|c|}
\hline Test velocity in $\%$ s & Muscle group & Mean and 95\% Cl \\
\hline 60 & IRD & $0.67(0.63-0.71)^{*}$ \\
& IRND & $0.58(0.54-0.62)$ \\
& ERD & $0.45(0.42-0.48)$ \\
& ERND & $0.45(0.42-0.48)$ \\
\hline 180 & IRD & $0.56(0.51-0.60)^{*}$ \\
& IRND & $0.49(0.44-0.53)$ \\
& ERD & $0.38(0.35-0.41)$ \\
& ERND & $0.38(0.35-0.41)$ \\
\hline 300 & IRD & $0.48(0.44-0.52)^{*}$ \\
& IRND & $0.43(0.40-0.47)$ \\
& ERD & $0.33(0.30-0.36)$ \\
& ERND & $0.34(0.31-0.36)$ \\
\hline
\end{tabular}

IRD = internal rotators dominant arm, IRND = internal rotators non-dominant arm, ERD = external rotators dominant arm, ERND = external rotators non-dominant arm. $*=$ significant difference $(P<0.0 \mathrm{I})$ between dominant and non-dominant arm.

\section{Table 3}

Mean and $95 \%$ confidence interval $(\mathrm{Cl})$ for the shoulder external-internal rotator ratios in percentage per test velocity.

\begin{tabular}{|c|c|c|}
\hline Test velocity in $\%$ s & Arm & Mean and 95\% Cl \\
\hline \multirow{2}{*}{60} & D & $68.1(64.2-72)$ \\
& ND & $77.1(73.1-81.1)^{*}$ \\
\hline \multirow{2}{*}{180} & D & $69.3(65.5-73.1)$ \\
& ND & $79.4(74.4-84.4)^{*}$ \\
\hline \multirow{2}{*}{300} & D & $70.7(67.4-74)$ \\
& ND & $79.7(74-85.5)^{*}$ \\
\hline
\end{tabular}

$\mathrm{D}=$ dominant arm, $\mathrm{ND}=$ non-dominant arm. $*$ significant difference $(\mathrm{P}<0.0 \mathrm{I})$ between dominant and nondominant arm

\section{Comments}

The present study yielded concentric isokinetic shoulder internal and external reference values for asymptomatic elite volleyball players. The results showed that at three different test velocities, the internal rotators were significantly stronger than the external rotators, and the internal rotators of the dominant arm were significantly stronger than of the non-dominant arm. The most striking finding of the study was that no significant 
differences were found between extremities in external rotation strength. Ratios of the dominant arm were significantly lower than of the non-dominant arm.

When comparing our data with other studies, we limited ourselves to studies dealing with I) elite athletes using specific overhead motions, 2) measurements in the same test position and 3) similar test protocols (e.g. test velocities, randomization). In view of the arm positions common in volleyball, we used the supine test position with $90^{\circ}$ abduction and $90^{\circ}$ - elbow flexion. 4,7,15,29,33,34,38 Comparing our results with other elite volleyball players, we only found two studies. ${ }^{33,34}$ Therefore, with some restrictions, we also want to compare the results with elite tennis players and baseball pitchers.

The difference between sides in shoulder internal rotators may result from regular training. ${ }^{3}$ Similar to baseball and tennis, volleyball players use one arm as the dominant arm to practice a large number of forceful spikes and overhead serves. These movements consist predominantly of concentric internal rotation and eccentric external rotation. This is the first study in which we found no significant differences between extremities in concentric external rotation strength in elite volleyball players. These findings are in contrast with those reported by Wang and Cochrane. ${ }^{33,34}$ They found that the external rotators were significantly weaker in the dominant arm during concentric measurements. This is an important finding since the external rotators play an important role in decelerating the arm rotation during spiking and serving actions. As the external rotator muscles slow down (eccentric) the overhead arm activity, high shoulder distraction forces occur. Eccentric contraction of the external rotators generates higher tension in controlling concentric muscle contraction of the internal rotators during the deceleration period of the spike or serve action. ${ }^{21}$ Training of these activities increases the risk of muscle damage or degeneration from eccentric overload. ${ }^{23}$ For this reason, the volleyball players in this study especially performed a preseason strengthening program, with the emphasis on the external rotators and scapular stabilizers. The strengthening program consisted of concentric exercises. Concentric training has been shown to increase the concentric and eccentric strength, but eccentric training does not increase concentric strength. ${ }^{24}$ We postulate that this preseason strengthening program could be the reason why we found no differences in concentric external rotation strength in this study. Wang and Cochrane ${ }^{33,34}$ found that the external rotators were significantly weaker in the dominant arm, which could be because they did not perform any preseason strengthening program. Comparisons with elite tennis players and baseball pitchers also show that there were no significant differences in concentric external rotation strength, the internal rotators were stronger than the external rotators, and the internal rotators of the dominant arm were stronger than the internal rotators of the non-dominant arm. ${ }^{11,12,13}$ 
In the shoulder, rotator cuff muscle balance is essential to maintain stability and ensure permanent centering of the humeral head. ${ }^{1,3}$ Previous studies on untrained, asymptomatic subjects noted a concentric external-internal strength ratio of 64 to $79 \%$, at various test velocities $\left(60^{\circ}\right.$ to $\left.300^{\circ} / \mathrm{s}\right)$ with minor differences between both shoulders. ${ }^{5,20,28}$ The present study shows that the external-internal ratio for the dominant arm is 68,1 to $70,7 \%$ and 77,1 to $79,7 \%$ for the non-dominant arm. The significant differences in internal rotation strength, combined with no differences in external rotation strength, explains why the ratios of the dominant arm are significantly lower than of the non-dominant arm. As these ratios are comparable to those in a normal population, we found no significant shoulder muscle imbalance in our elite volleyball players.

In their volleyball study, Wang and Cochrane 33 found a muscle ratio of 67 to $69 \%$ for the dominant arm and 97 to $98 \%$ for the non-dominant arm. Their second study revealed a muscle ratio of 70 to $73 \%$ for the dominant arm and 104 to $106 \%$ for the non-dominant arm. ${ }^{34}$ In both studies, the concentric external rotator strength of the dominant arm was significantly lower than of the non-dominant arm. Other studies on elite tennis players and baseball pitchers showed that the muscle ratio in the dominant arm is also significantly lower compared to the non-dominant arm but the concentric external rotation strength in the dominant arm is not different from the non-dominant arm. ${ }^{11,12,13}$ Muscle balance between shoulder rotation force couples and functional strength of the external rotators are important in normal shoulder function, including overhead athletes. ${ }^{21,22,33,34,36}$ As a result from the present study, we hypothesize that not only the muscle ratios are important but also the presence of significant differences in concentric external rotation strength between the dominant and non-dominant arm. Future studies should focus on the effects of external rotation strength training in the prevention of shoulder injuries in elite volleyball players. 


\section{References:}

I. Bigliani LU, Kelkar R, Flatow EL, et al. Glenohumoral Stability, Biomechanical properties of passive and active stabilizers. Clin Orthop Rel Res 1996; 330: 13-30.

2. Briner WW, Kacmar L. Common injuries in volleyball. Mechanisms of injury, prevention and rehabilitation. Sports Med 1997; I: 65-7I.

3. Codine P, Bernard PL, Pocholle M, et al. Influence of sports discipline on shoulder rotator cuff balance. Med Sci Sports Exerc 1997; I I: | 400- I 405.

4. Coleman SGS, Benham AS, Northcott SR.A three-dimensional cinematographical analysis of the volleyball spike.J of Sports Sc 1993; II:295-302.

5. Cook EE, Gray VL, Savinar E, et al. Shoulder antagonistic strength ratios: a comparison between collegelevel baseball pitchers and non-pitchers.J Orthop Sports Phys Ther 1987; 9:45I-46I.

6. Cybex 6000 User's Guide. New York: Cybex Division of Lumex, Inc. Ronkonkoma; 1993.

7. Davies GJ. A compendium of isokinetics in clinical usage. Onalaska: S\&S Publishers; 1992.

8. DiGiovine NM, Jobe FW, Pink M, et al.An electromyographic analysis of the upper extremity in pitching. J Shoulder Elbow Surg 1992; I: I5-25.

9. Dillman CJ, Fleisig GS, Andrews JR. Biomechanics of pitching with emphasis upon shoulder kinematics.J Orthop Sports Phys Ther 1993; 2: 402-408.

10. Dvir Z. Isokinetics muscle testing, interpretation and clinical applications. New York: Churchill Livingstone, 1995.

II. Ellenbecker TS.A total arm strength isokinetic profile of highly skilled tennis players. Isok. Exerc Sc 1991; I: 9-2I.

12. Ellenbecker TS. Shoulder internal and external rotation strength and range of motion of highly skilled junior tennis players. Isok Exerc Sci 1992; 2: 65-72.

13. Ellenbecker TS, Mattalino AJ. Concentric isokinetic shoulder internal and external rotation strength in professional baseball pitchers.J Orthop Sports Phys Ther 1997; 5; 323-328.

14. Ellenbecker TS, Roetert EP.Testing isokinetic muscular fatigue of shoulder internal and external rotation in elite junior tennis players.J Orthop Sports Phys Ther 1999; 5: 275-281.

15. Elliot B, Marsh T, Blanksby B.A three dimensional cinematographic analysis of the tennis serve. Int J Sport Biom 1986; 2: 260-27I.

16. Fleisig GS, Andrews JR, Dillman CJ, et al. Kinematics of baseball pitching with implications about injury mechanics. Am J Sp Med 1995; 2: 233-239.

17. Friedman RJ, Knetsche RP. Biomechanics of the rotator cuff. In: BurkheadWZ, ed. Rotator cuff disorders. Baltimore:Williams \& Wilkins; 1996: 45-56.

18. Hellwig EV, Perrin DH.A comparison of two positions for assessing shoulder rotator peak torque: the traditional frontal plane versus the plane of the scapula. Isok Exerc Sci 1991; 4: 202-206.

19. Holzgraefe M, Kukowski B, Eggert S. Prevalence of latent and manifest suprascapular neuropathy in high performance volleyball players. Br J Sp Med 1994; 3: 177- 179.

20. Ivey FM, Calhoun JH, Rusche K, et al. Isokinetic testing of shoulder strength: normal values. Arch Phys Med Rehabil 1985; 66: 384-386.

21. Khan AM, Guillet MA, Fanton GS.Volleyball: Rehabilitation and training tips. Sp Med and Arthrosc Rev 
200I; 9: 137-146.

22. Kugler A, Kruger-Franke M, Reininger S, et al. Muscular imbalance and shoulder pain in volleyball attackers. Br J Sp Med 1996; 30: 256-259.

23. Kuipers H. Exercise induced muscle damage. Int J Sports Med 1994; I5: I32-135.

24. Mont MA, Cohen DB, Campbell KR, et al. Isokinetic concentric versus eccentric training of shoulder rotators with functional evaluation of performance enhancement in elite tennis players. Am J Sp Med 1994; 4:5I3-5I7.

25. Newsham KR, Keith CS, Saunders JE, et al. Isokinetic profile of baseball pitchers internal/external rotation 180, 300, 450\% /sec. Med Sci Sports Exerc 1998; 10: I489-1495.

26. Pappas AM, Zawacki RM, Sullivan TJ. Biomechanics of baseball pitching A preliminary report. Am J Sp Med 1985; 4: 216-222.

27. Pappas AM, McCarthy CF, Zawacki RM. Care and rehabilitation of the throwing shoulder. In Pappas AM, ed. Upper extremity injuries in the athlete. Edinburgh: Churchill Livingstone Inc.; 1995: 277-30I.

28. Reid DC, Oedekoven G, Kramer JF, et al. Isokinetic muscle strength parameters for shoulder movements. Clin Biom 1989; 4; 97-104.

29. Rokito AS, Jobe FW, Pink MM, et al. Electromyographic analysis of shoulder function during the volleyball serve and spike.J Shoulder Elbow Surg 1998; 3: 256-263.

30. Ryu RKN, McCormick J, Jobe FW, et al.An electromyographic analysis of shoulder function in tennis players Am J Sp Med 1988; 5: 48I-485.

3I. Sirota SC, Malanga GA, Eischen JJ, et al.An eccentric and concentric strength profile of shoulder muscles in professional baseball pitchers. Am J Sp Med 1997; I: 59-64.

32. Tennent TD, Beach WR, Meyers JF.A review of the special tests associated with shoulder examination. Part II: laxity, instability, and superior labral anterior and posterior (SLAP) lesions. Am J Sp Med 2003; 2: 30I-307.

33. Wang HK, Cochrane T. Isokinetic performance and shoulder mobility in elite volleyball athletes from the United Kingdom. Br J Sports Med 2000; 34: 39-43.

34. Wang HK, Cochrane T. Mobility impairment, muscle imbalance, muscle weakness, scapular asymmetry and shoulder injury in elite volleyball athletes.J Sports Med Phys Fitness 200I; 4I: 403-4I0.

35. Wang HK, Cochrane T.A descriptive epidemiological study of shoulder injury in top level English male volleyball players. Int J Sports Med 200I; 22: 159-163.

36. Warner JJP, Micheli LJ, Arslanian LE, et al. Patterns of flexibility, laxity, and strength in normal shoulders and shoulders with instability and impingement. Am J Sports Med 1990; 18: 366-375.

37. Werner SL, Gill TJ, Murray TA, et al. Relationships between throwing mechanics and shoulder distraction in professional baseball pitchers. Am J Sp Med 200I; 3: 354-358.

38. Wilk KE, Arrigo CA,Andrews JR. Standardized isokinetic testing protocol for the throwing shoulder: the throwers series. Isok. Exerc Sci 1991; 2: 63-69.

39. Wilk KE, Andrews JR, Arrigo CA, et al. The strength characteristics of internal and external rotator muscles in professional baseball pitchers. Am J Sp Med 1993; I: 6I-66.

40. Witvrouw E, Cools A, Lysens R. et al. Suprascapular neuropathy in volleyball players. Br J Sports Med 2000; 34: 174-180. 


\section{Chapter 4}

Isokinetic strength values, conventional ratio and dynamic control ratio of shoulder rotator muscles in elite badminton players

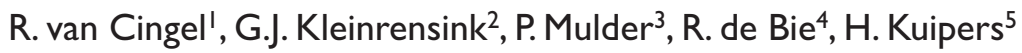

I Sports Medical Center Papendal,Arnhem, The Netherlands.

2 University Medical Center Rotterdam, Department Neuroscience, Rotterdam, The Netherlands.

${ }^{3}$ University Medical Center Rotterdam, Department of Epidemiology \& Biostatistics, Rotterdam, The Netherlands.

${ }^{4}$ Department of Epidemiology, Maastricht University, The Netherlands.

${ }^{5}$ Department of Movement Sciences, Maastricht University, The Netherlands.

In press: Isokinetics and Exercise Science 


\begin{abstract}
Nine male and seven female asymptomatic elite badminton players were tested bilaterally to determine concentric and eccentric strength values, conventional ratio and dynamic control ratio of shoulder rotator muscles. All tests were performed at $60^{\circ}$ and $120^{\circ} / \mathrm{s}$. The study shows significant differences that were similar for men and women; the dominant arm was stronger than the non-dominant arm, normalised peak torque values at $60 \%$ were higher than at $120 \%$, the concentric internal rotator strength (IRS) was larger than the concentric external rotator strength (ERS) and the eccentric ERS was larger than the concentric ERS. For females the eccentric ERS was larger than the concentric IRS as opposed to men in whom the concentric IRS was larger than the eccentric ERS. For both sexes the CVR for the dominant arm was significantly higher than for the non-dominant arm. The DCR at $60 \%$ s was significantly lower than at $120 \%$ and the DCR for females was significantly higher than for men. Data presented are important for interpreting isokinetic shoulder rotator strength tests in elite badminton players and could be relevant in rehabilitation and prevention of shoulder injuries.
\end{abstract}

\title{
Introduction
}

The shoulder is a complex joint characterised by a high degree of mobility combined with a significant need for dynamic stability. It has previously been reported that the rotator cuff muscles serve as dynamic stabilizers of the shoulder., ${ }^{3,1}$ Sports that involve repetitive overhead motions like baseball, volleyball, tennis and badminton require well coordinated and synchronised actions of the shoulder muscles to provide the optimal stabilization required during the immense forces which are produced at the shoulder girdle complex..$^{5,8,36}$ Several studies showed that the repetitive and forceful movements in overhead sports render the shoulder vulnerable to injuries. ${ }^{26,29,30}$ Fahlstrom et al. ${ }^{20}$ concluded that shoulder pain was a common and significant problem in world class badminton players with no differential prevalence between men and women. In their questionnaire study on 188 international top-level badminton players previous or present shoulder pain on the dominant side was reported by $52 \%$ of the players. Although each overhead sport has its own specific technique, there are similarities in the muscle activations among these overhead sports. ${ }^{35}$ In general, the overhead motion pattern can be divided into four phases; winding up, cocking, acceleration and deceleration. ${ }^{28,35}$ Overhead athletes depend on ballistic upper extremity motion which consists of a forceful concentric internal rotation and adduction of the shoulder joint throughout the acceleration phase, followed by an increase in eccentric activity of the external rotators during the follow through phase. During the deceleration phase high 
eccentric force must be produced in the external rotators (ER), which could predispose the muscles to injury. ${ }^{21,33}$

By using an isokinetic dynamometer, researchers have examined the conventional strength ratio (CVR) of external and internal shoulder rotators (ER $\left.{ }_{\text {con }}: I_{\text {con }}\right)$. The isokinetic concentric peak torque of the ER has been reported to be 64 to $80 \%$ of that of the concentric internal rotators (IR). 4,7,27,39 However, in overhead sports increased eccentric activity of the external rotators is required to decelerate the humerus and to centre the humeral head. ${ }^{13,23,37,40}$ To assess knee muscles function in a more functional approach, Dvir et al. ${ }^{15}$ have for the first time used the dynamic control ratio (DCR) by dividing the eccentric peak torque of the hamstrings by the concentric peak torque of the quadriceps. Bak and Magnusson ${ }^{2}$ have extended this concept, replacing the hamstrings by the shoulder ER and the quadriceps by the shoulder IR (ER $\mathrm{ecc}_{\mathrm{I}}$ : IR $\left.{ }_{\text {con }}\right)$. The DCR is of particular significance in those situations where the agonist and antagonist are working simultaneously to avert potential jeopardy to the joint. ${ }^{16}$ Indeed, David et al. ${ }^{\prime \prime}$ advocated that the conventional ratio may be less relevant then a DCR which related directly to the restraining effect of the eccentrically active ER muscles. Previously, the DCR was measured in volleyball players, ${ }^{44,45,49}$ baseball players, ${ }^{14,37}$ tennis players ${ }^{49}$ and swimmers. ${ }^{2}$ However, literature is very limited with respect to strength values, CVR and DCR in badminton players. To the best of our knowledge, only $\mathrm{Ng}$ et al. ${ }^{36}$ measured the work ratio's ( $\left.E R_{\text {ecc }}: I_{\text {con }}\right)$ in men for shoulder rotator muscles in the range of motion corresponding to the deceleration phase in overhead strokes. The work ratio of the dominant arm was significant lower than of the non-dominant arm.

Considering the important role of active stabilizers in shoulder biomechanics, we evaluated shoulder rotators performance in badminton players during overhead arm activities. The purpose of this study was to provide descriptive data for concentric and eccentric isokinetic peak torque values of shoulder rotator muscles, the CVR and DCR in the dominant and non-dominant arm of asymptomatic elite badminton players.

\section{Methods}

\section{Subjects}

Nine male and seven female asymptomatic elite badminton players participated in the study. All subjects were competing in the highest division of the Dutch Badminton league for at least two years and selected for the Dutch National team. Subjects practised 4 hours per day, 5 days a week. The physical characteristics of the subjects are outlined in Table I.All female players were right dominant. Eight men were right dominant and one was left dominant. Subjects were included after orthopedic examination. Exclusion criteria consisted of shoulder pain during the last year, excessive shoulder laxity (using 
the apprehension-, relocation- and release test, based on the criteria as described by Tennent et al. ${ }^{43}$ ), signs of neuropathy, a history of operation to either shoulder or injury in the past three months requiring cessation of badminton practise. All subjects voluntarily participated and gave their written informed consent.

\section{Table I}

Anthropometric data of the subjects. For men $\mathrm{N}=9$ and for women $\mathrm{N}=7$.

\begin{tabular}{|c|c|c|c|c|}
\hline Men & Minimum & Maximum & Mean & SD \\
\hline Age (years) & 19 & 35 & 25.4 & 5.2 \\
\hline Weight $(\mathrm{kg})$ & 68 & 95 & 78.1 & 8.8 \\
\hline Length $(\mathrm{cm})$ & 175 & 198 & 184 & 6.9 \\
\hline & & & & \\
\hline Women & Minimum & Maximum & Mean & SD \\
\hline Age (years) & 16 & 29 & 21.6 & 5.4 \\
\hline Weight $(\mathrm{kg})$ & 58 & 74 & 66.9 & 6.2 \\
\hline Length $(\mathrm{cm})$ & 160 & 180 & 173 & 7.1 \\
\hline
\end{tabular}

\section{Procedures}

All tests were performed on a CYBEX 6000 dynamometer, calibrated according to the operating manual. ${ }^{9}$ Testing was performed in supine position with $90^{\circ}$ abduction and $90^{\circ}$ elbow flexion; $0^{\circ}$ of shoulder rotation was defined with the forearm in the neutral position. ${ }^{12,44,45,47}$ Testing was conducted with subjects on the Upper Body Extremity Table (UBXT) allowing for muscle isolation and maximal trunk stability. Each subject performed 5 min. of warm-up stretch and active exercises to the upper limb prior to testing. The warm-up exercises were standard activities that the subjects would normally perform before a badminton match. After warm-up the humeral shaft was placed in line with the dynamometer axis of rotation. The pelvis and trunk were secured with stabilizing straps and the feet were supported. The procedure included two tests for each side. The side assessed first was randomly selected for both tests. Test I and 2 were performed at $60^{\circ}$ and $120 \%$ s. Test I assessed the peak torque of the IRs and ERs in the concentric mode whereas Test 2 assessed the corresponding eccentric strength. The testing order was always Test I followed by Test $2 .^{14}$ Subjects performed 4 sub maximal and I maximal trial prior to the assessment for the purpose of warm-up and familiarization. ${ }^{4,10,12,45}$ Actual measurement was performed with 5 maximum repetitions at $60^{\circ}$ and $120 \%$ s. The range of test was between $80^{\circ}$ external rotation and $50^{\circ}$ internal rotation. The rest period between each set was $30 \mathrm{sec}$. Recovery time between Test I and Test 2 was 5 min. Gravity correction was not used for this testing position because both the internal and 
external rotator muscles moved with and against gravity as they applied force. ${ }^{19,44,45}$ For both tests, the highest peak torque value of the five repetitions was used for subsequent data analysis. To ensure uniformity in testing procedures the same investigators performed all tests.

\section{Statistical analysis}

Normalized peak torque measurements $(\mathrm{Nm} / \mathrm{kg})$ were analyzed using mixed model ANOVA. Sex, age height and weight were entered as between-subject explanatory variables in the model. As within-subject explanatory factors we entered: dominancy (dominant versus non-dominant), velocity (60 versus I20) and concentric/eccentric (concentric internal/concentric external/eccentric external). In the model we tested the interactions between sex and the within-subject factors and the mutual interactions between the within-subject factors. A compound symmetry structure was imposed on the (co)variances of the residuals.

CVR and DCR measurements (in percentage) were also analyzed using mixed model ANOVA in the same way as the peak torque measurements, of course without entering the within-subject explanatory factor 'concentric/eccentric' in the model. All effects were considered significant if the 2 -sided $P$-value fell below 0.05 .

\section{Results}

Raw data of peak torque measurements, CVR and DCR are summarized by means and standard deviations in Table 2. The effects on the peak torque measurement of the explanatory variables are shown in Table 3. Age, height and weight did not have a significant effect on peak torque, but were retained in the model for all analyses. All other variables had a significant effect on the outcome measurement, as did the interaction between sex and concentric/eccentric. None of the other interactions reached significance.

The effects of the explanatory variables on the ratios CVR and DCR of the explanatory variables are presented in Tables 4 and 5 respectively. Age, height and weight did not have a significant effect, but were retained in the model. No significant interactions were found between the variables sex, dominancy and velocity. On CVR only dominancy appeared to have a significant effect. On DCR sex and velocity appeared to have significant effects. 
Table 2

Mean \pm SD for concentric internal and external rotation strength, eccentric external rotation strength in $\mathrm{Nm} / \mathrm{Kg}$, conventional ratio (CVR) and dynamic control ratio (DCR) in percentage for men and women at $60^{\circ}$ and $120^{\circ} / \mathrm{s}$.

\begin{tabular}{|c|c|c|c|c|c|}
\hline & $\begin{array}{c}\text { Con IR } \\
\text { Mean } \pm \text { SD }\end{array}$ & $\begin{array}{c}\text { Con ER } \\
\text { Mean } \pm \text { SD }\end{array}$ & $\begin{array}{c}\text { Ecc ER } \\
\text { Mean } \pm \text { SD }\end{array}$ & $\begin{array}{c}\text { CVR } \\
\text { Mean } \pm \text { SD }\end{array}$ & $\begin{array}{c}\text { DCR } \\
\text { Mean } \pm \text { SD }\end{array}$ \\
\hline Men D60 & $0.69 \pm 0.11$ & $0.49 \pm 0.08$ & $0.63 \pm 0.09$ & $72.2 \pm 11.6$ & $93.6 \pm 16.3$ \\
\hline Men ND60 & $0.59 \pm 0.09$ & $0.41 \pm 0.10$ & $0.56 \pm 0.08$ & $68.4 \pm 11.2$ & $95.9 \pm 8.5$ \\
\hline Men DI20 & $0.63 \pm 0.11$ & $0.45 \pm 0.08$ & $0.6 \mathrm{I} \pm 0.07$ & $71.6 \pm 11.4$ & $99.9 \pm 18.0$ \\
\hline Men NDI 20 & $0.54 \pm 0.11$ & $0.37 \pm 0.11$ & $0.52 \pm 0.08$ & $68.4 \pm 10.3$ & $98.2 \pm 10.7$ \\
\hline Women D60 & $0.45 \pm 0.09$ & $0.35 \pm 0.06$ & $0.52 \pm 0.10$ & $77.1 \pm 3.1$ & $113.3 \pm 5.8$ \\
\hline Women ND60 & $0.38 \pm 0.08$ & $0.28 \pm 0.07$ & $0.45 \pm 0.07$ & $73.0 \pm 4.0$ & $118.6 \pm 12.9$ \\
\hline Women DI20 & $0.42 \pm 0.09$ & $0.34 \pm 0.07$ & $0.54 \pm 0.09$ & $82.1 \pm 10.6$ & $129.4 \pm 11.9$ \\
\hline Women NDI20 & $0.35 \pm 0.09$ & $0.27 \pm 0.07$ & $0.42 \pm 0.07$ & $77.0 \pm 4.3$ & $125.3 \pm 13.4$ \\
\hline
\end{tabular}

$\mathrm{D}=$ dominant, $\mathrm{ND}=$ non dominant, $\mathrm{IR}=$ internal rotation, $\mathrm{ER}=$ external rotation

\section{Table 3}

Effects on peak torque of the explanatory variables considered, adjusted for each other and for age, height and weight.

\begin{tabular}{|l|c|c|c|}
\hline explanatory variable & effect (SE) & P-value & $95 \%$ CI \\
\hline dominancy (dominant versus non-dominant) & $0.083(0.008)$ & $<0.0005^{*}$ & 0.066 to 0.099 \\
\hline velocity $(60$ versus I 20) & $0.029(0.008)$ & $0.00 I^{*}$ & 0.012 to 0.045 \\
\hline conc ER versus conc IR females & $-0.092(0.015)$ & $<0.0005^{*}$ & -0.122 to -0.062 \\
\hline ecc ER versus conc IR females & $0.079(0.015)$ & $<0.0005^{*}$ & 0.049 to 0.109 \\
\hline ecc ER versus conc ER females & $0.171(0.015)$ & $<0.0005^{*}$ & $0.14 I$ to $0.20 I$ \\
\hline conc ER versus conc IR males & $-0.182(0.014)$ & $<0.0005^{*}$ & -0.209 to -0.156 \\
\hline ecc ER versus conc IR males & $-0.029(0.014)$ & $0.03 I^{*}$ & -0.056 to -0.003 \\
\hline ecc ER versus conc ER males & $0.153(0.014)$ & $<0.0005^{*}$ & 0.126 to 0.179 \\
\hline
\end{tabular}

$\mathrm{SE}=$ standard error $\mathrm{Cl}=$ confidence interval $*=$ significant difference 
Table 4

Effects on CVR of the explanatory variables considered, adjusted for each other and for age, height and weight.

\begin{tabular}{|l|c|c|c|}
\hline explanatory variable & effect (SE) & P-value & $\mathbf{9 5} \% \mathbf{C I}$ \\
\hline sex (male versus female) & $-4.6 I(4.55)$ & 0.33 & -14.63 to 5.40 \\
\hline dominant (dominant versus non-dominant) & $3.97(I .97)$ & $0.049 *$ & 0.01 to 7.93 \\
\hline Velocity (60 versus I20) & $-1.78(1.97)$ & 0.37 & -5.74 to 2.18 \\
\hline
\end{tabular}

$\mathrm{SE}=$ standard error $\mathrm{Cl}=$ confidence interval $*=$ significant difference

Table 5.

Effects on DCR of the explanatory variables considered, adjusted for each other and for age, height and weight.

\begin{tabular}{|l|c|c|c|}
\hline explanatory variable & effect (SE) & P-value & $\mathbf{9 5} \% \mathbf{C l}$ \\
\hline sex (male versus female) & $-32.84(7.6 \mathrm{I})$ & $0.00 I^{*}$ & -49.59 to -16.08 \\
\hline dominant (dominant versus non-dominant) & $-0.69(2.19)$ & 0.76 & 5.10 to 3.73 \\
\hline velocity (60 versus I20) & $-7.19(2.19)$ & $0.002 *$ & $-\mathrm{II} .60$ to -2.77 \\
\hline
\end{tabular}

$\mathrm{SE}=$ standard error $\mathrm{Cl}=$ confidence interval $*=$ significant difference

\section{Discussion}

The objectives of this study were to investigate the isokinetic peak torque of shoulder rotator muscles, the CVR and the DCR in the dominant and non-dominant arm of asymptomatic elite badminton players. In view of the arm positions common in badminton, we used the supine test position with $90^{\circ}$ abduction and $90^{\circ}$ - elbow flexion. ${ }^{12,4,45,47}$ The study shows significant differences that were similar for men and women; the dominant arm was stronger than the non-dominant arm, normalized peak torque values at $60 \% \mathrm{~s}$ were higher than at $120 \%$, the concentric IRs were stronger than the concentric ERs and the eccentric ERs were stronger than the concentric ERs. For females the eccentric ERs were stronger than the concentric IRs as opposed to men in whom the concentric IRs were stronger than the eccentric ERs. For both sexes the CVR for the dominant arm was significantly higher than for the non-dominant arm. The DCR at $60 \%$ s was significantly lower than at $120 \%$ and the DCR for females was significantly higher than for men.

As indicated in this study overhead sports often result in a significant increase of dominant concentric IR strength compared to the non-dominant arm. ${ }^{5,17,36,45}$ This difference may be the result of regular training. ${ }^{5,6,37}$ Similar to baseball, tennis and volleyball, badminton players use one arm as the dominant arm to practice a large 
number of overhead shots. ${ }^{32}$ Also the concentric ER strength in the dominant arm was significantly higher than in the non-dominant arm. Certain studies showed no significant differences, 1,5,17,18,19,38 whereas others revealed that the concentric ER strength was significantly lower in de dominant arm. ${ }^{44,45,48} \mathrm{It}$ is difficult to compare the muscle strength values in different studies on different sports as there were differences in test equipment, test velocities and arm positioning during testing. It is generally accepted that a significant decrease of concentric ER strength combined with a significant increase of the concentric IR strength leads to a lower CVR $\left(E_{\text {con }}: \mathrm{IR}_{\text {con }}\right)$ and may be a risk for shoulder injury. ${ }^{16,45}$ Previous studies on asymptomatic untrained subjects revealed a CVR of 64 to $80 \%$ with minor differences between both arms, at various test velocities $\left(60^{\circ}\right.$ to $\left.300^{\circ} / \mathrm{s}\right) .4,7,27,39$ The present study shows that the CVR for the dominant arm is significantly higher than for the nondominant arm. For men the CVR was 71.6 to $72.2 \%$ in de dominant arm and $68.4 \%$ in de non-dominant arm. For women the CVR was 77.1 to $82.1 \%$ in the dominant arm and 73 to $77 \%$ in the non-dominant arm. As these ratios are comparable to those in a normal population, we found no significant shoulder muscle imbalance in our elite badminton players.

Overhead activities consist predominantly of concentric internal rotation and eccentric external rotation. The external rotators play an important role in decelerating the arm rotation during overhead activities. ${ }^{21,28,48}$ As the external rotator muscles slow down the overhead arm activity with eccentric contractions, high shoulder distraction forces occur. Eccentric contraction of the external rotators generates higher tension in controlling concentric muscle contraction of the internal rotators during the deceleration period of overhead arm motions. Training of these activities increases the risk of muscle damage or degeneration from eccentric overload. $1,21,31,33$

The importance of determining eccentric strength of the external rotator muscles has been shown for healthy throwing athletes, ${ }^{34,42}$ volleyball players ${ }^{1,44,45}$ and swimmers. ${ }^{46}$ In these studies no difference was found in eccentric ER strength between the dominant and the non-dominant arm. To our knowledge, this is the first study in which the eccentric ER strength of the dominant arm was significantly stronger than of the nondominant arm in male and female elite badminton players. Again, differences in study outcome could be the result of differences in test equipment, test position and test speed.Additionally, we postulate that badminton players strengthen their external rotator muscles more than other overhead athletes due to the large number of overhead backhand shots, backhand smashes and backhand strokes in front or beside the body. 32

To gain a better insight at sport-specific shoulder function we determined the DCR $\left(E R_{\text {ecc }}: I R_{\text {con }}\right)$. The DCR relates directly to the restraining effect of the eccentrically active 
external rotator muscles and is a more functional approach to shoulder function than the CVR. 2,11,15,16 Previous studies suggest that the eccentric ER strength should be at least as large as concentric IR strength to maintain normal shoulder function. ${ }^{13,16,41,49}$ Wang and Cochrane ${ }^{45}$ reserved the term muscle imbalance for those situations in which the average eccentric ER strength was less than the average concentric IR strength in the same arm. Studies on healthy non athletic subjects showed a DCR of greater than I for both arms. ${ }^{24,37,46}$ West et al. ${ }^{46}$ found no significant differences between the dominant and the non-dominant arm, 106 and 107\% respectively.

Our study showed a DCR for woman of II3.3 to $129.4 \%$ for the dominant arm and I I 8.6 to $125.3 \%$ for the non-dominant arm. For men we found a DCR of 93.6 to $99.9 \%$ for the dominant arm and 95.9 to $98.2 \%$ for the non-dominant arm. In both gender no significant difference in DCR was found between the dominant and non-dominant arm. However, the DCR for women was significantly higher than for men which is due to the relatively high eccentric ER strength. Referring to the definition of Wang and Cochrane, ${ }^{45}$ we found no muscle imbalance in females. In men the DCR was almost I which implies a small detectable muscle imbalance in both arms. Other studies showed a DCR for the dominant and non-dominant arm in swimmers of 116 and $117 \%$ respectively ${ }^{46}$, in throwers of 117 and $148 \%$ respectively ${ }^{37}$ and in volleyball players of 96 to $117 \%$ and 122 to $142 \%$ respectively. ${ }^{45} \mathrm{Ng}$ et al. ${ }^{36}$ measured in badminton players the work ratio's (ER ecc $: \mathbb{R}_{\text {con }}$ ) for shoulder rotator muscles in the range of motion corresponding to the deceleration phase in overhead strokes. The work ratio (in joules normalized to body mass) of the dominant arm was I I0\% and of the non-dominant arm I30\%. Recently, Yildiz et al. ${ }^{49}$ measured asymptomatic overhead athletes in the same range of motion and found a DCR of 103\% for the dominant arm and I 19\% for the non-dominant arm. In contrast to all these findings Bak et al. ${ }^{2}$ found in swimmers a DCR of $108 \%$ on the injured side and of $\mathbf{8 9 \%}$ on the healthy side in swimmers. Unfortunately, no absolute strength values were provided and therefore it is impossible to delineate whether the high DCR on the involved side is an outcome of the eccentric external rotators or the concentric internal rotators.

Data as presented are important in interpreting isokinetic shoulder strength in elite badminton players and could be relevant in rehabilitation and prevention of shoulder injuries. Further research is needed to support the belief that a DCR of lower than I is correlated to shoulder injury in sports. 


\section{References}

I. Alfredson H, Pietila T and Lorentzon R. Concentric and eccentric shoulder and elbow muscle strength in female volleyball players and non-active females, Scan J Med Sci Sports 8 (1998), 265-270.

2. Bak K and Magnusson SP. Shoulder strength and range of motion in symptomatic and pain-free elite swimmers, Am J Sports Med 4 (1997), 454-459.

3. Bigliani LU, Kelkar R, Flatow EL et al. Glenohumeral stability, Clin Orthop and Rel Res 330 (1996), 13-30.

4. Chan KM, Maffulli N. Principles and practise of isokinetics in sports medicine and rehabilitation, Williams \& Wilkins, Hong Kong, 1996, page 37.

5. Cingel van R, Kleinrensink GJ, Stoeckart $R$ et al. Strength values of shoulder internal and external rotators in elite volleyball players, J Sports Rehabil I5 (2006), 236-244.

6. Codine P, Bernard PL, Pocholle M. Influence of sports discipline on shoulder rotator cuff balance, Med Sci Sports and Exerc II (1997), I400-I 405.

7. Cook EE, Gray VL, Savinar I et al. Shoulder antagonist strength ratios: a comparison between collegelevel baseball pitchers and non-pitchers, J Orthop Sports Phys Ther 9 (1987), 45 I-46I.

8. Cools AM, Witvrouw E, Mahieu $\mathrm{N}$ et al. Isokinetic scapular muscle performance in overhead athletes with and without impingement symptoms, J Athl Training 2 (2005), I04-I 10.

9. Cybex 6000 User's Guide, Cybex division of Lumex, Ronkonkoma, 1993.

10. Dauty M, Delbrouck C, Huguet D et al. Reproducibility of concentric and eccentric isokinetic strength of the shoulder rotators in normal subjects 40 to 55 years old, I E S II (2003), 95- 100.

II. David G, Margary ME, Jones MA. EMG and strength correlates of selected shoulder muscles during rotations of the glenohumeral joint, Clin Biomech 15 (2000), 95-102.

12. Davies GJ. A compendium of isokinetics in clinical usage, S\&S Publishers, Onalaska, 1992.

13. DiGiovene NM, Jobe F, Pink $M$ et al.An electromyographic analysis of the upper extremity in pitching,J Shoulder Elbow Surg I (1992), I5-25.

14. Dupuis C,Tourny-Chollet C, Delarue Y et al. Influence of baseball practise on strength ratios in shoulder rotator muscles: A new position for isokinetic assessment, I E S 12 (2004), I49-I57.

15. Dvir Z, Eger $\mathrm{G}$, Halperin $\mathrm{N}$ et al.Thigh muscle activity and anterior cruciate ligament insufficiency, Clin Biomech 4 (1989), 87-9I.

16. Dvir Z. Isokinetics: muscle testing, interpretation and clinical application, Churchill Livingstone, London, 2004.

17. Ellenbecker T. Shoulder internal and external rotation strength and range of motion of highly skilled junior tennis players, I E S 2 ( 1992), 65-72.

18. Ellenbecker T.A total arm strength isokinetic profile of highly skilled tennis players, I E S I (I99I), 9-2I.

19. Ellenbecker T, Roetert EP.Testing isokinetic muscular fatigue of shoulder internal and external rotation in elite junior tennis players, J Orthop Sports Phys Ther 5 (1999), 275-28I.

20. Fahlstrom M, Yeap JS, Alfredson $\mathrm{H}$ et al. Shoulder pain - a common problem in world-class badminton players, Scan J Med Sci Sports 16 (2006), I68-173.

21. Fleisig GS, Andews JR, Dillman CJ et al. Kinetics of baseball pitching with implications about injury mechanisms, Am J Sports Med 2 (1995), 233-239. 
22. Friedman RJ, Knetsche RP. Biomechanics of the rotator cuff, In:W.Z. Burkhead (ed), Rotator cuff disorders, Williams \& Wilkins, Baltimore, 1996.

23. Gowan ID, Jobe FW, Tibone JE et al.A comparative electromyographic analysis of the shoulder during pitching. Professional versus amateur pitchers, Am J Sports Med I5 (1987), 586-590.

24. Gulick DT, Dustman CS, Ossowski LL et al. Side dominance does not affect dynamic control strength ratios in the shoulder, I E S 9 (200I), 79-84.

25. Hellwig EV, Perrin DH.A comparison of two positions for assessing shoulder rotator peak torque: the traditional frontal plane versus the plane of the scapula, I E S 4 (I99I), 202-206.

26. Hutchinson MR, Laprade RF, Burnett QM et al. Injury surveillance at the USTA Boy's tennis championships: a 6-yr study, Med Sci Sports Exerc, 27 (1995), 826-830.

27. Ivey FM, Calhoun JH, Rusche K. Isokinetic testing of shoulder strength: normal values, Arch Phys Med Rehabil 66 (1985), 384-386.

28. Jobe FW,Tibone JE, Perry J et al.An EMG analysis of the shoulder in throwing and pitching: a preliminary report, Am J Sports Med I (1983), 3-5.

29. Jorgensen U,Winge S. Injuries in badminton, Sports Med I (1990), 59-64.

30. Kroner K, Schmidt SA, Nielsen AB et al. Badminton injuries, Br J Sp Med 2 (1990), 169- 172.

31. Kuipers H. Exercise induced muscle damage, Int J Sports Med I5 (1994), I32-I 35.

32. Lo D, Stark K. The badminton overhead shot, Nat Strength Cond Ass J 4 (I99I), 6-I 3 and 87-89.

33. Meister K. Injuries to the shoulder in the throwing athlete. Part I: biomechanics, pathophysiology, classification of injury, Am J Sports Med 2 (2000), 265-275.

34. Mikesky AE, Edwards JE, Wigglesworth JK et al. Eccentric and concentric strength of the shoulder and arm musculature in collegiate baseball pitchers, Am J Sports Med 5 (1995), 638-642.

35. Moynes DR, Perry J,Antonelli DJ et al. Electromyography and motion analysis of the upper extremity in sports, Phys Ther 66 (1986), 1905-1911.

36. Ng GYF, Lam PCW.A study of antagonist / agonist isokinetic work ratios of shoulder rotators in men who play badminton, J Orthop Sports Phys Ther 32 (2002), 399-404.

37. Noffal GJ. Isokinetic eccentric-to-concentric strength ratios of the shoulder rotator muscles in throwers and nonthrowers, Am J Sports Med, 4 (2003), 537-54I.

38. Newsham KR, Keith CS, Saunders JE et al. Isokinetic profile of baseball pitchers' internal/external rotation 180, 300, 450\%.s., Med Sci Sports Exerc 10 (1998), 1489-1495.

39. Reid DC, Oedekoven G, Kramer JF et al. Isokinetic muscle strength parameters for shoulder movements, Clin Biomech 4 (1989), 97-104.

40. Ryu RKN, McCormick J, Jobe FW et al.An electromyographic analysis of shoulder function in tennis players, Am J Sports Med 5 (1988), 48I-485.

4I. Scoville CR, Arciero RA, Taylor DC et al. End range eccentric antagonist/concentric agonist strength ratios:A new perspective in shoulder strength assessment, J Orthop Sports Phys Ther 3 (1997), 203-207.

42. Sirota SC, Malangna GA, Eischen JJ et al.An eccentric- and concentric-strength profile of shoulder external and internal rotator muscles in professional baseball pitchers, Am J Sports Med I (1997), 59-64. 
43. Tennent TD, Beach WR, Meyers JF.A review of special tests associated with shoulder examination. Part II: laxity, instability, and superior labral anterior and posterior (SLAP) lesions, Am.J Sports Med 2 (2003), 301-307.

44. Wang HK, Macfarlane A, Cochrane T. Isokinetic performance and shoulder mobility in elite volleyball players from the United Kingdom, BrJ Sports Med 34 (2000), 39-43.

45. Wang HK, Cochrane T. Mobility impairment, muscle imbalance, muscle weakness, scapular asymmetry and shoulder injury in elite volleyball athletes, J Sports Med Phys Fitness 4 I (200I), 403-4I0.

46. West D, Sole G, Sullivan SJ. Shoulder external- and internal-rotation isokinetic strength in master's swimmers, J Sports Rehabil 14 (2005), I2-19.

47. Wilk KE, Arrigo CA,Andrews JR. Standardized isokinetic testing protocol for the throwing shoulder: the throwers series, I E S 2 (I99I), 63-69.

48. Wilk KE,Andrews JR, Arrigo CA et al. The strength characteristics of internal and external rotator muscles in professional baseball players, Am J Sports Med I (1993), 6I-66.

49. Yildiz Y,Aydin T, Sekir $U$ et al. Shoulder terminal range eccentric antagonist/concentric agonist strength ratios in overhead athletes, Scan J Med Sci Sports 16 (2006), 174-180. 


\section{Chapter 5}

Learning effect in isokinetic testing of ankle invertors and evertors

R. van Cingel', G.J. Kleinrensink ${ }^{2}$, P. Rooijens ${ }^{2}$, E. Uitterlinden², G.Aufdemkampe ${ }^{3}$, R. Stoeckart ${ }^{2}$

I Sports Medical Center Papendal,Arnhem, The Netherlands.

2 Department of Anatomy, Erasmus University, Rotterdam, The Netherlands.

${ }^{3}$ Department of Physical therapy, Polytechnic of Utrecht, Utrecht, The Netherlands

Published: Isokinetics and Exercise Science. 200 I; 9: I 7 I- I 77 


\begin{abstract}
The purpose of this study was to determine whether a motor learning effect exists during concentric isokinetic testing of the ankle invertor and evertor muscles of the dominant and non-dominant leg. Thirty-three subjects aged 22 to 57 years without any experience in isokinetic testing, were randomly assigned to one out of three test velocity groups $\left(30^{\circ}, 60^{\circ}\right.$ or $\left.120^{\circ} / \mathrm{s}\right)$. Each velocity group consisted of I I subjects. Invertors and evertors of the dominant and non-dominant leg were tested.All subjects performed five sets of two maximal concentric inversion-eversion movements on a calibrated CYBEX 6000 dynamometer.

For the invertors of the dominant leg at $30^{\circ}$ and $120^{\circ} / \mathrm{s}$ the mean PKTQ\%BW generated in the second set was significantly higher than in the first set. For the evertors of the dominant leg and the invertors and evertors of the non-dominant leg no statistically significant difference was found.

To exclude possible bias of learning effects in concentric isokinetic testing of inversioneversion muscles, we advise a practice session of two sets of two maximal inversioneversion movements.
\end{abstract}

\title{
Introduction
}

Isokinetic testing is clinically accepted for evaluating muscle performance. The reliability of isokinetic testing protocols across repeated test sessions has been shown to be high for the knee, a joint that has been studied extensively., 12,16,20,30 Later, studies have been performed on other joints, such as the ankle. 6,10,13,14,18,21,23,26,31,32 The reliability of isokinetic measures for torque, power and work parameters has been established for ankle plantar-dorsiflexion 1,2,11,29 and inversion-eversion. ${ }^{1,2,11,15}$ However, no studies could be found in which the characteristics of a motor learning effect in concentric isokinetic testing of inversion-eversion (INV/EVER) movements of the ankle were examined.This is surprising, due to the high incidence of ankle sprains in athletes. Furthermore, in rehabilitation after ankle injuries much attention is paid to the ankle invertor and evertor muscles, due to their important role in stabilizing the ankle joint. In this study motor learning is defined as a set of processes associated with practice or experiences leading to relatively permanent changes in the capability for responding. ${ }^{27}$ In isokinetic testing of the INV/EVER movements, most authors agree on the necessity of having a specific warm-up period on the isokinetic dynamometer, prior to data collection. However, no uniformity exists concerning this warm-up procedure and the test position for INV/EVER movements. According to the literature, different warm-up protocols have been used: 3 sub maximal efforts ${ }^{18,21}$ or 2, 3 or 6 sub maximal efforts combined with I, 2, 3 or 4 maximal efforts $2,6,10,11,15,32$ or the test person was asked to practice without any further instructions. ${ }^{1,31}$ Oberg et al. ${ }^{23}$ used only a general warm-up 
on a bicycle ergometer. Hartsell combined a five-minute general warm-up with a specific warm-up, consisting of 3 sub maximal efforts and I maximal effort. ${ }^{7}$ For a specific warm-up different reasons have been described; I) to familiarize the subject with the testing condition, 2) to reduce risk of injury, 3) to create standardized conditions and 4) to minimize any practice effect. ${ }^{3,23,31}$ Practice effects were shown to have a major influence in the first stages of strength training. ${ }^{17,33}$ As a consequence, it can be questioned whether the above mentioned warm-up protocols eliminate a learning effect in isokinetic INV/EVER movement testing.

In isokinetic testing of the ankle INV/EVER movements no uniformity exists in test position. Different knee and ankle positions have been used. 2,5,6,7,10,II, I3, I4, 15, I8,21,31,32 It has been shown by Osternig et al. ${ }^{24}$ that during tibial rotary torque measurements with $90^{\circ}$ of knee flexion, the lateral and medial hamstrings exert a significant tibial torque component due to the location of their insertion and the line of action. This in turn may amplify the peak torque generated by the INV/EVER muscles. According to Frankel and Nordin tibial rotation is better restrained in the close packed position of the knee, which is near or at full extension. ${ }^{5}$ Consequently, measurements of the peak torque of the INV/EVER muscles are likely to be more accurate in a close packed than in a loose packed position. This theory was confirmed by Lentell et al. ${ }^{13}$ They used EMG to demonstrate that, in ankle muscle testing, hamstrings activity was significantly lower in $10^{\circ}$ of knee flexion than in $70^{\circ}$ of knee flexion. They suggested that testing in a loose packed position resulted in higher INV/EVER muscle strength values due to the contribution of the hamstrings and other tibial rotators. Therefore, the INV/EVER movements in this study were performed with the knee in the closed packed position. Concerning the selection of test velocities in INV/EVER muscle testing there is more agreement in literature. A study by Novick and Kelly revealed that eversion during walking occurred at $120^{\circ} / \mathrm{s}^{22}$ Based on other studies, Davies ${ }^{3}$ and Dvir ${ }^{4}$ concluded that, for the INV/EVER movements, the test velocity spectrum has to range from $30^{\circ}$ to $160 \%$, with $30^{\circ}$ to $120^{\circ}$ s being optimal. In isokinetic testing the preset angular velocity is reached only after a certain range of motion has been covered; the higher the preset value, the longer it takes to attain it. Using velocities higher than $120 \%$, it is very likely that test persons will not be able to perform isokinetically, as the velocities are too high for INV/EVER muscles and the range of motion is too limited. ${ }^{4}$ For these reasons we used test velocities of $30^{\circ}, 60^{\circ}$ and $120^{\circ} / \mathrm{s}$.

In this study each velocity group consisted of male and female individuals with different anthropometrical profiles. In order to eliminate differences in body weight, Thorstensson et al. ${ }^{28}$ recommended that strength should be expressed in torque output per unit of body weight. Nickson found a significant effect of both body weight and gender on absolute peak torque values at the ankle. ${ }^{2 l}$ Furthermore, with an increase in body 
weight, more lean muscle mass is potentially available to produce higher isokinetic moments. $4,6,25$ Therefore, we normalized our data using peak torque expressed as a percentage of body weight (PKTQ\%BW) as the main outcome parameter.

The purpose of the present study was to determine whether a learning effect exists during concentric isokinetic testing of the ankle INV/EVER movements. If a learning effect exists it has to be determined how many INV/EVER movements are needed to reach the plateau phase in the 'learning curve'.

\section{Methods}

\section{Subjects}

Thirty-three healthy volunteers, 21 females and 12 males, participated in this study.All subjects participated once or twice a week in recreational sport activities. Excluded from the study were people with; I) earlier experience with isokinetic exercise or testing, 2) contra-indication to resistive exercise, 3) major neuromusculoskeletal dysfunction of one or both lower extremities, 4) previous injury to one or both lower extremities in the last five years which required hospitalization or use of crutches for more than four days. The subjects were informed about the investigation procedures by means of an information letter and gave their written informed consent. Test persons were asked to refrain from heavy loading of the ankles during the 24-hour period preceding the test session. In this study we used three velocity groups $\left(30^{\circ}, 60^{\circ}\right.$ and $\left.120^{\circ} / \mathrm{s}\right)$. Each group consisted of I I subjects. Four males and seven females were randomly assigned to each group. There were no significant differences between the three groups (ANOVA, Alpha $=0.05$ ) for age, height and weight (Table I).

We allocated different subjects to different test velocities. A repeated measure design where every subject takes part in all experimental situations would result in the situation that all subjects were measured at three test velocities. Then only at the first test velocity the subjects would be inexperienced. In our opinion the experience at $30 \% \mathrm{~s}$ could possibly affect the motor learning effect at $60^{\circ}$ and $120^{\circ} / \mathrm{s}$.

Table I

Age, height and weight of the subjects in the three different groups (mean $\pm s d$ ).

\begin{tabular}{|l|c|c|c|}
\hline & $\begin{array}{c}\mathbf{3 0} / \mathbf{s} \\
(\mathbf{n}=1 \mathrm{I})\end{array}$ & $\begin{array}{c}\mathbf{6 0} / \mathbf{s} \\
(\mathbf{n}=1 \mathrm{I})\end{array}$ & $\begin{array}{c}\mathbf{1 2 0} / \mathbf{s} \\
(\mathbf{n}=\mathrm{II})\end{array}$ \\
\hline Age (years) & $32.4 \pm 5.6$ & $33.4 \pm 9.2$ & $34.4 \pm 11.4$ \\
\hline Height $(\mathrm{cm})$ & $176.3 \pm 10.6$ & $181.6 \pm 9.8$ & $174.5 \pm 7.5$ \\
\hline Weight $(\mathrm{kg})$ & $71.0 \pm 14.5$ & $75.8 \pm 17.4$ & $69.2 \pm 7.7$ \\
\hline
\end{tabular}




\section{Instrumentation}

To determine PKTQ\%BW at three different test velocities for reciprocal concentric INV/EVER movements of the ankle a Cybex 6000 isokinetic dynamometer with the INV/EVER footplate (Cybex, Division of Lumex Inc., Ronkonkoma, NY I I 779) was used. With the Cybex Upper Body Extremity Table (UBXT) it was not possible to position subjects in $10^{\circ}$ knee flexion. Therefore, we used a treatment bench (Manumed PR-E, Enraf Nonius). This bench raised the level of the subject position in relation to the dynamometer head, allowing for optimal positioning. ${ }^{13}$

\section{Procedures}

The three test velocity groups were matched for gender. Matching for body weight was not necessary as peak torque was expressed as a percentage of body weight (PKTQ\%BW). Before the test, body weight was assessed by means of a calibrated scale. The parameter peak torque was expressed in Newton meter $(\mathrm{Nm})$.

In the test protocol, I I subjects of each velocity group performed five sets of two maximal INV/EVER movements with a rest period of ten seconds between sets. The highest peak torque value of the two repetitions of each set was used for analysis. The II highest values of each set were averaged and used for statistical comparison. During the entire experiment the same investigators (P.R. and E.U.) carried out the data collection. Prior to the test session the subject performed a five-minute general warm-up on an electromagnetic bicycle ergometer (75 Watt, 70-80 rpm.). During this moderate warm-up period a brief history about the subjects sports and daily activities was taken. Leg dominance was determined by asking the subject which leg would be used to kick a ball between two lines on a wall.

Testing occurred in a seated position on a height adjustable treatment bench with the backrest at an angle of $100^{\circ}$. The dynamometer head was positioned in a $60^{\circ}$ posterior tilt to achieve $10^{\circ}$ plantar flexion. Reliability and torque output were reported to be highest in this position. ${ }^{2}$ The knee was placed in $10^{\circ}$ flexion, supported by a towel roll with a diameter of $14 \mathrm{~cm}$. The angle of the knee was assessed with a goniometer. The INV/EVER footplate of the Cybex 6000 unit was adjusted in the lowest position. To prevent foot movement within the shoe all subjects wore tight fitting sport-shoes, minimizing loss of force transmission to the dynamometer. The foot was secured on the footplate by two straps. Additional fixation straps were applied to the hip, thigh and knee of the tested leg. Additional stabilization of the knee was manually provided by one investigator. ${ }^{14}$ Once the subject was positioned and stabilized, no further practice movements were performed. 
Each subject performed five sets of two INV/EVER movements. After each set there was a rest period of ten seconds. During this break, instructions were given to repeat the procedure until data collection was completed.

Testing started with the dominant leg and with the foot in maximal eversion. Instructions were given to push as hard and fast as possible through the full range of motion in both directions. The subject was instructed to restrict movements to the foot and ankle and to keep the arms folded across the chest during data collection. Prior to each set the same investigator gave the instructions. No encouragement or visual feedback from the computer-screen was given during the test movements.

The data were collected in the exercise mode of the Cybex 6000 software. The dynamometer was calibrated once weekly, according to procedures specified in the operating manual. ${ }^{17}$

\section{Statistical Analysis}

All data were tested for normality by means of the Kolmogorov-Smirnov test. As all data appeared to be distributed normally a parametric repeated measure ANOVA per velocity group was performed with Tukey post hoc analysis. Level of significance was set at 0.05. All analyses were performed in SPSS, version 8.0.

\section{Results}

The mean PKTQ\%BW values of the five successive sets are presented in Figures I, 2 and 3. There were significant differences $(P<0.05)$ in inversion of the dominant leg between the first and second set at $30^{\circ}$ and $120 \%$, but not at $60 \%$ s. There were no significant differences in the eversion movement of the dominant leg. For the non-dominant leg no significant differences were found between the five successive sets. This holds both for the inversion and eversion movements.

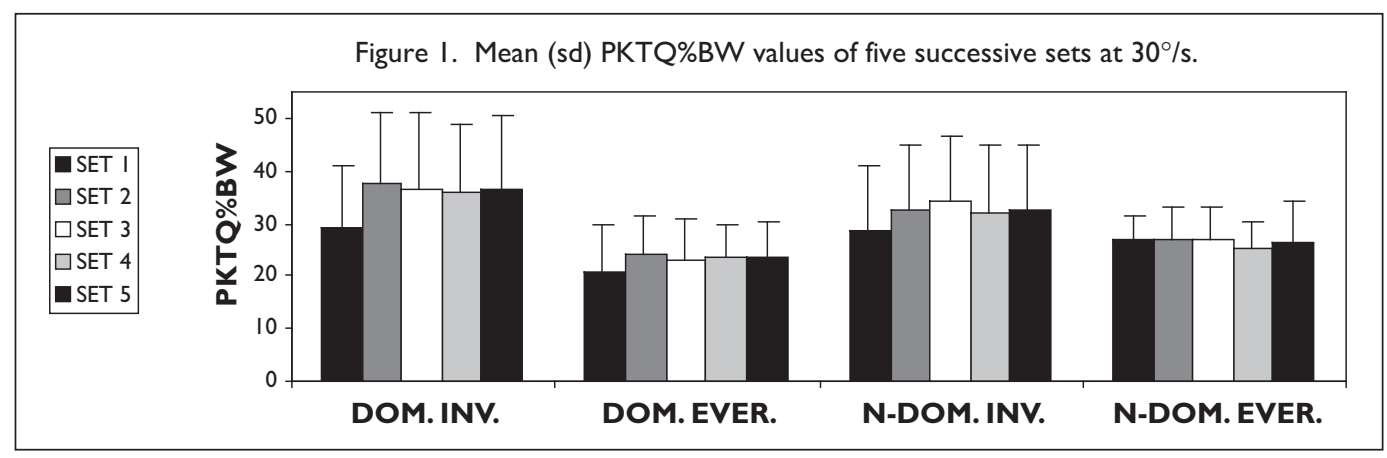



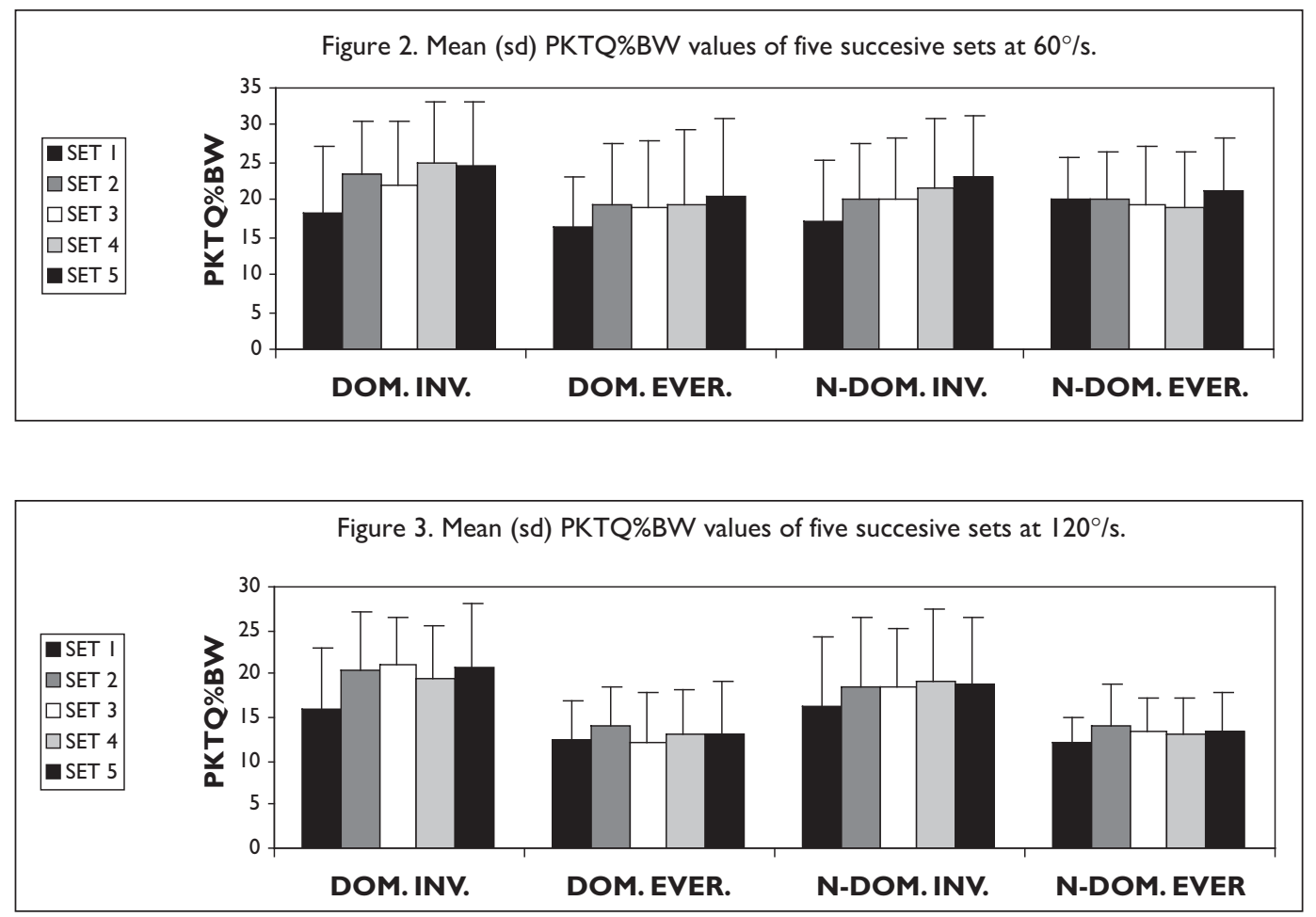

\section{Discussion}

In contrast to isokinetic testing of the knee, assessment of the INV/EVER movements of the ankle is more complex. These movements involve multiple joints, three movement axes, relatively shorter lever arms and less muscle masses. $3,4,11,25$ The more complex the movement, the greater the chance that substantial improvement of the task will occur due to learning by repetitions. ${ }^{27}$ In isokinetic testing of INV/EVER movements at the ankle consensus exists about the necessity of practice/warm-up sessions prior to actual data collection. However, due to lack of data concerning the learning effect of INV/EVER muscle performance on isokinetic dynamometers, there is much confusion about intensity and frequency of these practice sessions. No studies were available dealing with the minimal number of trials needed to obtain data without the bias of a motor learning effect.

The present study shows a statistically significant learning effect for the dominant invertors between the first and the second set at $30^{\circ}$ and $120^{\circ} / \mathrm{s}$. In other words, the learning effect stabilized after two sets of two maximal INV/EVER movements. For the dominant invertors at $60 \%$ s the increase of the mean PKTQ\%BW between the first and second set was $22,5 \%$, but this was not statistically significant. Based on our results a 
power analysis (beta $=0.80$, alpha $=0.05$ ) yielded a sample size of 20 to detect a significant difference between the first and second set at $60 \%$ s.

Hartsell concluded that the dominant ankle invertors were significantly stronger than the non-dominant invertors. ${ }^{7}$ This difference in males was within $10 \%$ and in females 15 to $20 \%$. In our study we found a non-significant increase of $22,5 \%$ for the dominant invertors at $60 \%$ s. This might imply that this increase nevertheless has clinical relevance. Karnofel et al. " concluded that after a specific warm-up of three sub maximal and three maximal INV/EVER movements, no evidence of significant increases in torque values occurred due to a learning effect. According to our results this might imply that a learning effect was already included in the specific warm-up. Surprisingly there is no statistically significant learning effect for the non-dominant invertors. This can be explained by the study of Hartsell. ${ }^{7}$ Hartsell suggests that the dominant invertors need more practice movements before the learning effect has been stabilized. Since Wong et al. ${ }^{32}$ could not find any significant difference in absolute peak torque and relative peak torque (PKTQ\%BW) between the dominant and non-dominant leg, this assumption requires further research. No statistically significant learning effect was found for the dominant and non-dominant evertors. This is possibly due to the larger range of the inversion motion than the eversion motion $\left(30\right.$ to $50^{\circ}$ versus 15 to $\left.20^{\circ}\right) .{ }^{19}$ The smaller range of motion may result in a less complex movement with a shorter 'learning curve'. The fact that the subjects in this study only performed five sets of two repetitions suggests that the improvement cannot be attributed to muscle hypertrophy. Increase in muscle strength resulting from training takes much longer. ${ }^{9}$ The most plausible explanation is that the improvement occurs due to motor learning, i.e. due to improved neuromuscular integration associated with practice. This physiological process is known to play a major role in learning new skills. $9,27,33$

\section{Conclusions}

Based on our results, healthy subjects with no previous experience in isokinetic testing show a statistical significant motor learning effect of the dominant invertors at $30^{\circ}$ and $120 \%$. This learning effect occurs rapidly and stabilizes after the second set. No significant differences were found for the evertors of the dominant leg nor for the invertors and evertors of the non-dominant leg. To exclude any chance of learning effect we advise to use at least two sets of two maximal INV/EVER trials as a specific warm-up. 


\section{References}

I. Baumhauer JF,Alosa DM, Renström PAFH et al. Test-retest reliability of ankle injury risk factors, Am J Sports Med. 23 (1995), 57I-574.

2. Cawthorn M, Cummings G, Walker JR et al. Isokinetic measurement of foot invertor and evertor force in three positions of plantarflexion and dorsiflexion, J Orthop Sports Phys Ther. 14 (199I), 75-8I.

3. Davies GJ.A compendium of isokinetics in clinical usage and rehabilitation techniques, Onalaska, S\&S publishers, 1992.

4. Dvir Z. Isokinetics: muscle testing, interpretation and clinical application, New York, Churchill Livingstone, 1995.

5. Frankel V, Nordin M. Basic biomechanics of the skeletal system, Philadelphia, Lea \& Febiger, 1980.

6. Gross MT, Brugnolotti JC, Relationship between multiple predictor variables and normal Biodex eversion-inversion peak torque and angular work, J Orthop Sports Phys Ther. 15 (1992), 24-3I.

7. Hartsell HD. Isokinetics and muscle strength ratios of the ankle invertors/evertors: A pilot study, Isok Exerc Sc. 3 (1994), I I6-12I.

8. Johson J, Siegel D. Reliability of an isokinetic movement of the knee extensors, Research Quarterly 49 (1978) 88-98.

9. Jones DA, Round JM. Training for power, in: Skeletal muscle in health and disease, D.A. Jones and J.M. Round, ed., Manchaster University press, Manchaster, 1992, pp. 98-I I 5.

10. Kaminski TW, Perrin DH, Mattacola CG et al. The reliability and validity of ankle inversion and eversion torque measurements from the Kin Com II isokinetic dynamometer, J Sports Rehab. 4 (1995), 210-218.

II. Karnofel H,Wilkinson K, Lentell GL. Reliability of isokinetic muscle testing at the ankle,J Orthop Sports Phys Ther. II (1989), I50-I54.

12. Kues J, Rothstein JM, Lamb RL. Obtaining reliable measurements of knee extensor torque produced during maximal voluntary contractions: an experimental investigation., Phys Ther. 72 (1990), 492-504.

13. Lentell GL, Cashman PA, Shiomoto KJ et al. The effect of knee position on torque output during inversion and eversion movements at the ankle, J Orthop Sports Phys Ther. 10 (1988), I77-I83.

14. Lentell GL, Katzman LL,Walters MR. The relationship between muscle function and ankle stability, J Orthop Sports Phys Ther. II (1990), 605-6II.

15. Leslie M, Zachazewski J, Browne P. Reliability of isokinetic torque values for ankle invertors and evertors, J Orthop Sports Phys Ther. II (1990), 612-616.

16. Levene JA, Hart BA, Seeds RH et al. Reliability of reciprocal isokinetic testing of the knee extensors and flexors, J Orthop Sports Phys Ther. 3 (1991), I21-127.

17. Lumex, Inc. Cybex 6000 Users Guide, New York: Lumex Inc, Ronkonkoma, 1993.

18. McKnight CM,Armstrong CW.The role of ankle strength in functional ankle instability,J Sp Rehab. 6 (1997), 21 -29.

19. Miller PJ.Assessment of joint motion, in: Measurements in physical therapy, J.M. Rothstein, ed., Churchill Livingstone, New York, 1985, pp. $104-109$. 
20. Molczyk L, Thigpen LK, Eickhoff J. et al. Reliability of testing the knee extensors and flexors in healthy adult woman using a Cybex II isokinetic dynamometer, J Orthop Sports Phys Ther. 14 ( 199I), 37-4I.

21. Nickson W. Normative isokinetic data on ankle invertors and evertors, Austr J Phys. 3 (1987), 85-90.

22. Novick A, Kelley DL. Position and movement changes of the foot with orthotic intervention during the loading response of gait, J Orthop Sports Phys Ther. II (1990), 30I-3I2.

23. Öberg B, Bergman T, Tropp H. Testing of isokinetic muscle strenght in the ankle. Med Sci Sports Exerc. 19 (1987), 318-355.

24. Osternig L, Bates B, James S. Patterns of tibial roatory torque in knees of healthy subjects, Med Sci Sports Exerc. 12 (1980), 195-199.

25. Perrin DH. Isokinetic Exercise and Assessment, Human Kinetic Publishers, Champaign, 1993.

26. Schief Von A, Büttner P, Noack W. Isokinetische messungen bei jugendlichen läufern, Sportverletzung Sportschaden 5 (1991), I86-192.

27. Schmidt RA. Motor control and learning, Human kinetics publishers, Champaign, 1988.

28. Thorstensson A, Larsson L, Tesch P. Muscle strength and fibre composition in athletes and sedentary men, Med Sci Sports Exerc. 9 (1977), 26-30.

29. Wennerberg D. Reliability of an isokinetic dorsiflexion and plantarflexion apparatus, Am J Sports Med. 19 (I99I), 519-522.

30. Wilhite MR, Cohen ES, Wilhite SC. Reliability of concentric and eccentric measurements of quadriceps performance using the Kin-Com dynamometer: the effect of testing order for three different speeds, J Orthop Sports Phys Ther. I5 (1992), I75-I82.

31. Wilkerson GB, Pinerola J], Caturano RW. Invertor vs. evertor peak torque and power deficiencies associated with lateral ankle ligament injury, J Orthop Sports Phys Ther. 26 (1997), 78-86.

32. Wong DLK, Glasheen-Wray M,Andrews LF. Isokinetic evaluation of the ankle invertors and evertors, J Orthop Sports Phys Ther. 5 (1984), 246-252.

33. Yue G, Cole KJ. Strength increases from the motor program: comparison of training with maximal voluntary and imaged muscle contraction, J Neurophysiol. 67 ( I 992), I I I4- I I 23. 


\section{Chapter 6}

\section{Repeated ankle sprains and delayed neuromuscular response: Acceleration time parameters}

R. van Cingel', G.J. Kleinrensink ${ }^{2}$, E. Uitterlinden ${ }^{3}$, P. Rooijens ${ }^{3}$, P. Mulder ${ }^{4}$, G.Aufdemkampe ${ }^{5}$, R. Stoeckart ${ }^{2}$

I Sports Medical Center Papendal,Arnhem, The Netherlands.

2 University Medical Center Rotterdam, Department Neuroscience, University Rotterdam, The Netherlands.

${ }^{3}$ University Medical Center, Rotterdam, The Netherlands.

${ }^{4}$ Department of Epidemiology \& Biostatistics, University Rotterdam, The Netherlands.

${ }^{5}$ Faculty of Health Care, University of Professional Education, Utrecht, The Netherlands.

Published: Journal of Orthopaedic and Sports Physical Therapy. 2006; 2: $72-79$ 


\section{Abstract}

Study Design: A comparative study.

Objectives:To assess whether in subjects with unilateral chronic ankle instability the dynamic reaction time of the affected ankle differs from the healthy ankle and from ankles of a control group.

Background: Reaction time is an essential element in joint protection against sudden unexpected excessive movement requiring fast and coordinated muscle action. During a sudden ankle inversion movement, a reflex action of the evertor muscles is needed to counteract the movement. Adequate neuromuscular response is crucial and a delayed response could contribute to inversion trauma and subsequently to chronic ankle instability. The isokinetic dynamometer acceleration time (ACC-TIME) provides valuable information on dynamic neuromuscular ability.

Material and Methods: Patients with unilateral chronic ankle instability $(n=I I)$ and healthy individuals in a control group $(\mathrm{n}=\mathrm{I})$ were tested on an isokinetic dynamometer during 3 sets of 3 reciprocal inversion/eversion movements of both ankles at $30^{\circ}$ and $120^{\circ} / \mathrm{s}$. Analysis of variance models were used to compare the ACC-TIME of the ankle affected ankle to the unaffected ankle of the same subjects and a control group.

Results: For the evertor muscles at $30^{\circ}$ and $120^{\circ} / \mathrm{s}$ a significantly prolonged ACC-TIME was found when comparing the affected ankles to the contralateral ankles and both ankles of the control group. For the invertor muscles at $120 \%$ s significantly prolonged ACC-TIME was found when comparing the affected ankle to the unaffected ankles of patients and those of the control group.

Conclusions: Because the most important evertor muscles are innervated by the fibular nerve, the significantly prolonged ACC-TIME of the affected ankle is consistent with the finding of a lower motor nerve conduction velocity of the fibular nerve after inversion trauma. The results support the concept of a delayed neuromuscular response as an important factor in the etiology of chronic ankle instability.

\section{Introduction}

Inversion trauma is a very common sports injury to the ankle. In a survey of 8000 sports injuries, $12.5 \%$ of the injuries were due to inversion trauma. ${ }^{15}$ Most patients return to their daily activities after a few days of rest. However, 6 months after trauma one third of these individuals still complain of sensations of 'giving way' and instability of the injured ankle. ${ }^{10,41}$

To explain remaining symptoms, studies dealing with chronic ankle instability (CAI) have focused on mechanical laxity and proprioceptive deficits. ${ }^{1,3,13,17,43}$ Furthermore, deficits in muscle strength were thought to play an important role. ${ }^{20,27,29}$ To assess muscle strength, 
generally, isokinetic testing has been used, with peak torque (the highest torque produced throughout the complete range of motion) as the main outcome variable. ${ }^{27,29,32,46}$ After reviewing the literature on ankle muscle strength measurements, Caulfield ${ }^{4}$ concluded that subjects with ankle instability have minimal or no deficits in peak evertor torque of the affected ankle compared to the uninvolved ankle and to normative data. Only Tropp ${ }^{44}$ showed significant evertor muscle weakness in patients with unstable ankles.

In addition to the capsule, ligaments, and muscles, arthrokinetic reflexes play an important role in protecting joints against damage due to large loading forces. ${ }^{7,14,47}$ Reaction time is an essential element in joint protection against injuries because joint loading, especially in sports activities, requires fast and coordinated muscle action. Consequently, neuromuscular dysfunction is seen as an important factor in the etiology of CAI. 14,22-26,30,37,45 Most published studies on reaction time $9,11,18,19,24,26,30,36,45$ are based on trapdoor experiments, measuring surface electromyography (EMG) response of lower leg muscles. To assess muscle recruitment, latency times (defined as the time between disturbance of the equilibrium and the first EMG signal) is often used as the outcome measure. Using a trapdoor experiment, no significant differences were recorded in latency time during ankle inversion when comparing stable ankles to sprained ankles. ${ }^{9,11,18,19,36}$ It was concluded that the fibularis longus and brevis muscles response time during sudden ankle inversion was too slow to offer protection. Other studies, however, showed a significant difference in evertor muscles latency time when comparing stable and unstable ankles during inversion movement of $30^{\circ} .22,24,26,30,37,45$ Evertor muscles of unstable ankles were shown to have a longer latency time and the latency time of the fibularis longus and brevis muscles increased with plantar flexion. ${ }^{32,37}$ Obviously, these conflicting results require further research with different methods. Furthermore, EMG studies have used relatively small inversion movements on trapdoor mechanisms not exceeding $35^{\circ}$ of inversion. ${ }^{45}$ However, an inversion trauma mostly occurs in dynamic situations like walking or running. Therefore we looked for a dynamic test that would allow an inversion/eversion (INV/EVER) movement over a large range of motion.

Speed and acceleration are important parameters of motor function, but they are less well investigated than strength and endurance. In fact, the time to produce force or the maximal rate of force production is important in most sporting activities. ${ }^{6}$ The evolution of isokinetic testing enables the force-time relationship to be studied in a more dynamic manner.The basic measurement provided by isokinetic dynamometers are torque data but additional measurements such as acceleration time (ACC-TIME) can be calculated from these torque data. ${ }^{8}$ The ACC-TIME parameter is defined as "the time required to accelerate to a preset dynamometer speed."6,31 
Chen et al. ${ }^{6}$ studied knee flexion/extension and suggested that the ACC-TIME parameter may provide valuable information regarding neuromuscular ability to produce maximal muscle action. Reviewing the literature, only 3 other studies on ACC-TIME were found, none related to the ankle joint. 6,33,34 In the present study, isokinetic INV/EVER movements were measured at 2 different test velocities (30 and $120 \%$ s). In our opinion, a delay in evertor muscle action would be, at least partly, due to a delay in motor nerve conduction velocity of the fibularis nerve. Previous studies showed a decrease in conduction velocity of the fibularis nerve after inversion trauma, both in the affected and unaffected leg. ${ }^{22}$ Furthermore, Rozzi et al. ${ }^{40}$ found in patients with unilateral functionally unstable ankles that, as a result of training, the balance score also improved in the contralateral untrained limb. This suggests that an effective training program stimulates centrally mediated neuromuscular control mechanisms responsible for the maintenance of balance and control. So, as a result of injury and training strategies, crossover effects might occur.

Therefore, we compared the affected ankle of patients with unilateral CAI with their unaffected ankle and both ankles of a control group. Because this is the first study in which the ACC-TIME was used to study patients with CAI, the purpose was 2-fold. First, we tested the hypothesis that patients with CAI have a delay in evertor muscle action time. Secondly, we studied the potential differences in evertor as well as invertor muscle ACC-TIME at $30^{\circ}$ and $120 \%$ s, between affected and unaffected ankles.

\section{Methods}

Subjects

The group of patients consisted of 4 men and 7 women with a history of unilateral CAI. No previous dysfunction of the contralateral (healthy) ankle was reported. Patients were included in the study when they a) had sought medical attention for at least I inversion trauma in the past which caused ankle ecchymosis with pain and swelling that required immobilization, b) had at least 3 ankle sprains over the last 6 months, occurring in daily life or during sporting activities, and c) were able to apply full weight bearing at least I week prior to testing. Excluded from the study were patients who had a) any form of treatment of the ankle in the last 3 months, b) a systemic disease that could result in a neuropathy, c) a previous leg or foot fracture or previous lower extremity surgery or d) a disease of the central nervous system.

The healthy control group also consisted of 4 male and 7 female subjects. In the control group both legs were tested. Subjects had no history of inversion trauma, no injury during the last 5 years to either lower extremity that required hospitalization or use of crutches for more than 4 days, and no disease of the peripheral or central nervous 
system. Both patients and control group individuals were active in recreational sport activities. Between groups, no significant differences were found for age, height, and body mass (Table I).All subjects gave their written informed consent. The protocol for this study was reviewed and approved by the institutional board of the Netherlands Olympic Committee * Netherlands Sports Confederation.

Table I

Subjects demographic data (mean $\pm S D$ )*.

\begin{tabular}{|c|c|c|c|}
\hline & CAI & Control Group & P-value \\
\hline Age (years) & $23.1 \pm 10.9$ & $28.5 \pm 5.0$ & $>.05$ \\
\hline Height $(\mathrm{cm})$ & $172.0 \pm 10.2$ & $177.5 \pm 9.6$ & $>.05$ \\
\hline Mass $(\mathrm{kg})$ & $63.7 \pm 13.1$ & $68.4 \pm 14.3$ & $>.05$ \\
\hline
\end{tabular}

* paired t-test, $\mathrm{CAI}$ versus control group, $\mathrm{CAI}=$ chronic ankle instability

\section{Instrumentation}

To determine ACC-TIME at 2 different test velocities, a Cybex 6000 isokinetic dynamometer with INV/EVER footplate (Cybex, Division of Lumex Inc., Ronkonkoma, NY I I779) was used. During INV/EVER measurements, the hamstring muscles have the potential to work dynamically to generate rotational torque on the tibia. ${ }^{39}$ To restrain tibial rotation and hamstring activity, the measurements of ankle motion have to be performed with the knee near or at full extension. ${ }^{12,39}$ Lentell et al. ${ }^{28}$ showed that during INV/EVER muscle testing, hamstring activity was significantly lower when tested with the knee at $10^{\circ}$ of flexion compared to $70^{\circ}$ of flexion. However, with the Cybex Upper Body Extremity Table (UBXT) it was not possible to position subjects in $10^{\circ}$ of knee flexion. Therefore, we used a treatment bench (Manumed PR-E, Enraf Nonius, Rotterdam, The Netherlands). With this bench the subjects were positioned to the level of the dynamometer head, thus minimizing knee flexion during testing. ${ }^{28}$

\section{Procedures}

The experimental and control groups were matched for gender. They were tested by the same 2 investigators at 2 test velocities $\left(30^{\circ}\right.$ and $\left.120^{\circ} / \mathrm{s}\right)$. The subjects were asked to refrain from performing strenuous activities of the ankles during the 24-hour period preceding the test session. Before the test session of the control group, a brief history about their sport and daily activities was taken. The patients with CAl were subjected to a complete intake protocol dealing with their CAI history. Prior to the test session, all subjects performed a 5-minute general warm-up on a bicycle ergometer (75 Watt, 70 - 
$80 \mathrm{rpm})$. The individual performing the isokinetic testing was blinded to the group assignment of the subjects and the side with CAI.

Neither the control group nor patients had prior experience with isokinetic testing. To become familiar with the apparatus and the testing procedures the subjects performed a specific warm-up of 5 submaximal INV/EVER trials at each test velocity, prior to the first measurement. During actual measurement, subjects had to perform 3 sets of 3 maximal repetitions at both test velocities. Between each set, subjects were provided a rest period of 30 seconds. To prevent fatigue effects due to the relatively strenuous testing at $30 \%$, the procedure started with testing at $120 \%$ s. For the subjects with unilateral CAI, testing started with the unaffected ankle. For the control group, the first side to be tested alternated between right and left side for each consecutive subject. To preserve blinding, the testing order for all subjects was made by an individual not involved with the isokinetic testing. Testing occurred in a seated position on a height adjustable treatment bench with the backrest at an angle of $100^{\circ}$. The knee was placed in $10^{\circ}$ flexion, supported by a towel roll.

The knee angle was assessed with a goniometer. The dynamometer head was positioned in a $60^{\circ}$ posterior tilt to achieve $10^{\circ}$ plantar flexion at the ankle. Reliability and torque output have been reported to be highest in this position. ${ }^{5}$ The INV/EVER footplate of the dynamometer was adjusted in the lowest position and in such a way that the axis of the dynamometer shaft transected the superior edge of the lateral malleolus. The same basic configuration has been used in previous studies. ${ }^{5,28}$

To prevent foot movement within the shoe, all subjects wore tight fitting sport shoes, minimizing loss of force transmission to the dynamometer. The foot was secured on the footplate by 2 straps. Additional fixation straps were applied to the thigh and knee of the tested leg. To avoid unwanted hip rotation, additional stabilization of the knee was manually provided by an investigator. ${ }^{27,29}$ Once the subject was positioned and stabilized, no further practice movements were performed.

Testing started with the foot in maximal eversion. Instructions were given to push as hard and as fast as possible through the entire range of motion in both directions. ${ }^{27}$ The subject was instructed to restrict movements to the foot and ankle and to keep the arms folded across the chest during data collection. No encouragement or visual feedback from the computer-screen was given during test movements. The dynamometer was calibrated once a week, according to procedures specified in the operating manual. ${ }^{31}$

\section{Data Analysis}

Each subject performed 3 sets of 3 repetitions at both test velocities. In each set the isokinetic dynamometer software reports the highest peak torque out of 3 repetitions. 
The 3 ACC-TIMES corresponding to these 3 highest peak torque values were averaged after an appropriate transformation, as described below.

The data were analyzed with a mixed-model analysis of variance (ANOVA), using PROC MIXED of SAS Version 8.2. The dependent variable was ACC-TIME measured in seconds, which had a highly positively skewed distribution. After logarithmic transformation (the average of 3 replicates of In[ACC-TIME + 0.0I] was taken), the shape of the distribution became almost symmetrical. The ACC-TIME was measured for 2 muscle groups; the invertors and the evertors. Data for each muscle group were analyzed separately. The outcome variable ACC-TIME was analyzed after a 2-fold transformation. First, a shift of 0.01 second was added to ACC-TIME and then the logarithm was taken. As a consequence the percent difference estimates were conservative.

With the log-transformed ACC-TIME as outcome variable, a linear model was specified containing the following 3 explanatory dichotomous factors; the between-subjects factor PATIENT (patient versus controls) and the 2 within-subject factors, AFFECT (affected versus unaffected ankles) and SPEED (30 versus $\left.120^{\circ} / \mathrm{s}\right)$. In the mixed-model ANOVA used, the effects of these explanatory factors on the outcome variables were the fixed effects.

In addition to modeling the fixed effects, a structure for the random effects was defined. This random-effects structure was specified in which the total residual variance was decomposed into a between-subjects and a within-subject component, with the latter component further decomposed into a between-ankle within-subjects component and a within-ankle within-subjects component. All parameters of interest in the model were estimated using the restricted-maximum-likelihood method.

In specifying the model for the fixed effects, first a full factorial model containing the 3 dichotomous explanatory factors was built. In a complete factorial design the full model would contain 8 fixed effects to be estimated. However, as control subjects by definition contributed only unaffected ankles to the data, we had an incomplete factorial design for which the full model contained only 6 effects to be estimated. The 6 fixed effects in the full model could be explained as follows. There were a total of 3 comparisons of interest; mean differences in log-transformed ACC-TIME between affected and unaffected ankles within patients, between unaffected ankles of patients and ankles of the control group, and between affected ankles of patients and ankles of the control group. These 3 mean differences, including confidence limits, were estimated under the 2 SPEED conditions $\left(30^{\circ}\right.$ and $\left.120^{\circ} / \mathrm{s}\right)$, resulting in a total of 6 fixed effects.

Proper estimates of these 6 fixed effects and their confidence limits were obtained from the restricted maximum likelihood method used in PROC MIXED, while correctly and automatically taking into account the specified structure in the between- and withinsubjects residual variance components. The next step was to test the null hypothesis that 
the 3 mean differences were the same under either SPEED condition. If this null hypothesis (no effect modification by SPEED) was accepted, then a more parsimonious model fits to the data almost as well as the full model.

As mentioned above, the mean differences of interest were estimated after logarithmic transformation of ACC-TIME. This transformation implies that these estimated differences and their confidence limits had to be back-transformed by taking their antilog. As a consequence of this back-transformation, differences and their confidence limits were transformed into ratios between geometric means of ACC-TIME.A ratio $R$ between 2 geometric means was translated into a percent difference by simply taking $100(R-I)$, which was the percent difference of the geometric means of 2 groups, expressed as a percentage of the geometric mean of one of the groups: $\left[\left(\mathrm{gm}_{1}-\mathrm{gm}_{2}\right)\right.$ / $\left.\mathrm{gm}_{2}\right] \times 100$, where gm, and $\mathrm{gm}_{2}$ are geometric means of 2 groups to be compared. Before analyzing the effects of explanatory variables on ACC-TIME, we examined the reliability of the ACC-TIME measurements through the intraclass correlation coefficient (ICC) for unaffected ankles in patients and controls (separately as well as together), and for affected ankles in patients. A similar analysis was performed for both muscle groups (evertors and invertors) separately. The ICC was calculated as the ratio of the betweensubjects variance to the total of the between and within-subjects variance. ${ }^{2}$ Here, the latter component was based on the average of 3 log-transformed replicate measurements and was therefore divided by 3. We also calculated the standard error of an average of 3 replicated measurements on the logarithmic scale. This standard error could be interpreted approximately as the coefficient of variation of an average of 3 untransformed measurements For all tests the level of significance was set at .05.

\section{Results}

The mean and geometric mean ACC-TIME values in milliseconds of the evertor and invertor muscles, derived from the affected and unaffected ankles of patients and from the average of both ankles of controls, are presented in Table 2. The geometric mean was corrected by subtracting 10 milliseconds from the back-transformed mean of $\ln (\mathrm{ACC}$ TIME + 10).

The 3 comparisons of interest were the mean differences in ACC-TIME between affected and unaffected ankles within patients, between unaffected ankles of patients and ankles of the control group, and between affected ankles of patients and the ankles of the control group (Table 3). The effect modification by SPEED of these 3 comparisons was significant for the invertor muscles $(P=.022)$ only and not for the evertor muscles $(P=.88)$; therefore, for the invertors, the 3 comparisons of interest were presented separately for the 2 SPEED levels. 
All differences between unaffected ankles in patients and ankles in the control group were not significant $(P>.05)$. Differences between affected and unaffected ankles (either within patients or between patients and individuals in the control group) for the invertors were significant at $120 \%$ s. These differences were also significant for the evertors at $30^{\circ}$ and $120^{\circ} / \mathrm{s}$, and were more precisely estimated than the differences on the invertors. The main effect of speed on the ACC-TIME for the evertor muscles was significant $(P<.000 \mathrm{I})$. ACC-TIME for the evertor muscles at $30 \%$ s was $30 \%$ lower $(95 \%$ $\mathrm{Cl},-44 \%$ to $-26 \%$ ) than at $120 \%$ s (not presented in Table 3 ).

As for the random-effects structure, it appeared that the residual variance components, expressed as percentages of the total residual variance, were the same for evertors and invertors; $13 \%$ of the total residual variance was attributed to between-subjects variability and, of the remaining $87 \%$ caused by within-subjects variability, $10 \%$ were attributed to the between-ankles within-subjects component and $77 \%$ to the withinankles component.

Table 4 presents the decomposition of the total variance in a between-subjects and a within-subject component of the average of 3 ACC-TIME measurements, after natural logarithmic transformation and adjustment for the fixed effects of speed and group. The measurement was defined as the average of 3 replicated measurements after natural logarithmic transformation. Based on this decomposition, we calculated the ICC and the coefficient of variation (CV) as indicated in the data analysis section.

\section{Table 2}

Mean \pm SD (GM) and geometric mean ACC-TIME values (milliseconds) for ankle evertor and invertor muscles of the affected ankle $(n=I I)$, an unaffected ankle $(n=I I)$ of individuals with chronic ankle instability, and the average of both ankles of a control group $(n=1 \mathrm{I})$.

\begin{tabular}{|c|ccc|ccc|ccc|cc|c|}
\hline \multirow{2}{*}{ Group Ankle } & \multicolumn{4}{|c|}{ Evertor 30 } & \multicolumn{4}{|c|}{ Evertor I 20 } & \multicolumn{3}{c|}{ Invertor 30 } & \multicolumn{2}{c|}{ Invertor I20 } \\
& Mean & SD & GM & Mean & SD & GM & Mean & SD & GM & Mean SD GM \\
\hline Patient affected & 19 & \pm 21 & 12 & 33 & \pm 16 & 27 & 6 & \pm 4 & 5 & 39 & \pm 46 & 24 \\
Patient unaffected & 6 & \pm 6 & 5 & 15 & \pm 8 & 13 & 12 & \pm 13 & 8 & 17 & \pm 12 & 13 \\
\hline Control & 8 & \pm 6 & 5 & 13 & \pm 5 & 13 & 7 & \pm 7 & 5 & 12 & \pm 5 & 9 \\
\hline
\end{tabular}

ACC-TIME = acceleration time, GM = geometric means of ACC-TIME (milliseconds), corrected by subtracting 10 milliseconds from the back-transformed means of $\ln ($ ACC-TIME +10$)$. 
Table 3

Percent difference in acceleration time (ACC TIME), its $95 \% \mathrm{Cl}$ and $\mathrm{P}$ value of the affected ankle (AA) versus the unaffected ankle (UA) of subjects with chronic ankle instability and versus those in the control group (CS), and of the unaffected ankle (UA) versus the control groups (CS) as estimated by the model.

\begin{tabular}{|c|c|c|c|c|c|c|c|c|c|}
\hline \multirow[b]{3}{*}{$\begin{array}{c}\text { Comparison } \\
\mathrm{R}\end{array}$} & \multirow{2}{*}{\multicolumn{3}{|c|}{$\begin{array}{c}\text { Evertors } \\
30^{\circ} \text { and } 120^{\circ} / \mathrm{s} \text { Combined }\end{array}$}} & \multicolumn{6}{|c|}{ Invertors } \\
\hline & & & & \multicolumn{3}{|c|}{$30^{\circ}$} & \multicolumn{3}{|c|}{$120 \% \mathrm{~s}$} \\
\hline & $\begin{array}{l}\text { Percent } \\
\text { difference }\end{array}$ & $95 \% \mathrm{Cl}$ & $\begin{array}{c}\mathrm{P} \\
\text { value }\end{array}$ & $\begin{array}{l}\text { Percent } \\
\text { difference }\end{array}$ & $95 \% \mathrm{Cl}$ & $\begin{array}{c}\mathrm{P} \\
\text { value }\end{array}$ & $\begin{array}{l}\text { Percent } \\
\text { difference }\end{array}$ & $95 \% \mathrm{Cl}$ & $\begin{array}{c}P \\
\text { value }\end{array}$ \\
\hline AA/UA & 54 & 23 to 49 & .001 & -19 & -44 to 16 & .25 & 43 & 0 to 105 & .052 \\
\hline $\mathrm{AA} / \mathrm{CS}$ & 57 & 25 to 96 & $<.001$ & -1 & -30 to 39 & .94 & 75 & 24 to 146 & .002 \\
\hline UA/CS & 2 & -19 to 27 & .89 & 22 & -13 to 72 & .25 & 22 & -13 to 72 & .25 \\
\hline
\end{tabular}

I. For the evertors both SPEED conditions were combined because there was no significant interaction based on SPEED.

2. Percent difference is $100(R-I)=100\left[\left(g_{1}-g_{2}\right) / g m_{2}\right]$, with $R=g m_{1} / g m_{2}$.

Table 4

Variance components and intraclass correlation coefficient (ICC) of the average of 3 log-transformed replicate acceleration time (ACC-TIME) measurements (in seconds). The ICC is calculated as the ratio of the between-subjects variance to the total of between-subjects and one third of the within-subjects variance. The coefficient of variation (CV) of an average of 3 untransformed replicates is calculated as the square root of one third of the within subjects variance.

\begin{tabular}{|l|c|c|c|c|c|c|c|c|}
\hline & \multicolumn{4}{|c|}{ Evertors } & \multicolumn{4}{c|}{ Invertors } \\
\hline & UA (PA + CS) & UA PA & UA CS & AA PA & UA (PA + CS) & UA PA & UA CS & AA PA \\
\hline Between-subjects & 0.067 & 0.097 & 0.052 & 0.178 & 0.131 & 0.174 & 0.108 & 0.236 \\
\hline Within-subjects / 3 & 0.036 & 0.022 & 0.043 & 0.071 & 0.039 & 0.045 & 0.036 & 0.066 \\
\hline ICC & 0.65 & 0.82 & 0.55 & 0.71 & 0.77 & 0.80 & 0.75 & 0.78 \\
\hline CV & 0.19 & 0.15 & 0.21 & 0.27 & 0.20 & 0.21 & 0.19 & 0.26 \\
\hline
\end{tabular}

$\mathrm{AA}=$ affected ankle, $\mathrm{CS}=$ control group, $\mathrm{PA}=$ patients with chronic ankle instability, UA = unaffected ankle.

\section{Discussion}

When actively stabilizing the ankle, arthrokinetic reflexes (also called 'joint protecting' reflexes) play an important role. In case of a sudden inversion movement of the ankle joint, the effectors of the reflex are formed by the evertor muscles counteracting this movement. ${ }^{47}$ Therefore reaction time of these muscles is crucial and a delay could lead to inversion trauma and subsequently to CAl. It is of interest to know whether the 
neuromuscular response is decreased in patients with CAl. For this purpose we assessed the ACC-TIME in patients with chronic recurrent ankle sprains.

At $30^{\circ}$ and $120^{\circ} / \mathrm{s}$ the evertor muscles of the affected ankle of patients with CAl showed a significantly slower ACC-TIME. When compared to the unaffected contralateral ankle and both ankles of a control group, the ACC-TIME values of the evertor muscles were significantly increased by $54 \%$ and $57 \%$ respectively. This substantial increase may reflect a delay in neuromuscular response (i.e. slower motor recruitment) of the muscles specifically engaged in counteracting inversion and inversion trauma.

Caulfield ${ }^{4}$ stated that CAI can lead to extensive neuromuscular dysfunction of the invertor muscles as well. Indeed we found a significantly prolonged ACC-TIME for the invertor muscles when tested at $120 \%$, comparing the affected ankle invertors to the unaffected ankle and to the ankles of a control group (43\% and $75 \%$ ). No significant differences were found for the invertor muscles when tested at $30 \%$ s.

The question remains whether we chose the appropriate test velocities. In contrast to a velocity of $120 \%$ s, a velocity of $30 \%$ is not functional during walking and running. In walking, eversion occurs at $120 \%$ s. $^{38}$ During running, plantar flexion and dorsiflexion occur at $430^{\circ}$ and $540^{\circ} / \mathrm{s}$. ${ }^{42}$ So, to assess neuromuscular response it would be better to use higher test velocities than $120 \%$ s. However, it is very difficult to perform isolated, reciprocal INV/EVER movements at such high velocities. In isokinetic testing the preset angular velocity is reached only after performing a certain range of motion. The higher the preset value, the longer it takes to reach that value. Using velocities higher than $120 \%$, it is very likely that individuals would not be able to reach the predetermined speed, as the velocities are too high for the INV/EVER muscles and the range of motion is limited. ${ }^{8,16}$ In addition, previous studies have shown a high test/retest reliability of 0.80 to 0.93 measuring INV/EVER peak torque values at $30^{\circ}$ to $120^{\circ} / \mathrm{s}^{21,27}$ At $150^{\circ}$ and $210^{\circ} / \mathrm{s}$ the reliability decreased to 0.65 and $0.6 \mathrm{I}$ respectively. ${ }^{27}$ In this study the reliability (ICC) of the average of 3 log-transformed replicate ACC-TIME measurements was 0.75 to 0.80 for the invertors and 0.55 to 0.82 for the evertors. The coefficient of variation was 0.19 to 0.26 for the invertors and 0.15 to 0.27 for the evertors. The coefficient of variation expresses the standard error of an average of three repeated measurements as proportion of the mean level of these measurements. We propose that the reliability may be further improved by taking an average of more than 3 replicates.

The present study shows that for patients suffering from CAI the ankle evertors are more affected than ankle invertors. This is in agreement with the findings in publications where slower motor nerve conduction velocity of the fibular nerves was measured after inversion trauma. ${ }^{22,37}$ The principal evertor muscles (fibularis longus, brevis and tertius and extensor digitorum longus) are innervated by the fibular nerve, whereas the invertor muscles are innervated by the tibial nerve. Because of their position with respect to the 
inversion-eversion axis, the fibular nerve rather than the tibial nerve will be affected by inversion trauma. Therefore, delay of neuromuscular response can be expected in the muscles innervated by the fibular nerve.

Consequently, patients with lowered motor nerve conduction velocity could have more difficulties to accelerate to a preset dynamometer speed compared to healthy individuals. This may results in a significant longer ACC-TIME of the evertor muscles in the affected ankles of patients with CAl. Previous studies using (static) trapdoor setups combined with EMG measurements show conflicting results in patients with CAI. Therefore, this ACC-TIME parameter, combined with a more dynamic assessment, can be seen as a preliminary effort to attain a more functional test.

The results of this study support our hypothesis that evertor muscles are more affected than invertor muscles in patients with CAl. Clinically this is important because muscle reaction time is a major factor in the rehabilitation of patients with $\mathrm{CAI}$. Further research to assess the importance of the ACC-TIME parameter may contribute to rehabilitation strategies for patients with ankle instability. Future studies should focus on; I) the quantitative relation between ACC-TIME delay and CAI in daily life and sporting activities, 2) the prognostic value of ACC-TIME values, 3) ACC-TIME as outcome variable in the evaluation of rehabilitation modalities such as coordination training of the ankle and lower extremity, and 4) the relationship between a delay in ACC-TIME values and changes in perception of passive INV/EVER movements.

Our study revealed no significant differences in ACC-TIME between the patients unaffected ankle and the control group. This may indicate that in future studies the injured ankle can be compared to the unaffected (contralateral) ankle without using a control group.

\section{Conclusions}

The present study shows that the ACC-TIME for the evertor muscles tested at $30^{\circ}$ and $120 \%$ is significantly longer for the affected ankle of subjects with unilateral CAI compared to their contralateral ankle and to the ankles of a control group. This longer ACC-TIME is consistent with previous data, showing a lower motor nerve conduction velocity of the fibular nerve after inversion trauma. 


\section{References}

I. Boruta P, Bishop J, Braly G et al.Acute lateral ankle injuries: a literature review. Foot Ankle. 1990; I I: 107-I I 3.

2. Brennan RL. Generalizability Theory. New York, Springer-Verlag; 200I, p.35.

3. Cass J, Morrey B.Ankle instability: Current concepts, diagnosis and treatment. Mayo Clin Proc. 1984;59:165-170.

4. Caulfield B. Functional instability of the ankle joint. Features and underlying causes. Physiotherapy, 2000;86:40I-4II.

5. Cawthorn M, Cummings G,Walker JR et al. Isokinetic measurement of foot invertor and evertor force in three positions of plantar flexion and dorsal flexion.J Orthop Sports Phys Ther. 1991; | 4:75-8I.

6. Chen WL, Su FC, Chou YI. Significance of acceleration period in a dynamic strength testing study.J Orthop Sports Phys Ther. 1994;19:324 - 330.

7. Cohen LA, Cohen ML. Arthrokinetic reflex of the knee. Am J. Physiol. 1956; 184:433-437.

8. Dvir Z. Isokinetics: muscle testing, interpretation and clinical application. New York, Churchill Livingstone; 1995.

9. Ebig M, Lephart S, Burdett RG et al.The effect of sudden inversion stress on EMG activity of the peroneal and tibilais anterior muscles in the chronically unstable ankles.J Orthop Sports Phys Ther. 1997; 26: 73-77.

10. Ent FWC van der. Lateral ankle ligament injury (dissertation). Rotterdam, Erasmus University Rotterdam; 1984.

II. Fernandez N,Allison G, Hopper D. Peroneal latency in normal and injured ankles at varying angles of perturbation. Clin Orthop. 2000; 375: 193-210.

12. Frankel V, Nordin M. Basic biomechanics of the skeletal system. Philadelphia, Lea \& Febiger; 1980.

13. Freeman MAR. Instability of the foot after injuries to the lateral ligament of the ankle.J Bone Joint Surg. 1965;47B:669-677.

14. Freeman MAR, Dean MRE, Hanham IWF.The etiology and prevention of functional instability of the foot.J Bone Joint Surg. 1965;47B:678-685.

15. Galen WChC van, Diederiks JPM. Sportblessures breed uitgemeten. Een onderzoek naar aantal aard en achtergronden van sportblessures in de loop van een jaar (English abstract). Haarlem, DeVrieseborch; 1990.

16. Handel H, Dickhuth $\mathrm{HH}$, Mayer $\mathrm{F}$ et al. Prerequisites and limitations to isokinetic measurements in humans. Investigations on a servomotor-controlled dynamometer. Eur J Appl. Physiol. 1996; 73: 225-230.

17. Heilman A, Braly G, Bishop J et al.An anatomic study of subtalar instability. Foot Ankle. 1990; 10:224-228.

18. Isakov E, Mizrahi J, Solzi P et al. Response of the peroneal muscles to sudden inversion of the ankle during standing.J Sports Biomech. 1986; 2: 100-109.

19. Johnson MB, Johnson CL. Electromyographic response of peroneal muscles in surgical and nonsurgical injured ankles during sudden inversion.J Orthop Sports Phys Ther. 1993; 18: 497-50 I.

20. Kaminski TW. Concentric and eccentric force-velocity relationships between uninjured and functionally unstable ankles (dissertation). Charlottesville, University of Virginia; 1996.

2I. Karnofel H,Wilkinson K, Lentell G. Reliability of isokinetic muscle testing at the ankle.J Orthop Sports Phys Ther. 1989; I I: I50-154. 
22. Kleinrensink GJ , Stoeckart R, Meulstee J et al. Lowered motor conduction velocity of the peroneal nerve after inversion trauma. Med Sci Sports Exerc. 1994;26:877-883.

23. Konradsen L, Olesen S, Hansen HM. Ankle sensorimotor control and eversion strength after acute ankle injuries. Am J Sports Med. 1998;26:72-77.

24. Konradsen L, Ravn B.Ankle instability caused by prolonged peroneal reaction time. Acta Orthop Scand. 1990;61:388-390.

25. Konradsen L, Ravn JB, Sorensen AL. Proprioception at the ankle: the effect of an aesthetic blockade of ligament receptors.J Bone and Joint Surg. 1993;75 B: 433-436.

26. Konradsen L, Ravn J.B. Prolonged peroneal reaction time in ankle instability. Int. J. Sports Med. I991; I2: 290-292.

27. Lentell GL, Baas B, Lopez D et al.The contributions of proprioceptive deficits, muscle function, and anatomic laxity to functional instability of the ankle.J Orthop Sports Phys Ther. 1995;21:206-215.

28. Lentell GL, Cashman PA, Shimoto KJ et al.The effect of knee position on torque output during inversion and eversion movements at the ankle.J Orthop Sports Phys Ther. 1988; 10: I 17-183.

29. Lentell GL, Katzman LL,Walters MR. The relationship between muscle function and ankle stability.J Orthop Sports Phys Ther. 1990;1 1:605-6II.

30. Löfvenberg R, Kärrholm J, Sundelin G et al. Prolonged reaction time in patients with chronic lateral instability of the ankle. Am J Sports Med. 1995; 23:4I4-4I7.

31. Lumex, Inc. Cybex 6000 Users Guide. Ronkonkoma, New York: Lumex, Inc; 1993.

32. Lynch SA, Eklund $U$, Gottlieb $D$ et al. Electromyographic latency changes in the ankle musculature during inversion moments. Am J Sports Med. 1996; 24: 362-369.

33. Madsen OR. Torque, total work, power, torque acceleration energy and acceleration time assessed on a dynamometer: reliability of knee and elbow extensor and flexor strength measurements. Eur J Appl Physiol. 1996;74:206-210.

34. Madsen OR. Trunk extensor and flexor strength measured by the Cybex 6000 dynamometer. Assessment of short-term and long-term reproducibility of several strength variables. Spine. 1996;21:2770-2776.

35. McKnight CM,Armstrong CW.The role of ankle strength in functional ankle instability.J Sports Rehab. 1997;6:21-29.

36. Nawoczenski DA, Owen MG, Ecker ML et al. Objective evaluation of peroneal response to sudden inversion stress.J Orthop Sports Phys Ther. 1985; 7: 107-109.

37. Nitz AJ, Dobner JJ, Kersey D. Nerve injury and grades II and III ankle sprains. Am J Sports Med. 1985; 13:177-182.

38. Novick A, Kelley DL. Position and movement changes of the foot with orthotic intervention during the loading response of gait.J Orthop Sports Phys Ther. 1990; I I:301-312.

39. Osternig L, Bates B, Tropp H. Patterns of tibial rotatory torque in knees of healthy subjects. Med Sci Sports Exerc. 1980; 12:195-199. 
40. Rozzi SL, Lephart SM, Sterner R et al. Balance training for persons with functionally unstable ankles. J Orthop Sports Phys Ther. 1999; 29: 478-486.

4I. Schaap GR, Keizer de G, Marti K. Inversion trauma of the ankle. Arch Orthop Trauma Surg. 1989;108:373-275.

42. Smith LS, Clarke TE, Hamill CL et al.The effects of soft and semirigid orthoses upon rear foot movement in running. J Am Pod Med Assoc. 1986;76:227-233.

43. Staples O. Result study of ruptures of lateral ligaments of the ankle. Clin Orthop 1972;85:50-58.

44. Tropp H. Pronator muscle weakness in functional instability of the ankle joint. Int J Sports Med. 1986; 7: 29I-294.

45. Vaes P, Gheluwe van B, Duquet W. Control of acceleration during sudden ankle supination in people with unstable ankles.J Orthop Sports Phys Ther. 2001;31:741-752.

46. Wilkerson GB, Pinerola JJ, Caturano RW. Invertor vs. evertor peak torque and power deficiencies associated with lateral ankle ligament injury.J Orthop Sports Phys Ther. 1997;26:78-86.

47. Wilkerson GB, Nitz AJ. Dynamic ankle stability: Mechanical and neuromuscular interrelationships. J. Sport Rehab. 1994; 3: 43-57. 

Chapter 7

General Discussion 


\section{Introduction}

The main purpose of this thesis was to gain a better insight into mechanisms at the basis of overuse and repetitive sports injuries of the ankle and shoulder joints. This chapter discusses the findings of this thesis. The first part of the discussion reflects on the position paper presented in chapter 2 . The second part reflects on the main findings presented in the chapters 3 to 6 . The discussion is concluded with some remarks on the implications of isokinetic testing and suggestions for further research are presented.

\section{Terminology}

Training and testing are two main issues in sports rehabilitation and athletic training. When describing these issues the terms 'open' (OKC) and 'closed' (CKC) kinetic chain are popular in clinical research. However, these terms have frequently led to polarizing and contradictory discussions in scientific literature and in daily practice of therapists, clinicians and trainers. For clinical intervention a systematic classification of exercise and movements appears to be more adequate than terms like OKC and CKC.A more detailed approach in describing exercise might include the specific intervention goal, the type of exercise, training devices and training criteria. It would be helpful to define the forms of training and testing stratified by the muscle groups or joints involved.Therefore, we propose to use the terms 'single-joint' and 'multi-joint' exercises. Isokinetic dynamometry is an example of such single-joint testing and training. In addition to the terms single-joint and multi-joint the site of resistance application and the direction of force can be an element in defining the exercise or testing profile. The direction of the applied force can be parallel or perpendicular to the limb. In that respect, a parallel force to the limb (e.g. leg press) could be a more appropriate term than 'closed kinetic chain' and a perpendicular force (e.g. leg extension) could be used instead of 'open kinetic chain'. In general, the definitions of terms should support the understanding of physiological relationships and in particular they should not be used as value judgments in training and clinical rehabilitation. Depending on the task and/or state of rehabilitation it should be recognized that both type of exercises have their place in training, therapy and testing. It seems reasonable to assume that both forms are necessary to improve sensorimotor capacity and function.

\section{Assessment of dynamic joint stability}

To assess dynamic joint stability, meaning stability during motion, four studies in this thesis were carried out with an isokinetic dynamometer which is a reliable and safe way of analyzing muscular performance and muscle activation characteristics. ${ }^{2,13,15}$ 
Two studies were carried out on asymptomatic elite overhead athletes to assess muscle performance (chapter 3 and 4). In chapter 3 the concentric shoulder internal and external rotation strength of the dominant and non-dominant arm of elite volleyball players was assessed. Comparisons were made for peak torque and the conventional ratio (CVR) between the dominant and non-dominant arm. To our knowledge this is the first study in which no significant differences were found between extremities in concentric external rotation strength in elite volleyball players.

Overhead activities consist predominantly of concentric internal rotation and eccentric external rotation. The external shoulder rotators play an important role in decelerating the arm rotation during overhead activities. Therefore, the assessment of the external rotators in a concentric mode is less specific. To asses shoulder function in a more functional way we examined the peak torque, CVR and the dynamic control ratio (DCR) in elite badminton players (chapter 4). The DCR consists of dividing the eccentric peak torque of the external rotators by the concentric peak torque of the internal rotators. Because of the limited scientific data concerning these two populations, we had to compare our descriptive results with athletes performing other overhead sports (e.g. tennis players and baseball pitchers).

When interpreting test results many clinicians assume that torque values of the uninjured extremity can be used as the standard control value for judging the level of recovery during rehabilitation. This especially holds for the lower extremity. ${ }^{14,15}$ Confounding this interpretation is the influence of limb dominance, or in case of athletes, the effect of neuromuscular specificity of various sports on bilateral strength relationships. In general, few bilateral differences are found in the lower extremities of sedentary individuals and of most athletes. Athletes in bilaterally symmetrical upper extremity sport activities (e.g. swimming and rowing) show few differences between dominant and non-dominant sides. However, athletes in bilaterally asymmetrical upper extremity activities (e.g. throwing and volleyball) may show dominant side muscle group strength as much as $15 \%$ greater than the non-dominant side. ${ }^{14}$ In one of the classical reviews on muscle performance evaluation, Sapega suggested that in healthy individuals bilateral differences less than $10 \%$ can be considered normal, difference of 10 to $20 \%$ possibly abnormal and those over $20 \%$ probably abnormal. ${ }^{15}$

For healthy athletes participating in asymmetrical overhead sports often there is no satisfactory intrinsic standard or reference available. In these situations, normative data are necessary in order to discriminate normal from abnormal. This becomes quite complex, because the data must be specific for the population as well as for the testmode or technique. Therefore, in this thesis we used an isokinetic dynamometer to determine normative data for shoulder rotator muscle strength in asymptomatic elite overhead athletes. The peak torque data collected from different test modes were 
normalized for body weight and used to compare and interpret test data from individuals with different anthropometric values. For these studies we had to use small sample sizes because only a small number of athletes were able to perform on European,World and Olympic championships.

It is important to state that normative data collected in various studies are always dynamometer-specific and not directly applicable to other testing systems. This is due to differences in instrumentation, testing protocols, data reduction and output. ${ }^{7}$ Additionally, we have to confirm whether the shoulder strength profiles we obtained are a prerequisite for optimal performance or that athletes are predestined for overuse injuries. Further research will be required to answer this question.

In chapter 6 we assessed the acceleration time (ACC-TIME) as a muscle activation characteristic in athletes with chronic ankle instability (CAI). Because motor learning effects can affect the reliability of isokinetic measurements, we first had to determine a possible 'learning curve' during concentric isokinetic testing of the ankle invertor and evertor muscles of the dominant and non-dominant leg (chapter 5). The assessment of a possible motor learning effect and the ACC-TIME parameter were used in this thesis because, despite the high incidence of ankle injuries, we could not find any studies in which this was determined.

To determine the possible motor learning effect, healthy subjects without previous experience of isokinetic testing performed five sets of two concentric inversion/eversion movements. The results showed a statistical significant motor learning effect of the dominant invertor muscles at 30 and $120 \%$ s. This learning effect occurred rapidly and stabilized after the second set. No significant differences were found for the evertors of the dominant leg, nor for the invertors and evertors of the non-dominant leg. To exclude any chance of learning effect we recommend to use at least two sets of two maximal inversion/eversion trials as a specific warm-up.

Inversion trauma of the ankle is a very common sports injury. ${ }^{5,18}$ Most patients return to their daily activities after a few days of rest. However, six months after trauma, one third of the patients still complain of sensations of giving way and instability of the injured ankle. ${ }^{4,16}$ In his review Caulfield concluded that subjects with ankle instability have no or minimal deficits in peak evertor torque of the affected ankle compared to the unaffected ankle and to normative data. 'To explain remaining symptoms chapter 6 refers to the measurement of the ACC-TIME as a muscle activation characteristic. Isokinetic dynamometry was used as a dynamic test for inversion/eversion movements of the ankle in which the ACC-TIME was derived from a maximal voluntary contraction. We compared the affected ankle of patients with unilateral CAI with their unaffected ankle and both ankles of a control group. The main purpose of this study was to test the 
hypothesis that patients with CAI have a delay in evertor muscle action time. The results supported our hypothesis and showed that at $30^{\circ}$ and $120 \%$ s the evertor muscles of the affected ankle of patients with CAI had a significant slower ACC-TIME. Compared to the unaffected contralateral ankle and both ankles of a control group, the ACC-TIME values of the evertor muscles were significantly increased by $54 \%$ and $57 \%$ respectively. This substantial increase may reflect a delay in neuromuscular response (i.e. slower muscle recruitment) of the muscles specifically engaged in counteracting inversion and inversion trauma. This is in agreement with the findings in publications where slower motor nerve conduction velocity of the fibular nerve was measured after inversion trauma., ${ }^{9} 11$

The question remains whether we chose the appropriate test velocities. In contrast to a velocity of $120 \%$, a velocity of $30 \%$ is not functional during walking and running. In walking, eversion occurs at $120 \%{ }^{12}$ During running, plantar flexion and dorsiflexion occur at $430 \%$ to $540 \%$ s. ${ }^{17}$ So, to assess neuromuscular response it would be better to use test velocities higher than $120 \%$. However, it is difficult to perform isolated, reciprocal inversion/eversion movements at such high velocities. In isokinetic testing the preset angular velocity is reached only after performing a certain range of motion. The higher the preset velocity value, the longer it takes to reach that value. Using velocities higher than $120 \%$ it is very likely that individuals would not be able to reach the predetermined speed, as the velocities are too high for the inversion/eversion muscles and the range of motion is limited. ${ }^{3,6}$

The results of this study show that patients with CAl show a delay in evertor muscle action time. Still another question remains: "What is the mechanism that causes this delayed muscle action?" This needs further research, but speculating on the subject, different systems could be involved: the afferent and efferent systems, processing of the central nervous system, the neuromuscular junction or the muscle itself.

\section{Practical implications of isokinetic dynamometry}

One of the major problems using isokinetic devices is that in natural movements of the human body, the angular velocity is not constant throughout the range of motion of the joint. In normal movements, human muscle follows the so-called stretch-shortening cycle in which the eccentric stretching phase of the muscle-tendon unit is followed by concentric contractions, and the angular velocity changes along with the changing joint angle. ${ }^{7}$ Since isokinetic movement is unnatural and its training effect very specific, it is not surprising that in many countries healthy athletes and their coaches have not well accepted isokinetic training in their training programs. However, isokinetic dynamometers have enabled the reliable quantification of peak torque data, and the measurements with these devices can be made isometrically at various angular positions 
and concentrically or eccentrically with a large variety of angular speeds.,7,15 This makes isokinetic dynamometry a valuable tool for testing and training in sports rehabilitation. It also may be important in explaining overuse and repetitive injuries. With careful and critical application, isokinetics does occupy a position in diagnosing differences in muscular performance and muscle activation characteristics. Using isokinetic dynamometry in sports rehabilitation or for collecting normative data in asymptomatic subjects, it is important to have knowledge of the potential effects of variation in subject factors and test procedures on measurements. Factors that may affect measurements need to be identified and these effects need to be appreciated by clinicians and researchers. In their extensive review Keating and Matyas elaborated on these factors and divided them in subject-related factors and movement-related factors. ${ }^{8}$ Subjectrelated factors were age, gender, weight, athletic background, disability and limb dominance. Movement-related factors were range of motion in which values were obtained, type of muscle contraction, pretest procedures (warm-up, gravity correction, test position, stabilization, axes alignment, lever arm length, preload, damp/ramp settings), test conditions (speed, test sequence, rest intervals, feedback) and type of data analysis (the data selected and how they are analyzed). They concluded that, in the majority of the publications, the authors failed to provide sufficient detail needed for accurate replication of test procedures or for comparisons with other studies. Effective development of normative data, formation of ratios, comparison of measurements across studies and relating measurements with other performance criteria all require descriptions of variables relating to subjects and testing.

\section{Suggestions for further research}

Human movement is more than a motor process only. In fact there is permanent interaction between perceptive, cognitive and motor processes. ${ }^{10}$ Further knowledge of these interactions is important to better understand and to influence the possible pathokinesiology that occurs after injury. In this thesis we mainly focused on biomechanical and neuromuscular aspects that may lay at the basis of overuse and repetitive injuries. To expand the body of knowledge of pathokinesiology further studies should focus on the influences of specific cognitive functions (e.g. double tasks) on motor control, and on motor learning aspects. 


\section{References}

I. Caulfield B. Functional instability of the ankle joint. Features and underlying causes. Physiotherapy. 2000; 86: $40|-4| I$.

2. Davies GJ. A compendium of isokinetics in clinical usage. Onalaska,Wisconsin: S\&S Publishers; 1992.

3. Dvir Z. Isokinetics: Muscle testing, Interpretation and Clinical Applications. New York, NY: Churchill Livingstone; 2004.

4. Ent van de FWC. Lateral ankle ligament injury [dissertation]. Erasmus University Rotterdam, The Netherlands; 1984.

5. Galen van WCC, Diederiks JPM. Sportblessures breed uitgemeten. Een onderzoek naar aantal, aard en achtergronden van sportblessures in de loop van een jaar. Haarlem, The Netherlands: De Vrieseborch; 1990.

6. Handel M, Dickhuth HH, Mayer F. et al. Prerequisites and limitations to isokinetic measurements in humans. Investigations on a servomotor-controlled dynamometer. Eur J Appl Physiol. 1996; 73: 225-230.

7. Kannus P. Isokinetic evaluation of muscular performance: implications for muscle testing and rehabilitation. In J Sports Med. 1994; I5: SII-SI8.

8. Keating JL, Matyas TA. The influence of subject and test design on dynamometric measurements of extremity muscles. Phys Ther. 1996; 8: 866-889.

9. Kleinrensink GJ, Stoeckart R, Meulstee J et al. Lowered motor conduction velocity of the peroneal nerve after inversion trauma. Med Sci Sports Exerc. 1994; 26: 877-883.

10. Mulder T. Beweging in gedachten. In: Baak van J, Bartels J, Heusden van B,Wildevuur C, ed. Lichaam en geest. Budel: Damon; 2006: 99-106.

II. Nitz AJ, Dobner JJ, Kersey D. Nerve injury and grades II and III ankle sprains. Am J Sports Med. 1985; I3: 177-I82.

12. Novick A, Kelley DL. Position and movement changes of the foot with orthotic intervention during the loading response of gait. J Orthop. Sports Phys Ther. 1990; II:30 I-3 I2.

13. Osternig LR. Isokinetic dynamometry: implications for muscle testing and rehabilitation. Exerc Sports Sc. Rev. 1986; 14: 45-80.

14. Perrin DH. Isokinetic Exercise and Assessment. Leeds, UK: Human Kinetics; 1993.

15. Sapega AA. Muscle performance evaluation in orthopaedic practice.J Bone Joint Surg (Am). 1990; 10 : I562-1574.

16. Schaap GR, de Keizer G, Marti K. Inversion trauma of the ankle. Arch Orthop Trauma Surg. 1989; 108: 273-275.

17. Smith LS, Clarke TE, Hamill Cl et al.The effects of soft and semi-rigid orthoses upon rear foot movement in running. J Am Podiatr Med Assoc. 1986; 76: 227-233.

18. Vriend I, Kampen van B, Schmikli S et al. Ongevallen en Bewegen in Nederland (OBiN) 2000 - 2003. Amsterdam: Stichting Consument en Veiligheid; 2005. 

Chapter 8

\section{Summary}

Samenvatting

Dankwoord

Curriculum Vitae 


\section{Summary}

Every year around I.5 million Dutch recreational and elite athletes sustain new injuries. These sports injuries are divided into acute and overuse injuries and it is estimated that each year in the Netherlands there are 1.2 million acute injuries and 300.000 overuse injuries. About $50 \%$ of all injuries require medical attention, mostly from a physician or physiotherapist. Medical attention to overuse injuries is higher than to acute injuries (56\% versus $50 \%$ ). Physiotherapy plays an important role in the prevention and treatment of sports injuries. Therefore, research is needed to establish a solid basis of rehabilitation programs and injury prevention. The main purpose of this thesis was to gain a better insight into mechanisms at the basis of overuse and repetitive injuries of the ankle and shoulder joints in athletes. To assess dynamic joint stability four studies were carried out with an isokinetic dynamometer, which is a reliable and safe way of analyzing muscular performance and muscle activation characteristics.

Chapter I provides a general introduction to this thesis and elaborates on issues like dynamic joint stability, pathokinesiology and isokinetic dynamometry. Secondly the main objectives of the studies are described.

In chapter 2 the terms 'open' and 'closed' kinetic chain are discussed.Training and testing are two main issues in sports rehabilitation and athletic training. The terms open and closed kinetic chain have frequently led to polarizing and contradictory discussions in scientific literature and in daily practice of therapists and trainers. Depending on the task and/or state of rehabilitation it should be recognized that both type of exercises have their place in training, therapy and testing. In the position paper presented we tried to clarify most misunderstandings and suggestions are put forward to use other terms or to use a more detailed approach in describing exercises and testing situations.

In chapter 3 a descriptive study on shoulder muscles of asymptomatic elite Dutch volleyball players was carried out. The concentric shoulder internal and external rotation strength of the dominant and non-dominant arm was assessed. Comparisons were made for peak torque and the conventional ratio. Compared to other volleyball studies, the most striking finding was that no significant differences were found between extremities in concentric external rotation. Data presented are important for interpreting isokinetic shoulder rotator strength tests in elite volleyball players and could be relevant in rehabilitation and prevention of shoulder injuries. 
Overhead activities consist predominantly of concentric internal and eccentric external rotation. The external shoulder rotators play an important role in decelerating the arm rotation during overhead activities. To assess shoulder function in a more functional way in chapter $\mathbf{4}$ we examined the peak torque, conventional ratio and dynamic control ratio of the dominant and non-dominant arm in asymptomatic elite Dutch badminton players. The dynamic control ratio consists of dividing the eccentric peak torque of the external rotators by the concentric peak torque of the internal rotators. The study showed significant differences that were similar for men and women. Only the dynamic control ratio for females was significantly higher than for men.

Chapters 5 and 6 focus on isokinetic ankle measurements in athletes with or without chronic ankle instability. Because motor learning effects can affect the reliability of isokinetic measurements, a possible learning curve of ankle invertor an evertor muscles should be determined. Chapter 5 examined the possible learning curve during concentric isokinetic testing of ankle invertor and evertor muscles of the dominant and non-dominant leg. It is concluded that to exclude any chance of learning effect, healthy athletes not experienced in isokinetic testing had to perform at least two sets of two maximal inversion/eversion trials prior to the test.

In chapter $\mathbf{6}$ the acceleration time as a muscle activation characteristic was assessed. The aim of the study was to determine whether in subjects with unilateral chronic ankle instability the acceleration times of the affected ankle invertors/evertors differs from those of the healthy ankle and from those times of ankles of a control group. At $30^{\circ}$ and $120 \%$ the evertor muscles of the affected ankle of patients with chronic ankle instability showed significantly slower acceleration time values. When compared to the unaffected contralateral ankle and both ankles of a control group, the acceleration time values of the evertor muscles were significantly increased by $54 \%$ and $57 \%$ respectively.

Chapter 7 presents a general discussion on the findings of this thesis. The first part of the discussion reflects on the position paper presented in chapter 2. The second part reflects on the main findings presented in the chapters 3 to 6 . The discussion is concluded with some remarks on the implications of isokinetic testing and suggestions for further research are presented. 


\section{Samenvatting}

Jaarlijks lopen gemiddeld I,5 miljoen Nederlandse sporters een nieuwe blessure op. Naar schatting doen zich per jaar in Nederland I,2 miljoen acute sportblessures en 300.000 overbelastingsblessures voor. Bij ongeveer $50 \%$ van alle sportblessures is medische interventie noodzakelijk, voornamelijk door een arts of fysiotherapeut.

Overbelastingsblessures vragen iets meer behandeling dan acute blessures (56\% versus $50 \%)$. De fysiotherapeut speelt een belangrijke rol in de preventie en behandeling van sportblessures. Wetenschappelijk onderzoek is nodig om een goede basis te scheppen voor revalidatieprogramma's en blessurepreventie.

Het doel van dit proefschrift is een beter inzicht te verkrijgen in de mechanismen die ten grondslag liggen aan acute en overbelastingsblessures van de enkel en schouder bij sporters. In het onderzoek naar dynamische gewrichtsstabiliteit zijn vier studies uitgevoerd met een isokinetische dynamometer, een veilige en betrouwbare manier voor het evalueren van spierkracht en spieractivatie.

Hoofdstuk $I$ is een algemene inleiding op dit proefschrift en gaat dieper in op aspecten van dynamische gewrichtsstabiliteit, pathokinesiologie en isokinetische dynamometrie. Tevens worden de doelstellingen van de diverse hoofdstukken toegelicht.

In hoofdstuk 2 worden de begrippen 'open' en 'gesloten' keten bediscussieerd. Trainen en testen zijn belangrijke aspecten in sportrevalidatie en bij trainingsprogramma's voor sporters. De begrippen open en gesloten keten hebben regelmatig geleid tot polarisatie en tegenstrijdige discussies in de wetenschappelijke literatuur en in de dagelijkse praktijk van fysiotherapeuten en trainers. Afhankelijk van de taak en/of de fase van de revalidatie is het belangrijk te realiseren dat beide oefenvormen een plek verdienen in training, testen en revalidatieprogramma's. In de gepubliceerde 'position paper' is geprobeerd misverstanden te ontrafelen en een suggestie mee te geven voor het gebruik van andere terminologie of een meer gedetailleerde beschrijving te geven van oefeningen en testsituaties.

In hoofdstuk 3 is een descriptieve studie uitgevoerd naar de functie van schouderspieren bij gezonde Nederlandse topvolleyballers. In deze studie werd de concentrische kracht van endorotatoren en exorotatoren van de dominante en niet dominante arm gemeten waarbij de peak torque en de conventional ratio werden vergeleken. In vergelijking met andere volleybalstudies was het meest opvallend dat tussen beide armen geen significante verschillen werden gevonden in de concentrische kracht van de exorotatoren. De gepresenteerde data zijn belangrijk voor de interpretatie 
van schouderrotatorenkracht bij topvolleyballers en kunnen relevant zijn voor de revalidatie en preventie van schouderblessures.

Bovenhandse sportactiviteiten bestaan voornamelijk uit concentrische endorotatie en excentrische exorotatie. De exorotatoren van de schouder zijn belangrijk bij de deceleratie van de armrotatie tijdens bovenhandse sportactiviteiten. Om de schouderrotatoren meer sportspecifiek te testen is in hoofdstuk $\mathbf{4}$ onderzoek gedaan naar de peak torque, conventional ratio en dynamic control ratio van de dominante en niet dominante arm bij gezonde Nederlandse topbadmintonners. Bij de dynamic control ratio wordt excentrisch peak torque van de exorotatoren gedeeld door de concentrische peak torque van de endorotatoren. De studie liet significante verschillen zien, die gelijk waren voor mannen en vrouwen. Alleen de dynamic control ratio voor vrouwen was significant hoger dan voor mannen.

Hoofdstuk 5 en 6 behandelen isokinetische enkelmetingen van sporters met en zonder chronische enkelinstabiliteit. Omdat motorische leereffecten de betrouwbaarheid van isokinetische metingen kunnen beïnvloeden is het belangrijk vast te stellen of er sprake is van een mogelijke 'learning curve' bij inversie en eversie bewegingen van de enkel. In hoofdstuk 5 is onderzocht of er een mogelijke 'learning curve' bestaat tijdens het isokinetisch testen van concentrische enkel inversie en eversie bewegingen van het dominante en niet dominante been. Geconcludeerd werd dat, om de kans op een leereffect uit te sluiten, gezonde sporters zonder ervaring in isokinetische metingen minimaal twee sets van twee maximale inversie/eversie herhalingen moeten maken voorafgaand aan de test.

In hoofdstuk $\mathbf{6}$ is onderzoek gedaan naar een spieractivatie parameter, de 'acceleration time'. Het doel van deze studie was om vast te stellen of de acceleration time van de enkel invertoren en evertoren bij personen met chronische enkelinstabiliteit aan de aangedane zijde anders was ten opzichte van de gezonde zijde en de enkels van een controle groep. Op $30^{\circ}$ en $120^{\circ}$ s toonde de evertoren van de aangedane enkel significant tragere acceleration time waarden.Vergeleken met de gezonde zijde en beide enkels van de controle groep waren de acceleration time waarden van de evertoren significant toegenomen, respectievelijk $54 \%$ en $57 \%$.

Hoofdstuk 7 is de algemene discussie naar de bevindingen van dit proefschrift. Het eerste deel reflecteert op de 'position paper', gepresenteerd in hoofdstuk 2 . Het tweede deel gaat in op de voornaamst bevindingen uit de hoofdstukken 3 tot en met 6 . De discussie eindigt met opmerkingen en implicaties, gericht op het uitvoeren van isokinetische metingen. Tevens worden enkele suggesties voor vervolgonderzoek gedaan. 


\section{Dankwoord}

Dit proefschrift komt voort uit passie voor het vak sportfysiotherapie en is gerealiseerd met steun van velen. Een aantal personen wil ik in het bijzonder bedanken voor hun bijdrage.

Ten eerste de proefpersonen. Zonder hen zou het onmogelijk zijn deze onderzoeken uit te voeren. Dank voor jullie beschikbaarheid.

Patrick en Elian, voor jullie was het enkelonderzoek een afstudeeropdracht, voor mij het begin van een leerzame weg. Dank voor de fijne samenwerking.

Prof. dr. Harm Kuipers, beste Harm, ons eerste contact was via de telefoon waarin ik je uitlegde wat ik van plan was en vroeg of je mijn promotor wilde zijn. Met data onder de arm bezocht ik je in Maastricht. Na een uur stond ik enigszins verward weer buiten. Je nuchterheid werd verwoord in 'one liners' als: "ziet er goed uit, begin maar vast te schrijven" en "het is maar een proefschrift." lk begreep er niets van, was het echt zo simpel? Gaandeweg ben ik je steeds beter gaan begrijpen. Je was er als ik je nodig had, waarvoor dank en waardering.

Prof. dr. Rob de Bie, beste Rob, het was voor mij belangrijk iemand vanuit de fysiotherapie toe te voegen aan het begeleidingsteam. Je was een enorme steun en ik ben je dankbaar voor de vele waardevolle adviezen. Nu inderdaad alleen nog een zaaltje huren.

Dr. Gert Jan Kleinrensink, beste Gert Jan, jouw proefschrift was de aanzet tot ons eerste gezamenlijke onderzoek. Op een andere manier kijken naar de zogenaamde 'zwikkers' werd onze uitdaging. Je vakmanschap, je humor en je positieve instelling maakten de reisjes naar Rotterdam zeer de moeite waard. Het tandem dat jij met Rob vormde was voor mij een bron van inspiratie.

Dr. Rob Stoeckart, beste Rob, jouw bijdrage aan dit proefschrift is groot. Schrijftaal, logica, kritisch lezen, opbouw van een artikel etc., je hebt me veel geleerd. In de auto hebben we regelmatig gesproken over de voortgang van diverse artikelen, maar ook over de rode draad van het proefschrift. Het was een genoegen, je was als een meester voor me.

Dr. Paul Mulder, beste Paul, dank voor je steun en de uitleg die je me steeds weer moest geven over statistische bewerkingen. Ik heb wederom ingezien dat mijn 'wiskundeknobbel' slechts rudimentair aanwezig is.

Geert Aufdemkampe, beste Geert, jouw 'geheime koffer' heeft meerdere keren goed werk verricht. Je betrokkenheid bij diverse artikelen heeft me goed gedaan.

Dr.Wim Hullegie, beste Wim, je inzet als vakfilosoof is een aanwinst voor de sportfysiotherapie. Moge de toekomst bestaan uit nog meer goede gesprekken. 
Prof. dr. Frank Mayer, dear Frank, I always enjoyed our good conversations and appreciate your interest in my work. All other friends of EISCSA, meeting you is always a great pleasure. It is the perfect mix of sharing knowledge, skills, pleasure, good food and excellent wine.

Carla, dit is dan het resultaat van al die jaren vrijetijdsbesteding op zolder. Het promotietraject werd gekenmerkt door ups en downs. Zonder jouw steun was dit proefschrift nooit geschreven.

Noor en Maartje, lieve meiden, het was soms moeilijk uit te leggen waar ik mee bezig was. Ik ben blij dat het af is, vanaf nu gaan we vaker leuke dingen doen. 


\section{Curriculum Vitae}

Robert van Cingel werd op 22 maart 1964 geboren in Hengelo (O). Na de middelbare school sloot hij in 1985 het Centraal Instituut Opleiding Sportleiders (CIOS) in Arnhem af met als specialisaties tennis en atletiek. In de periode |987 - 199| volgde hij de opleiding Fysiotherapie in Arnhem. Daarna specialiseerde hij zich in sportfysiotherapie en orthopedische manueel therapie.Van I99I - 1993 voerde hij een zelfstandige praktijk in Arnhem.

Sinds 1993 is de auteur verbonden aan Sport Medisch Centrum Papendal, tot 1997 bekend als de afdeling Sportgeneeskunde van NOC*NSF.Van 1997 - 2003 werd de functie van fysiotherapeut gecombineerd met een beleidsfunctie bij NOC*NSF. In de periode 1997 - 2000 was hij parttime werkzaam bij de toenmalige afdeling Sport \& Gezondheid en mede verantwoordelijk voor de ontwikkeling van het na- en bijscholingstraject voor sportfysiotherapeuten in Nederland. Vervolgens was hij van 2000 - 2003 parttime werkzaam bij de afdeling Topsport en verantwoordelijk voor de ontwikkeling en implementatie van persoonlijke ontwikkelprogramma's voor topcoaches (Mastercoach in Sports). Sinds 2004 is hij fulltime als directeur verbonden aan Sport Medisch Centrum Papendal.

In 2003 startte hij Physioknowledge, een organisatie die zich richt op de na- en bijscholing van fysiotherapeuten. De auteur bekleedt diverse functies binnen de Nederlandse Vereniging voor Fysiotherapie in de Sportgezondheidszorg (NVFS) en de International Federation of Sports Physiotherapy (IFSP). Sinds de oprichting in 1998 heeft hij een bestuursfunctie in de European Interdisciplinary Society for Clinical and Sports Application (EISCSA). 